\title{
The multiple functions of the numerous Chlamydia trachomatis secreted proteins: the tip of the iceberg
}

\author{
Joana N. Bugalhão ${ }^{1}$ and Luís Jaime Mota ${ }^{1, *}$ \\ 1 UCIBIO, Departamento de Ciências da Vida, Faculdade de Ciências e Tecnologia, Universidade NOVA de Lisboa, Caparica, Portugal. \\ * Corresponding Author: \\ Luís Jaime Mota, Departamento de Ciências da Vida, Faculdade de Ciências e Tecnologia, Universidade NOVA de Lisboa, 2829-516 \\ Caparica, Portugal; phone: 351-21-2948530 (extension 11118); E-mail: ljmota@fct.unl.pt
}

\begin{abstract}
Chlamydia trachomatis serovars are obligate intracellular bacterial pathogens mainly causing ocular and urogenital infections that affect millions of people worldwide and which can lead to blindness or sterility. They reside and multiply intracellularly within a membrane-bound vacuolar compartment, known as inclusion, and are characterized by a developmental cycle involving two morphologically and physiologically distinct chlamydial forms. Completion of the developmental cycle involves the secretion of $>70$ C. trachomatis proteins that function in the host cell cytoplasm and nucleus, in the inclusion membrane and lumen, and in the extracellular milieu. These proteins can, for example, interfere with the host cell cytoskeleton, vesicular and non-vesicular transport, metabolism, and immune signalling. Generally, this promotes $C$. trachomatis invasion into, and escape from, host cells, the acquisition of nutrients by the chlamydiae, and evasion of cell-autonomous, humoral and cellular innate immunity. Here, we present an in-depth review on the current knowledge and outstanding questions about these C. trachomatis secreted proteins.
\end{abstract}

doi: 10.15698/mic2019.09.691

Received originally: 26.06.2019;

in revised form: 29.07.2019,

Accepted 02.08.2019,

Published 21.08.2019.

Keywords: host-pathogen interactions, Chlamydia trachomatis, protein secretion, type III secretion, effectors.

\begin{abstract}
Abbreviations:
3D - three-dimensional, co-IP - coimmunoprecipitation, DUB - deubiquitinase, DUF582 - domain of unknown function 582, EB elementary body, ER - endoplasmic reticulum, ESCRT - endosomal sorting complexes required for transport, F-actin - filamentous-actin, FFAT two phenylalanines in an acidic tract, G-actin globular-actin, GGTases - geranylgeranyl transferases, IF - immunofluorescence, IFN interferon, Inc - inclusion membrane protein, $\mathbf{L D}$ - lipid droplet, MCS - Membrane contact site, MOMP - major outer membrane protein, MVB multivesicular body, PIP2 - phosphatidylinositol (4,5)-bisphosphate, PIP3 - phosphatidylinositol (3,4,5)-trisphosphate, Pmp - polymorphic membrane protein, $\boldsymbol{R B}$ - reticulate body, siRNA small-interfering RNA, SLD - SNARE-like domain, SNARE - soluble $\mathrm{N}$-ethylmaleimide-sensitive factor attachment protein receptor, SH2 - SRC homology 2, T2S - type II secretion, T3S - type III secretion, TGN - trans-Golgi network, mRNA messenger RNA, VAMP - vesicle-associated membrane protein.
\end{abstract}

\section{INTRODUCTION}

Chlamydia trachomatis serovars are human pathogens causing mostly ocular and genital infections $[1,2]$. These infections affect millions of people worldwide and if left untreated can lead to blindness or sterility. C. trachomatis strains comprise three biovars, which can be further divided into 15 main serovars, based on antigenic variation of the major outer membrane protein (MOMP): the trachoma biovar (serovars A-C); the genital biovar (serovars D-K); and the lymphogranuloma venereum (LGV) biovar (serovars L1L3). Most $C$. trachomatis infections are caused by genital strains, but studies on host cell-C. trachomatis interactions are usually performed with a prototype serovar L2 strain. 
C. trachomatis is member of a Phylum (Chlamydiae) of Gram-negative bacteria, comprising one Class (Chlamydiia) and one Order (Chlamydiales), characterised by obligate growth within eukaryotic cells and including species that infect vertebrates, invertebrates, and eukaryotic microorganisms such as amoeba [3]. Among the Chlamydiales, the Chlamydiacea Family currently consists of 16 Chlamydia species [4], including $C$. trachomatis. In addition, the Chlamydiacea comprises $C$. pneumoniae, causing pulmonary infections in humans, and pathogens of a wide range of non-human vertebrates. Among the latter, C. abortus, C. caviae, C. felis, and C. psittacci have zoonotic potential.

The Chlamydiales are characterized by a developmental cycle involving two distinct morphological forms, the small, infectious and non-replicative, elementary bodies (EBs; $0.3 \mu \mathrm{m}$ in diameter), and the larger, non-infectious and replicative, reticulate bodies (RBs; $\sim 1 \mu \mathrm{m}$ in diameter) (reviewed in $[5,6])$. This cycle has been intensively studied in $C$. trachomatis using cultured cells as a model for the epithelial tissue encountered by this bacterium during in vivo infection and can take $\sim 48-72 \mathrm{~h}$, depending on the strain (Figure 1). Adherence of EBs to the surface of host cells leads to chlamydial internalization and to the formation of a membrane-bound compartment, a Chlamydiacontaining vacuole generally known as inclusion. About $2 \mathrm{~h}$ after internalization, the intravacuolar EBs start differenti- ating into RBs, which begin to replicate $\sim 6 \mathrm{~h}$ post-infection. Multiple rounds of chlamydial replication result in a large inclusion occupying a significant part of the host cell cytoplasm. From $\sim 24$ to $48-72 \mathrm{~h}$ post-infection, RBs redifferentiate asynchronously into EBs. The inclusion is then filled with EBs (the infectious progeny), which after release from the host cell can infect neighbouring cells (Figure 1).

C. trachomatis interferes with a wide range of host cell processes during its developmental cycle (reviewed in [6]; Figure 1). Subversion of host receptor-mediated signalling and of the actin cytoskeleton and its key regulators promotes chlamydial adherence and invasion of host cells. While intracellularly, $C$. trachomatis reshapes the protein and lipid composition of the inclusion membrane by selective interactions with molecules controlling and mediating host cell vesicular trafficking, segregating from the endolysosomal pathway and forming a unique and stable vacuolar compartment that localizes near the centrosome. The interaction with host cell vesicular and non-vesicular transport pathways also enables $C$. trachomatis to acquire nutrients and lipids required for its growth. In addition, among other aspects, intravacuolar $C$. trachomatis modulates host cell survival and death and the innate immune signalling. Finally, to exit from the host cell, $C$. trachomatis subverts the host cell cytoskeleton and calcium-signalling.

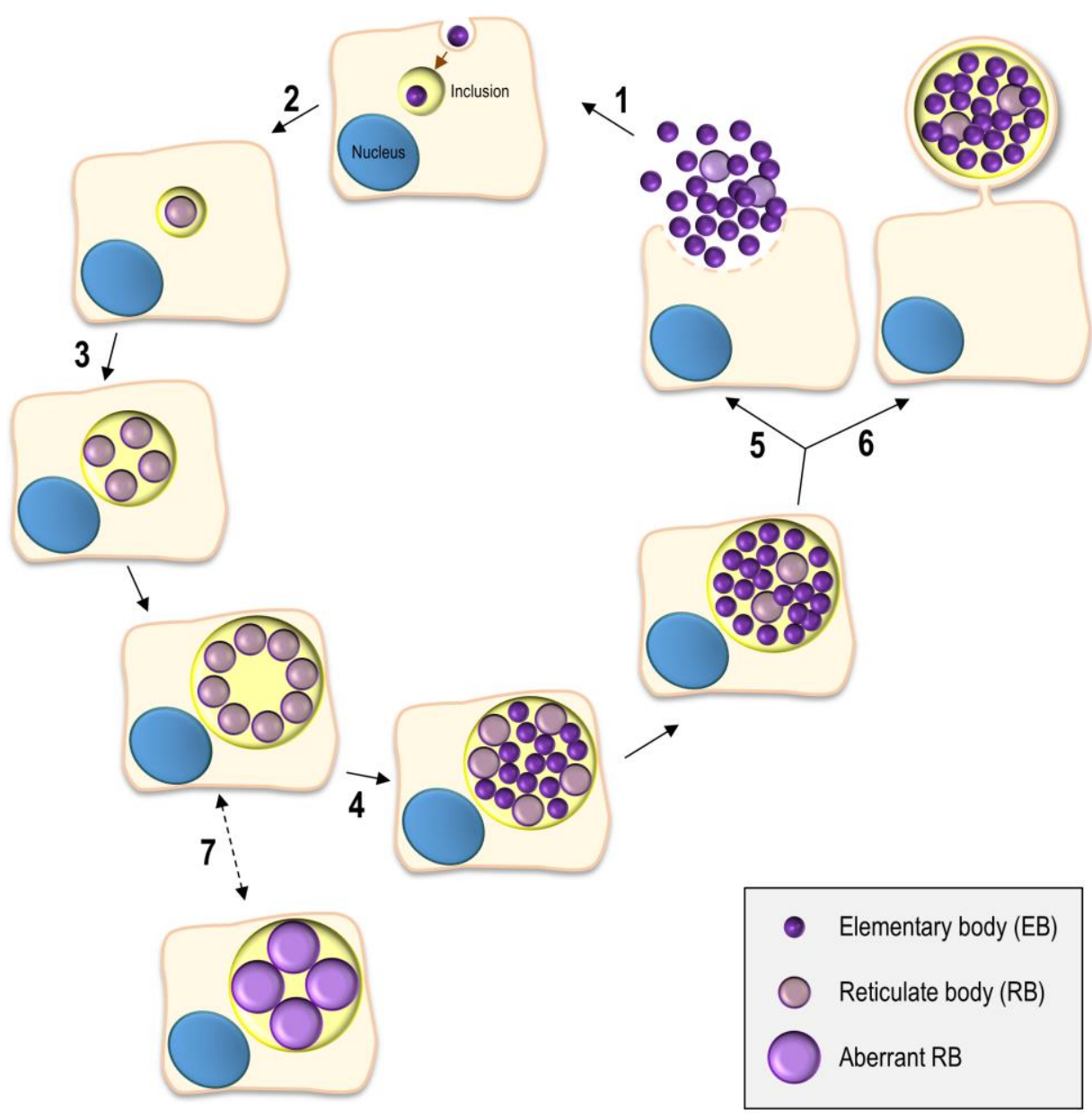

FIGURE 1: The chlamydial developmental cycle. (1) Adhesion to host cells by $C$. trachomatis EBs released from previously infected cells triggers the delivery of T3S effectors that overall mediate actin rearrangements resulting in chlamydial invasion, inhibition of interaction with the endocytic pathway, and modulation of host cell survival and immune signalling ( 0-2 $\mathrm{h}$ postinfection). (2) The nascent inclusion segregates from the phagolysosomal pathway, the EBs differentiate into RBs, and the inclusion migrates along microtubules to a perinuclear centrosomal region $(\sim 2-6 \mathrm{~h}$ postinfection). (3) The RBs start replicating exponentially leading to a large inclusion occupying most of the host cell cytoplasm ( 6-24 h post-infection). (4) The RBs redifferentiate asynchronously into EBs ( 24-48 h post-infection). (5) \& (6) The EBs (infectious progeny) and a few lasting RBs are released by host cell lysis (5) or extrusion (6) ( 48-72 h postinfection). (7) Under certain stress conditions (antibiotics or cytokines) there is the reversible formation of aberrant RBs, a persister-like chlamydial form. 
Completion of the developmental cycle and subversion of host cells processes by $C$. trachomatis involves the timely secretion of many chlamydial proteins. We will survey and discuss the knowledge on the identity and function of C. trachomatis secreted proteins that participate or might participate in the subversion of host cell processes. This knowledge has significantly increased in recent years because of developments in methods to genetically manipulate $C$. trachomatis [7-15] (and reviewed in [16]) that followed or paralleled the first description of a system to transform C. trachomatis [17].

\section{PROTEIN TRANSPORT SYSTEMS IN C. TRACHOMATIS}

Gram-negative bacteria use several protein transport systems that are essential for interactions with other cells and with the extracellular environment [18-20]. In the case of C. trachomatis, its genome encodes the Sec system, a type II secretion (T2S) system, a type III secretion (T3S) system, Sec-exported polymorphic membrane proteins (Pmps) containing type $\mathrm{V}$ secretion (T5S) system/autotransporter signals, and several other outer membrane proteins [21, 22] (Figure 2). The Sec- and T3S system-dependent transport of $C$. trachomatis proteins by heterologous bacteria $[23,24]$, the isolation and characterization of C. trachomatis mutants in the T2S system-associated ATPase [14] and in PmpD [25], and different biochemical, gene expression and proteomic analyses [26-29], showed the functionality and importance of all these protein transport systems for the C. trachomatis developmental cycle and for Chlamydia-host cell interactions. All together, these systems enable the delivery of chlamydial proteins to different aqueous and membranaceous compartments within bacterial and mammalian host cells (Figure 2). The use in C. trachomatis-infected cells of small molecules reported to inhibit the Sec system and the T3S system also initially indicated the importance of these protein transport systems for chlamydiae [24, 30-32]. However, in the case of the use of small molecules that can inhibit T3S systems, they have been later shown to chelate iron [33] and to bind chlamydial protoporphyrinogen oxidase (HemG) [34]. Therefore, conclusions based on the use of these small molecules to define the importance of the T3S secretion pathway for $C$. trachomatis are questionable.

Chlamydial outer membrane proteins, such as the Pmps [35], outer membrane complex protein B (OmcB) [36], MOMP [37-39], or C. trachomatis adhesin 1 (Ctad1) [40] are important for the initial contact and adhesion of C. trachomatis with host cells [6], but they will not be further described here. We will focus on $C$. trachomatis proteins: (i) that localize in the inclusion membrane, functioning as effectors mediating the chlamydiae-host cell interaction; (ii) that localize and function as effectors in the host cell plasma membrane, cytoplasm or nucleus; (iii) that localize in the inclusion lumen, where they function and/or from where they might be transported into the inclusion membrane and/or host cell cytosol, or are released in the extracellular environment after chlamydial exit.

\section{IDENTIFICATION OF C. TRACHOMATIS INC PROTEINS AS T3S SUBSTRATES}

The most prominent group of Chlamydia proteins mediating bacterial-host cell interaction are the inclusion membrane proteins (Incs) $[6,41]$. Although the amino acid sequences of Incs from the same Chlamydia species are mostly unrelated to each other $[42,43]$, they are all characterized for localizing at the inclusion membrane and for

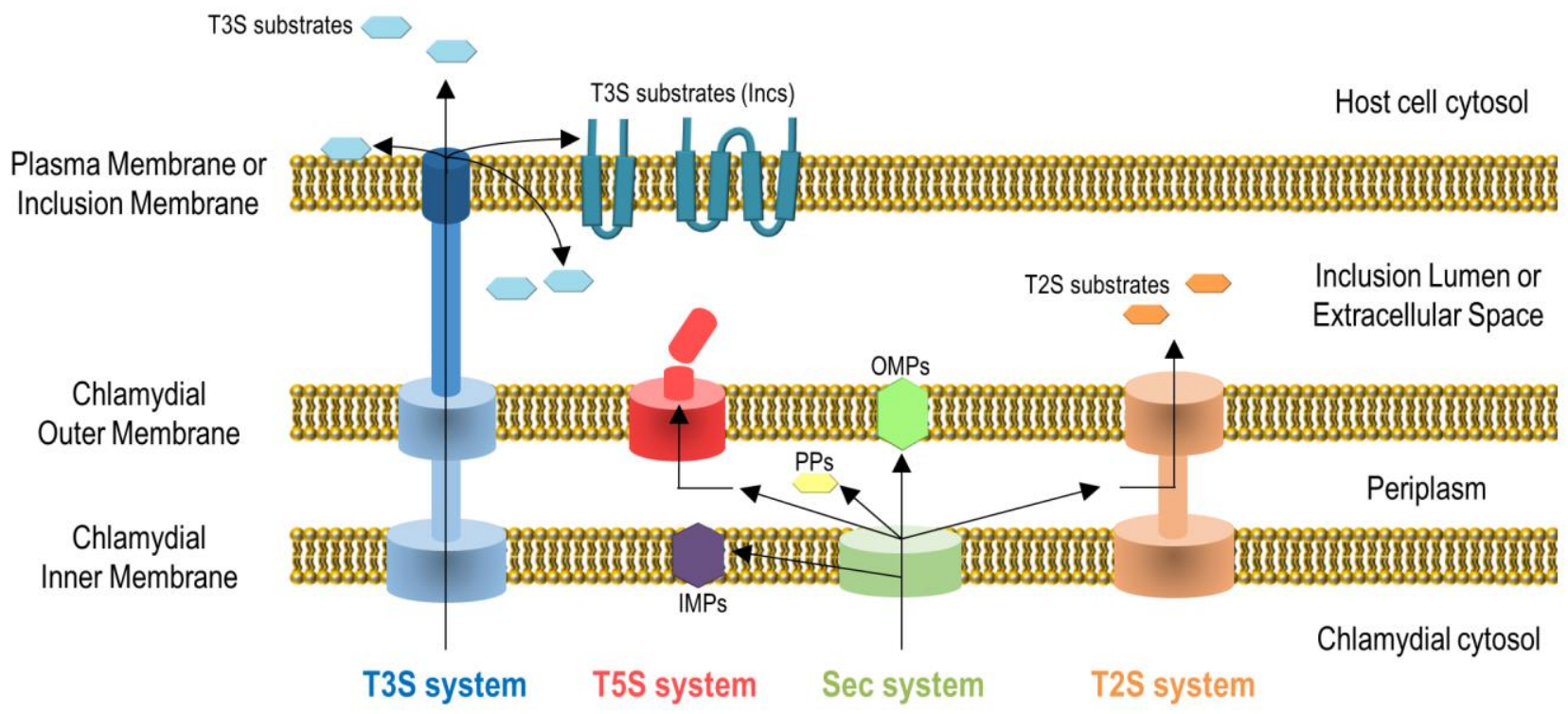

FIGURE 2: Secretion systems used by $C$. trachomatis to transport proteins to different aqueous and membranaceous chlamydial and host cell compartments. It is unclear how some chlamydial T3S substrates are transported into the inclusion lumen or how Incs insert into the inclusion membrane. IMPs, chlamydial inner membrane proteins; PPs, chlamydial periplasmic proteins; OMPs, chlamydial outer membrane proteins. See list of abbreviations and main text for details. 
at least one bilobed hydrophobic motif $[6,41]$. Thirty-six bona fide Incs have been identified in $C$. trachomatis (Table $1)$, and several more might exist $[42,43]$. Other members of the Chlamydiales, including endosymbionts of free-living amoeba [44], also likely possess large numbers of Incs [42, 43].

The first report of the identification of an Inc dates to 1995 [45]. By using sera of guinea pigs infected with C. psittaci or immunized with killed EBs, proteins absent in purified EBs or in uninfected cells were localized at the inclusion membrane by immunofluorescence (IF) microscopy [46]. The same sera were used to screen an expression library of $C$. psittaci DNA, and this led to the identification of a gene encoding an inclusion membrane protein, named IncA [45]. A similar approach led to the identification of C. psittaci IncB and IncC [47]. Data from the first genome of $C$. trachomatis, released in 1998 [21], revealed orthologues of Incs A, B, and C [47, 48], which were shown to localize at the inclusion membrane of $C$. trachomatis [48-50]. Moreover, sera obtained from rabbits immunized with the membrane fraction of HeLa cells infected by C. trachomatis led to the identification of Incs D, E, F, and G [51].

After the identification of Incs A, B and C, the characteristic bilobed hydrophobic region was used to search the genome of $C$. trachomatis for genes that could encode additional Incs [49]. By raising antibodies against the putative $C$. trachomatis Incs and showing by IF microscopy that they localize at the inclusion membrane, the bilobed hydrophobic region was defined as a characteristic motif of Incs and a determinant of their localization [49]. In subsequent studies, similar or related approaches were used to identify additional C. trachomatis Incs [50, 52-57], and to predict more putative Incs by bioinformatics $[42,43]$. The development of tools to genetically manipulate $C$. trachomatis $[7,9,17,58]$, helped in the identification of additional bona fide Incs [59], but it also revealed several putative Incs that did not localize at the inclusion membrane [59]. Different timings and levels of expression of the tetracycline-inducible system used could affect protein localization; but it is also possible that some of the bioinformatically predicted Incs do not localize at the inclusion membrane.

The lack of a cleavable Sec signal peptide on the first identified Incs and the discovery of homologues of T3S system genes in Chlamydia [21,60], suggested that Incs could be T3S substrates $[47,49,51,61]$. Methods for genetic manipulation of Chlamydia were unavailable at the time, but it had been shown that chlamydial proteins could be type III secreted by heterologous bacteria [23]. Using this methodology, the $\mathrm{N}$-terminal region of Incs was shown to contain a signal capable of mediating secretion of hybrid proteins by the T3S system of Shigella flexneri [62, 63], which established the concept of Incs as T3S substrates. In subsequent studies several $C$. trachomatis Inc proteins were confirmed as T3S substrates $[42,59,64]$.
THE FUNCTIONS OF C. TRACHOMATIS INC PROTEINS

Analyses of $C$. trachomatis gene expression revealed at least three classes of Incs depending on their corresponding messenger RNA (mRNA) levels during the chlamydial developmental cycle: early-cycle Incs (highest mRNA levels between $\sim 2-6 \mathrm{~h}$ post-infection); mid-cycle Incs (highest mRNA levels between $\approx 6-20 \mathrm{~h}$ post-infection); late-cycle Incs (highest mRNA levels after $20 \mathrm{~h}$ post-infection) [52, 64-66]. This suggested roles of Incs at distinct stages of the chlamydial developmental cycle, an idea which is generally being confirmed as the host cell subverting functions of Incs are being characterized.

\section{Incs modulating host cell vesicular trafficking}

As an intravacuolar pathogen, $C$. trachomatis manipulates host cell vesicular trafficking at least to avoid the phagolysosomal route leading to bacterial destruction and to intercept vesicles containing nutrients required for bacterial growth and inclusion expansion [67]. Given their localization, Incs are natural candidates for subversion of vesicular trafficking, and, until now, three C. trachomatis Incs (IncA, IncE and CpoS (Chlamydia promoter of survival); Table 1) have been shown to be directly involved (Figure 3A).

\section{Homotypic fusion between inclusions}

C. trachomatis normally resides and multiplies within a single inclusion containing several chlamydiae. In contrast, C. trachomatis-infected cells microinjected with anti-IncA antibodies show multiple inclusions within a single host cell [68]. Furthermore, C. trachomatis clinical isolates residing in multiple inclusions within infected cells have mutations in incA and lack the IncA protein in the inclusion membrane $[69,70]$. This led to the concept that IncA mediates the fusion between inclusions within infected cells (Figure 3A), which was confirmed when $C$. trachomatis incA insertional mutants were generated and characterized $[8,71]$.

In eukaryotic cells, membrane fusion requires interactions between soluble $\mathrm{N}$-ethylmaleimide-sensitive factor attachment protein receptors (SNAREs) in opposing lipid bilayers [72]. Bioinformatics disclosed the presence of two SNARE-like domains (SLD1 and SLD2) in IncA [73, 74]. Yeast and bacterial two-hybrid, and different biochemical experiments, revealed homotypic IncA:IncA interactions [68, 73, 75-77]. The C-terminally-located SLD2 of IncA is required for the homotypic interactions [75, 77], and SLD1 and part of SLD2 are needed for fusion between inclusions [71, 76, 77]. This indicates that SNARE-like IncA:IncA interactions mediate the fusion between inclusions (Figure 3A). However, the recent determination by X-ray crystallography of the three-dimensional (3D) structure of almost all the cytosolic region of IncA [78], indicates that its structure differs from SNAREs and resembles instead a domain of the Huntingtin-interacting protein-1 related (HIP1R) that mediates associations between actin and clathrin-coated structures $[78,79]$.

C. trachomatis IncA can also interact with mammalian SNAREs (vesicle-associated membrane proteins (VAMPs) 3, 7 , and 8 ), which are recruited to the periphery of the inclu- 
TABLE 1: C. trachomatis known Inc proteins ${ }^{\mathrm{a}}$.

\begin{tabular}{|c|c|c|c|c|c|}
\hline \multicolumn{3}{|c|}{ Inc protein (annotation/name) } & \multirow{2}{*}{$\begin{array}{l}\text { Host cell pro- } \\
\text { tein targets }{ }^{b}\end{array}$} & \multirow[b]{2}{*}{ Proposed functions } & \multirow[b]{2}{*}{ References } \\
\hline $\begin{array}{l}\text { Strain } \\
\text { D/UW3 }\end{array}$ & $\begin{array}{l}\text { Strain } \\
\text { L2/434 }\end{array}$ & General & & & \\
\hline СТ005 & CTL0260 & IncV & VAPA/B & $\begin{array}{l}\text { Formation of ER-inclusion MCS; non- } \\
\text { vesicle lipid uptake by } C \text {. trachomatis. }\end{array}$ & $\begin{array}{c}{[52,59,125} \\
189]\end{array}$ \\
\hline СT006 & CTL0261 & - & Unknown & Unknown. & [59] \\
\hline CT101 & CTL0356 & MrcA & ITPR3 & $\begin{array}{l}\text { Promotion of chlamydial extrusion; } \\
\text { localize at inclusion microdomains. }\end{array}$ & {$[52,128,130]$} \\
\hline CT115 & CTL0370 & $\operatorname{lncD}$ & CERT & $\begin{array}{l}\text { Formation of ER-inclusion MCS; non- } \\
\text { vesicle lipid uptake by } C \text {. trachomatis. }\end{array}$ & {$[50,51,120]$} \\
\hline CT116 & CTL0371 & IncE & SNX5/6 & $\begin{array}{l}\text { Modulation of retromer-dependent } \\
\text { trafficking. }\end{array}$ & $\begin{array}{c}{[50,51,59,86-} \\
88]\end{array}$ \\
\hline CT117 & CTL0372 & IncF & Unknown & Heterophilic Inc-Inc interactions. & {$[50,51,59,75]$} \\
\hline CT118 & CTL0373 & IncG & $14-3-3 \beta$ & Unknown; associates with LDs. & $\begin{array}{c}{[50,51,145} \\
221]\end{array}$ \\
\hline CT119 & CTL0374 & IncA & VAMP3/7/8 & $\begin{array}{l}\text { Homotypic inclusion fusion; regulation } \\
\text { of host cell vesicular trafficking; associ- } \\
\text { ates with LDs. }\end{array}$ & $\begin{array}{c}{[8,48,50,51} \\
69,74,77,78 \\
189,220]\end{array}$ \\
\hline CT134 & CTL0389 & - & Unknown & Unknown. & [59] \\
\hline CT135 & CTL0390 & - & Unknown & $\begin{array}{l}\text { Important for chlamydial virulence in a } \\
\text { mouse infection model. }\end{array}$ & {$[59,149,150]$} \\
\hline CT147 & CTL0402 & - & Unknown & Unknown. & {$[50,59,65]$} \\
\hline CT179 & CTL0431 & - & Unknown & Unknown. & [59] \\
\hline CT192 & CTL0444 & - & Unknown & Unknown. & [59] \\
\hline CT222 & CTL0475 & - & Unknown & $\begin{array}{l}\text { Heterophilic Inc-Inc interactions; local- } \\
\text { izes at inclusion microdomains. }\end{array}$ & {$[52,59,75,128]$} \\
\hline CT223 & CTL0476 & IPAM & CEP170 & $\begin{array}{l}\text { Modulation of the microtubule net- } \\
\text { work; inhibition of host cell cytokinesis; } \\
\text { localizes at inclusion microdomains. }\end{array}$ & $\begin{array}{c}{[49,50,52,59} \\
109,133]\end{array}$ \\
\hline CT224 & CTL0477 & - & Unknown & $\begin{array}{l}\text { Inhibition of host cell cytokinesis; local- } \\
\text { izes at inclusion microdomains. }\end{array}$ & {$[52,59,133]$} \\
\hline CT225 & CTL0477A & - & Unknown & Inhibition of host cell cytokinesis. & {$[50,52,133]$} \\
\hline CT226 & CTL0478 & - & Unknown & Unknown. & {$[50,52,56,59]$} \\
\hline CT227 & CTL0479 & - & Unknown & Unknown. & {$[52,59]$} \\
\hline CT228 & CTL0480 & - & MYP1 & $\begin{array}{l}\text { Inhibition of chlamydial extrusion; lo- } \\
\text { calizes at inclusion microdomains. }\end{array}$ & $\begin{array}{c}{[50,52,138,} \\
140]\end{array}$ \\
\hline CT229 & CTL0481 & Cpos & RABs & $\begin{array}{l}\text { Control of inclusion membrane stability } \\
\text { and/or host cell death, and of host cell } \\
\text { vesicular trafficking. }\end{array}$ & $\begin{array}{c}{[49,50,52,59} \\
96-98,100]\end{array}$ \\
\hline CT232 & CTL0484 & IncB & Unknown & Localizes at inclusion microdomains. & {$[50,59,128]$} \\
\hline CT233 & CTL0485 & IncC & Unknown & $\begin{array}{l}\text { Control of inclusion membrane stabil- } \\
\text { ity; localizes at inclusion microdomains. }\end{array}$ & {$[49,50,59,100]$} \\
\hline CT249 & CTL500A & - & Unknown & Unknown. & {$[50,52,57]$} \\
\hline CT288 & CTL0540 & - & CCDC146 & Localizes at inclusion microdomains. & {$[49,50,59,135]$} \\
\hline CT345 & CTL0599 & - & Unknown & Unknown. & {$[59]$} \\
\hline
\end{tabular}


TABLE 1: C. trachomatis known Inc proteins ${ }^{\text {a }}$ (continued).

\begin{tabular}{|c|c|c|c|c|c|}
\hline \multicolumn{3}{|c|}{ Inc protein (annotation/name) } & \multirow{2}{*}{$\begin{array}{l}\text { Host cell pro- } \\
\text { tein targets }{ }^{b}\end{array}$} & \multirow[b]{2}{*}{ Proposed functions } & \multirow[b]{2}{*}{ References } \\
\hline $\begin{array}{l}\text { Strain } \\
\text { D/UW3 }\end{array}$ & $\begin{array}{l}\text { Strain } \\
\text { L2/434 }\end{array}$ & General & & & \\
\hline CT358 & CTL0612 & - & Unknown & Unknown. & {$[50]$} \\
\hline СТ383 & CTL0639 & - & Unknown & $\begin{array}{l}\text { Modulation of inclusion membrane } \\
\text { stability. }\end{array}$ & {$[59,100]$} \\
\hline CT440 & CTL0699 & - & Unknown & Unknown. & {$[50]$} \\
\hline CT442 & CTL0701 & CrpA & Unknown & Unknown. & {$[49,50,53,59]$} \\
\hline CT449 & CTL0709 & - & Unknown & Unknown. & [59] \\
\hline CT483 & CTL0744 & - & Unknown & Unknown. & [52] \\
\hline CT565 & CTL0828 & - & Unknown & Unknown. & {$[52]$} \\
\hline CT618 & CTL0882 & - & Unknown & Associates with LDs. & {$[50,54,221]$} \\
\hline СТ813 & CTL0184 & InaC & $\begin{array}{l}\text { 14-3-3 pro- } \\
\text { teins, ARF1/4, } \\
\text { VAMP7/8 }\end{array}$ & $\begin{array}{l}\text { Modulation of post-translational modi- } \\
\text { fication of microtubules, and of F-actin } \\
\text { and Golgi redistribution around the } \\
\text { inclusion. }\end{array}$ & $\begin{array}{c}{[15,50,52,55,} \\
74,112]\end{array}$ \\
\hline СТ850 & CTL0223 & - & DYNLT1 & $\begin{array}{l}\text { Inclusion positioning at the centro- } \\
\text { somal region; localizes at inclusion } \\
\text { microdomains. }\end{array}$ & {$[52,128]$} \\
\hline
\end{tabular}

aProteins with the characteristic hydrophobic bilobal domain and which have been experimentally detected at the inclusion membrane. See list of abbreviations and main text for abbreviations and protein nomenclature, respectively.

bOnly interactions of $C$. trachomatis Incs (and not of Incs from other Chlamydia species) with host cell proteins were considered; while potential interactions between several $C$. trachomatis Incs and many human proteins have been described by large scale proteomics [85], only those further validated are specified in Table 1.

sion [74]. The interaction depends on the SLDs of IncA and the recruitment of the SNAREs is reduced in cells infected by $C$. trachomatis lacking IncA [74]. Moreover, IncA inhibits endocytic SNARE-mediated fusion and both SLD1 and SLD2 can perform this activity [77, 80]. This suggests that IncA has an inhibitory action on the SNAREs it interacts with (Figure 3A).

In summary, IncA mediates inclusion fusion and has the capacity to inhibit endocytic membrane fusion (Figure $3 \mathbf{A}$ ). Because incA is expressed at mid-cycle $[52,64]$, this ability to inhibit fusion with endocytic vesicles should not be relevant for the initial segregation of the nascent inclusion from the endolysosomal pathway, but could however help to protect the inclusion from unwanted vesicle fusion. Epidemiological and clinical studies indicated that infection with $C$. trachomatis isolates with incA mutations results in milder symptoms and reduced bacterial load [81]. Moreover, a non-fusogenic clinical strain with an incA mutation revealed slower growth in cultured cells [82]. However, a more recently characterized $C$. trachomatis incA nullmutant strain reveals no growth defect in cultured cells [71]. This suggests a possible functional redundancy of IncA with other unidentified $C$. trachomatis proteins that should also contribute to inhibition of fusion with endocytic vesicles.

\section{Subversion of the retromer}

The retromer is a protein complex, including at least one sorting nexin (SNX), which recycles cargo from endosomes to the plasma membrane or to the trans-Golgi network (TGN) [83]. Proteomics of isolated C. trachomatis inclusions and a screen for human proteins interacting with $C$. trachomatis Incs both disclosed the importance of the retromer in chlamydial host cell infections [84, 85]. Several SNXs are enriched in the inclusion [84], and IncE binds SNXs 5 and 6 [85] (Figure 3A). The IncE:SNX5 interaction has been studied at a structural level [86-88]. This eventually revealed that IncE competes with cation-independent mannose 6-phosphate receptor (Cl-M6PR) for binding to SNX5, and that the SNX5:CI-M6PR interaction is inhibited during host cell infection by $C$. trachomatis [86-88]. M6PRs are involved in transport of newly synthesized lysosomal enzymes from the TGN to endosomes, and their subsequent recycling back to the Golgi requires the retromer [89]. As depletion of retromer components, and in particular of SNX5, increases the production of chlamydial infectious progeny $[84,85]$, this indicates that retromer restricts 
C. trachomatis infection and that IncE might subvert retromer and lysosomal function by binding SNXs 5 and 6 . This IncE-dependent subversion of the retromer might, for example, enable $C$. trachomatis to acquire nutrients, or to avoid lysosome- or autophagy-mediated killing [90].

\section{Targeting of RAB GTPases}

RAB GTPases are master regulators of eukaryotic vesicular trafficking [91], and several of them (RABs 1, 4, 6, 8, 10, 11, $14,34,35,39 a, 39 b)$ have been reported to localize at, or in close proximity of, the $C$. trachomatis inclusion membrane [92-96]. Despite this, until now, only one $C$. trachomatis protein, Inc CpoS (Table 1), has been shown to bind and modulate the function of RABs (Figure 3A).

Yeast two-hybrid and pull-down experiments first revealed an interaction between CpoS and RAB4 [97]. More recently, co-immunoprecipitation (co-IP) experiments from mammalian cells ectopically expressing CpoS, or infected by $C$. trachomatis encoding epitope-tagged $C$ poS, revealed or confirmed interactions of this Inc with RABs $1,2,4,6,8$, $10,14,18,33,34$, and 35 [85, 96, 98]. Furthermore, recruitment to the periphery of the inclusion of all these RABs was impaired in cells infected by $C$. trachomatis cpoS null mutants $[96,98]$, and depletion of RABs $4,6,14$, or 35 reduced the production of infectious progeny $[93,96,99]$.

Expression of CpoS is toxic to yeast cells, which led to the identification of proteins related with clathrin-coated vesicles that when overexpressed suppressed CpoSmediated toxicity [96]. Somewhat in line with this, CpoS is required for the accumulation of transferrin (the transferrin receptor (TFRC) traffics through clathrin-dependent transport from the plasma membrane to endosomes and by subsequent RAB-dependent recycling) and of $\mathrm{Cl}-\mathrm{M} 6 \mathrm{PR}$ (this receptor traffics through clathrin- and RAB-dependent transport from the TGN to endosomes and subsequent RAB-dependent recycling) near the inclusion membrane [96] (Figure 3A). Furthermore, this accumulation of transferrin is dependent on RABs 4 and 35 [96]. In summary, by targeting multiple RABs, CpoS is an important regulator of host cell vesicular trafficking in C. trachomatis-infected cells. Accordingly, cpoS C. trachomatis mutants are attenuated in the generation of infectious progeny in cultured cells and in mice infection models [98, 100]. The activity of Cpos might be important for acquisition of nutrients, avoidance of fusion of the inclusion with lysosomes, stability of the inclusion membrane, and/or modulation of host cell death (as further described below).

\section{Incs controlling inclusion membrane stability and host cell death}

Intracellular pathogens must ensure the integrity of their replicative niche and therefore they often inhibit host cell death [101]. Intravacuolar pathogens also need to control the stability of the membrane of the pathogen-containing vacuole [102], because cytosolic release of the pathogen can lead to host cell death [103]. C. trachomatis Incs CpoS, IncC and CT383 (Table 1) have been reported to control these processes in Chlamydia-infected cells.
CpoS derives its name from the observation that cells infected by $C$. trachomatis cpoS null mutants die much more frequently than cells infected by the wild-type strain [98]. This has been described in two separate studies that diverge in the explanation for the cytotoxic effect of CpoSdeficient $C$. trachomatis $[98,100]$.

In one study, Weber et al. performed insertional mutagenesis of eleven inc genes eventually revealing that infection by $C$. trachomatis cpoS, incC, or ct383 null mutants resulted in increased host cell death [100]. As the cpoS mutant $[98,100]$, the inc $C$ and $c t 383$ mutants were also defective for generation of infectious progeny in cultured cells and attenuated in a mouse infection model [100]. Because IF microscopy of cells infected by each of the three inc mutants revealed both multiple inclusions per infected cell and premature lysis of the inclusion membrane, the increased cytotoxicity was proposed to be a consequence of the release of the chlamydiae in the host cell cytosol [100]. Additional experiments suggested that the cytosolic release of each of the three inc mutant chlamydiae leads to autophagy-dependent host cell death [100].

In the study by Sixt et al. [98], infection by a cpos mutant was shown to activate the stimulator of interferon genes (STING), leading to its re-localization from the endoplasmic reticulum (ER) to perinuclear vesicles and to the triggering of a signalling pathway that results in an enhanced interferon (IFN) response [98]. While host cell death promoted by infection with cpoS mutant $C$. trachomatis was reduced in STING-deficient cells, this reduction was not observed upon pharmacological inhibition of the transport of STING from the ER into perinuclear vesicles or of the downstream signalling pathway [98]. This indicates that the IFN response and host cell death promoted by CpoS-deficient $C$. trachomatis are independent processes [98]. Experiments with inhibitors of an ER calcium pump known to interact with STING suggested that the cytotoxicity associated with infection by CpoS-deficient $C$. trachomatis could be related with control of calcium pools in the ER [98].

In summary, in one model, lack of CpoS leads to inclusion lysis and autophagy-dependent host cell death [100], while in the other absence of CpoS does not significantly affect stability of the inclusion membrane but leads to the activation of host cell death that is partially dependent on STING [98].

\section{Incs modulating the Golgi and the host cell cytoskeleton}

C. trachomatis manipulates and remodels the eukaryotic cytoskeleton (intermediate filaments, microfilaments, microtubules, and septins) at different stages of the developmental cycle [104-110], and promotes the redistribution of the Golgi complex around the inclusion [111]. Thus far, C. trachomatis Incs IPAM (inclusion protein acting on microtubules) and InaC (inclusion membrane protein for actin assembly) (Table 1) have been shown to be involved in the subversion of microtubules and microfilaments and in Golgi redistribution. 
A

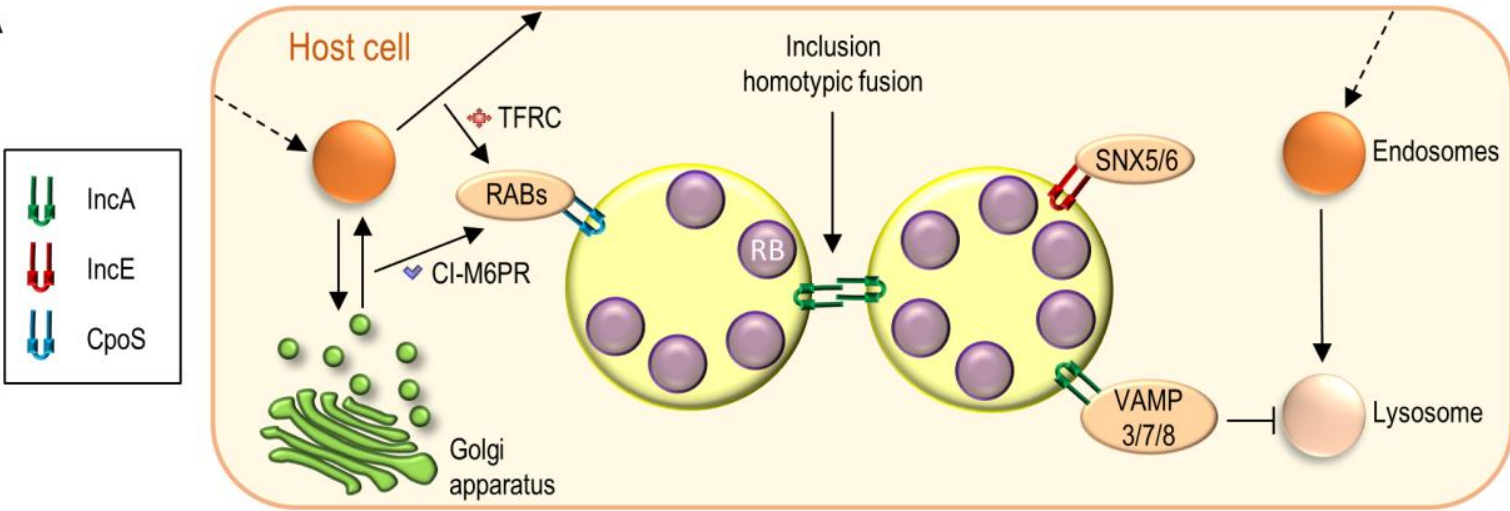

B

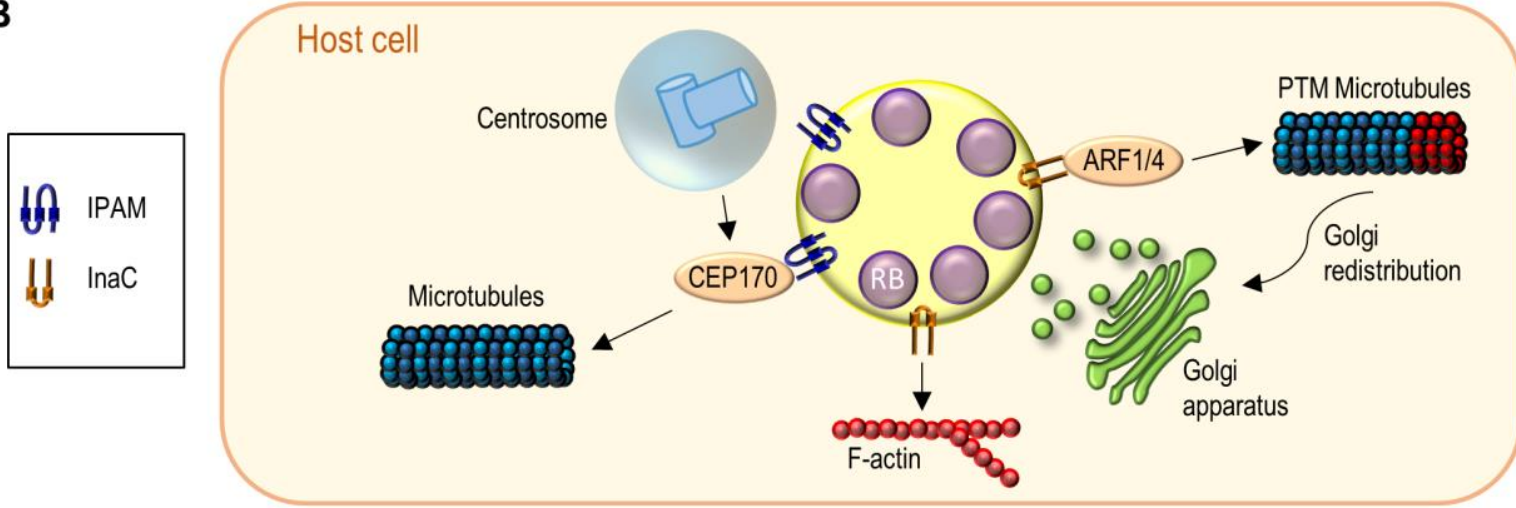

C

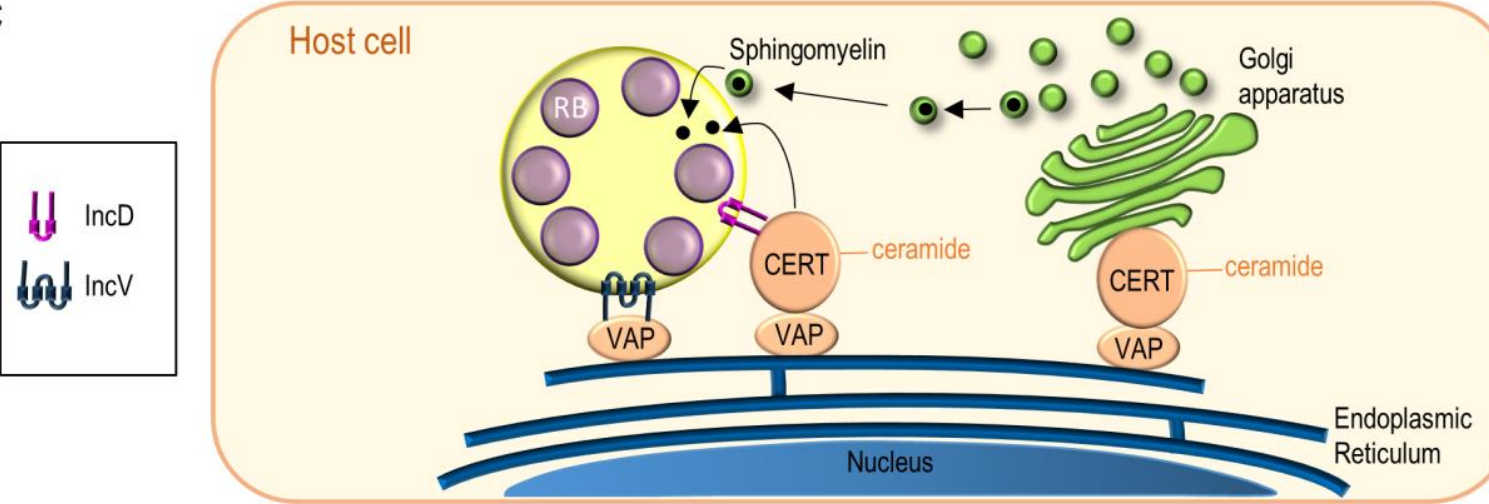

D

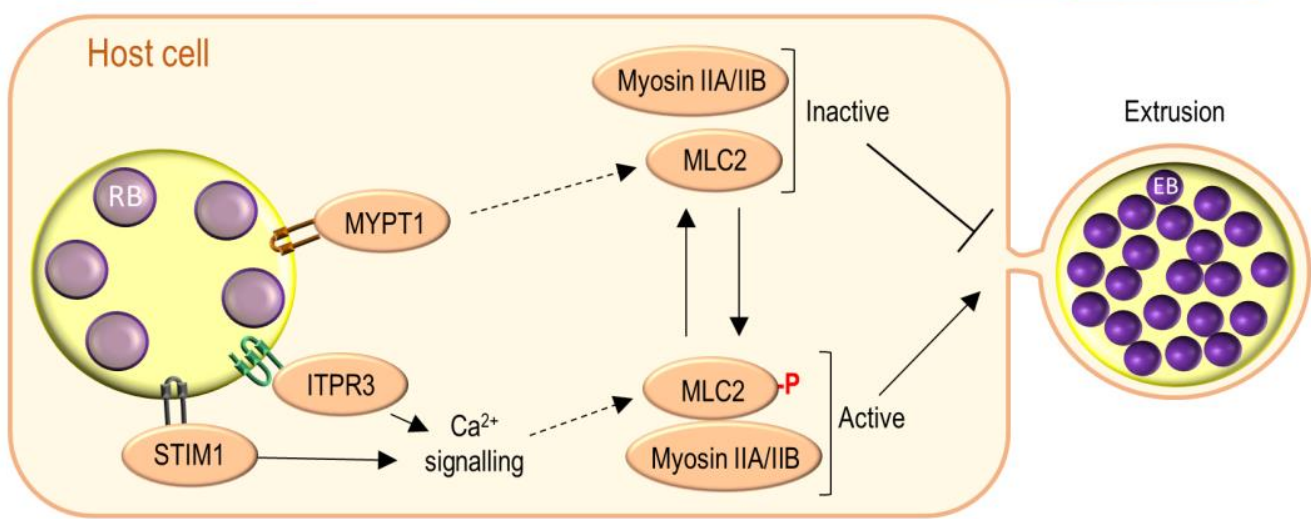

FIGURE 3: Functions of $C$. trachomatis Incs effectors. (A) Incs subverting host cell vesicular transport (IncA, IncE, CpoS). (B) Incs interfering with microfilaments and microtubules (IPAM, InaC), and mediating Golgi redistribution around the inclusion (InaC); PTM, posttranslationally modified. (C) Incs participating in ER-inclusion MCSs (InCD, IncV). (D) Incs modulating chlamydial extrusion by subverting $\mathrm{Ca}^{2+}$ signalling and myosin II function (CT228, MrcA). An unknown Inc possibly recruits STIM1 to the inclusion membrane. The number of transmembrane domains illustrated for each Inc is based on [42]. See list of abbreviations, main text, and Table 1 for details. 


\section{Microtubule remodelling}

Host cell microtubules accumulate in a nest-like structure around the $C$. trachomatis inclusion, which suggested the involvement of an Inc [109]. IPAM was singled out as a candidate, based on the similarity of its primary structure with human centrosomal and microtubule-related proteins [109]. In infected cells, IPAM localizes at the inclusion membrane in patches near the centrosome $[59,109]$. In uninfected cells, ectopically expressed IPAM associates with the centrosome and alters the organization of microtubules [109]. IPAM binds centrosomal protein 170 (CEP170) and this host cell protein is required for accumulation of microtubules around the inclusion, proper inclusion morphology, generation of infectious progeny, and for the effect of ectopically expressed IPAM on the organization of microtubules [109]. Thus, IPAM likely remodels microtubules in infected cells through CEP170 (Figure 3B).

\section{Actin remodelling and Golgi redistribution}

Filamentous (F)-actin also accumulates around the inclusion [106]. A collection of chemically mutagenized C. trachomatis strains was used to screen for the chlamydial genes involved in this F-actin accumulation [15]. This led to the identification of the gene encoding InaC [15], which was then also shown to be necessary for Golgi redistribution around the inclusion [15] (Figure 3B). Although experiments with drugs interfering with actin polymerization suggested that InaC-dependent remodelling of F-actin around the inclusion could be required for Golgi redistribution [15], analyses of cells infected by a C. trachomatis strain overexpressing InaC indicated that these are two independent processes [112].

Eukaryotic ADP ribosylating factors (ARFs) are small GTPases regulating vesicular trafficking, actin remodelling and the structure of the Golgi complex [113], and they are also targeted by $C$. trachomatis. InaC binds and recruits ARFs 1 and 4 to the periphery of the inclusion $[15,112]$. Moreover, InaC mediates the activation of ARFs 1 and 4, and this leads to the induction of post-translational modifications of microtubules that promote Golgi redistribution around the inclusion [108, 112] (Figure 3B). On the other hand, there is currently no evidence for a role of ARFs in F-actin remodelling mediated by InaC [112].

F-actin remodelling and Golgi redistribution have been suggested to stabilize the inclusion and to promote the acquisition of lipids $[106,111]$, respectively. However, inaC mutants do not display a defect in trafficking of sphingolipids to the inclusion [15, 112]. Furthermore, there are disparate observations regarding the ability of $C$. trachomatis ina $C$ null mutants to generate infectious progeny in cultured cells, as a defect was observed with one mutant [112], but not with other two $[15,100]$. Finally, as IncA, InaC possesses a SLD and can bind VAMPs 7 and 8 [74], but the significance of these interactions is unknown.

\section{Incs in ER-inclusion membrane contact sites}

Eukaryotic organelles can interact through membrane contact sites (MCSs), corresponding to areas of close apposition between membranes involving tethering and func- tional protein complexes, but where membrane fusion does not occur [114]. Besides intercepting vesicular trafficking to obtain host cell lipids [115-118], Chlamydia can also obtain lipids through an ER-inclusion MCS. At least two C. trachomatis Incs (IncD and IncV; Table 1) are involved.

In mammalian cells, the transport of ceramide from the ER to the Golgi involves an MCS and is mediated by the ceramide transporter (CERT); ceramide is then converted into sphingomyelin by synthases in the Golgi [119] (Figure 3C). A small-interfering RNA (siRNA) screen [120], and the observation that, although sphingomyelin is essential for chlamydial growth, blocking vesicular transport of sphingomyelin does not inhibit chlamydial replication [116, 121, 122], both eventually led to the identification of CERT as an important player in C. trachomatis growth [120, 122].

CERT, its ER binding partners (VAMP-associated protein $A$ (VAPA) and VAPB), and host cell sphingomyelin synthases were shown to localize near the inclusion membrane by IF microscopy [120, 122]. Immunoelectron microscopy revealed the localization of CERT in the inclusion membrane presumably connecting with VAPB in nearby ER tubules, thus suggesting the concept of an ER-inclusion MCS [120]. Furthermore, depletion of CERT, VAPA/B, or sphingomyelin synthases reduced the generation of infectious progeny [120]. The physical proximity between the ER and the inclusion has also been revealed by electron tomography [123]. This included the identification of regions, termed pathogen synapses, where T3S system complexes connect the chlamydiae to the inclusion membrane specifically at the points of contact with the ER [123].

How is CERT recruited to the inclusion membrane? Immunoprecipitation from extracts of cells infected by C. trachomatis and ectopically expressing epitope-tagged CERT revealed an interaction with IncD that was further validated [120]. Furthermore, recruitment of CERT to the inclusion membrane is increased in cells infected by $C$. trachomatis overexpressing IncD [124]. Recruitment of VAPA/B to the periphery of the inclusion also correlates with IncD expression, but this occurs indirectly through CERT:VAPA/B interactions mediated by a two phenylalanines in an acidic tract (FFAT) motif in CERT [124]. In summary, ceramide is thought to be transported from the ER into the inclusion through a MCS involving a VAPA/B:CERT:IncD complex (Figure $3 C$ ). In the inclusion, ceramide should be converted into sphingomyelin by a sphingomyelin synthase recruited to the inclusion membrane through a currently unknown mechanism [122].

Another C. trachomatis Inc (IncV) is a factor establishing ER-inclusion tethering [125]. An interaction between IncV and VAPA/B was first reported in a large-scale proteomics screen for human proteins interacting with $C$. trachomatis Incs [85]. The IncV:VAPA/B interaction was subsequently validated and shown to depend on FFAT motifs in IncV [125]. Recruitment of VAPA/B to the periphery of the inclusion is much increased in cells infected by $C$. trachomatis overexpressing IncV, and slightly reduced in cells infected by a $C$. trachomatis incV mutant [125]. Different experiments support that IncV mediates ER-inclusion tethering through its binding to VAPA/B [125] (Figure 3C). A 
C. trachomatis incV mutant does not display a growth defect in cultured cells [100], seemingly suggesting that IncV is not essential for the presumed transport of ceramide into the inclusion by the VAPA/B:CERT:IncD complex in the ER-inclusion MCS. This would indicate that other chlamydial factors should also be involved in establishing ERinclusion tethering. However, ceramide can also be delivered into the inclusion by vesicular transport and the negative impact of depleting CERT on infectious progeny might be explained by reasons other than the role of this host protein in the ER-inclusion MCS.

\section{Incs concentrated at inclusion microdomains and near the centrosome}

About $2 \mathrm{~h}$ after invasion of host cells by $\mathrm{C}$. trachomatis, the nascent inclusion migrates along microtubules towards the centrosome propelled by the minus end-directed microtubule dynein motor $[126,127]$. Several $C$. trachomatis Incs (MrcA (myosin regulatory complex subunit A), CT222, IPAM, CT224, CT228, IncB, IncC, CT288, and CT850; Table 1) have been shown to concentrate at regions of the inclusion membrane near the centrosome, known as inclusion microdomains, which are also enriched in cholesterol and in the phosphorylated active form of Src family kinases [128]. These kinases are involved in the control of a wide range of cellular processes and they have been shown to play several roles in chlamydial infection of host cells that vary between Chlamydia species [129]. The stromal interaction molecule 1 (STIM1) is also present at inclusion microdomains [130], and has been localized to the ER-inclusion MCSs [131]. This suggested that inclusion microdomains [128], the ER-inclusion MCSs $[120,125]$, and the pathogen synapses [123], could correspond to the same structure [130], a possibility which needs to be further examined.

Based on the functions of the associated Incs, the inclusion microdomains have been described as platforms for interaction with the centrosome, microtubules and the actin-myosin cytoskeleton [128, 132]. As described above, IPAM binds a centrosomal protein (CEP170) to modulate the microtubule cytoskeleton [109]; in addition, the ectopic expression of IPAM or of Inc CT224 (as well as of Inc CT225, which, up to now, has not been shown to concentrate at inclusion microdomains) in uninfected mammalian cells inhibits cytokinesis [133]. Although little is known about the function of $C$. trachomatis IncB, its orthologue from $C$. psittaci can bind synaptosome-associated protein (SNAP)-associated protein (SNAPIN) and this might enable the inclusion to associate with microtubules [134]. Inc CT288 binds the centrosomal protein coiled-coil domain containing 146 (CCDC146) [135]; CCDC146 is recruited to the periphery of the inclusion but this is independent of CT288, which might however modulate the function of CCDC146 at the inclusion [135]. Inc CT850 binds dynein light chain Tctex-type 1 (DYNLT1) [132], a dynein subunit; DYNLT1 is found at inclusion microdomains and its depletion affects the association of the inclusion with centrosomes [132]. СT228 and MrcA control chlamydial host cell exit by extrusion and what is known about their function is described below. Finally, some Incs in the microdomains could be primarily involved in heterophilic Inc:Inc interactions helping to stabilize the inclusions and/or organize the microdomains [128], which is also described further below.

Incs controlling chlamydial exit from infected host cells Chlamydial release from infected cells can occur by host cell lysis (preceded by permeabilization of the inclusion membrane) or extrusion (in which the entire inclusion is ejected from the host cell) [105] (Figure 1). C. trachomatis Inc proteins MrcA and CT228 (Table 1) have been shown to regulate extrusion.

In the first description of chlamydial extrusion, it was shown that this process is dependent on the actin motor protein non-muscle myosin II [105]. This motor is comprised by different subunits including a heavy chain with motor and contractile properties (e.g., myosin IIA or IIB isoforms) and a regulatory light chain (e.g., myosin light chain 2 (MLC2)) [136]. Phosphorylation of MLC2 by myosin light chain kinase (MLCK) strongly enhances the activity of the motor, which is inhibited when MLC2 is dephosphorylated by myosin phosphatase. In turn, the activities of MLCK and of the myosin phosphatase are also regulated. For example, the activity of MLCK requires activation by $\mathrm{Ca}^{2+} /$ calmodulin [136], and the myosin phosphatase is inactive when one of its subunits, the myosin phosphatase target subunit 1 (MYPT1), is phosphorylated [137]. C. trachomatis infection of host cells depleted of MLCK, MLC2, or myosin IIA or IIB, showed that chlamydial extrusion depends on all these proteins [138].

Yeast two-hybrid screens revealed that MrcA binds the inositol 1,4,5-trisphosphate receptor type 3 (ITPR3) [130], belonging to a family of channels mediating release of $\mathrm{Ca}^{2+}$ from intracellular stores [139], and that Inc CT228 binds human MYPT1 [138]. The MrCA:ITPR3 and CT228:MYPT1 interactions were validated in C. trachomatis-infected cells $[130,138]$ (Figure 3D). Infection of cultured cells using wild-type C. trachomatis, and mrcA or ct228 null mutant strains, revealed that MrcA is necessary for the localization of ITPR3 at inclusion microdomains [130], and that CT228 is needed for the presence of MYPT1 at the periphery of the inclusion [140]. Furthermore, MrcA and ITPR3 are required for the localization of the phosphorylated forms of MYPT1 (inactive) and of MLC2 (active) at inclusion microdomains [130]. The phosphorylated active form of MLCK also localizes at inclusion microdomains but this is MrCA- and CT228independent $[130,138,140]$. Finally, myosin IIA and IIB can also be detected at inclusion microdomains, but this is at least CT228-independent [138, 140]. Thus, MrcA recruits ITPR3 to inclusion microdomains, while CT228 recruits MYPT1 to the inclusion periphery. The localization at inclusion microdomains of the phosphorylated forms of MYPT1 and MLC2, both indicative of localized activity of myosin II, is also MrcA-dependent, likely through the MrcA:ITPR3 interaction (Figure 3D).

Infection of cultured cells with wild-type or $\operatorname{mrcA}$ mutant strains revealed that extrusion is promoted by MrcA [130]. Furthermore, as mentioned above, STIM1 has been localized at inclusion microdomains and, as ITPR3, STIM1 also controls intracellular $\mathrm{Ca}^{2+}[130,141]$. In uninfected 
cells, STIM1 localizes at the ER where it senses depletion of $\mathrm{Ca}^{2+}$ stores and, in these conditions, mediates the influx of $\mathrm{Ca}^{2+}$ into cells [141]. Presumably there is an Inc, which remains to be identified, recruiting STIM1 to the inclusion membrane (Figure 3D). Cultured cells infected by wild-type C. trachomatis after depletion of ITPR3 or STIM1, or after chelation of intracellular $\mathrm{Ca}^{2+}$, all showed a reduction in inclusion extrusion [130]. Therefore, $\mathrm{Ca}^{2+}$ signalling is modulated by $C$. trachomatis to promote inclusion extrusion, at least through the MrcA:ITPR3 interaction and by cooption/subversion of STIM1 [130]. Interference with $\mathrm{Ca}^{2+}$ signalling could help $C$. trachomatis to promote the activation of the $\mathrm{Ca}^{2+} /$ calmodulin-dependent kinase MLCK or to activate kinases that phosphorylate/inhibit MYPT1 [130, 136]. Regardless of the exact mechanism, this would activate myosin II activity by favouring the phosphorylated active state of MLC2. On the other hand, infection of cultured cells with wild-type $C$. trachomatis or ct228 null mutant strains showed that inclusion extrusion is inhibited by CT228 [140]. In addition, infection experiments in MYPT1depleted cells indicate that this inhibitory role of CT228 depends on MYPT1 [140].

In summary, the direct or indirect action of Inc proteins on the enzymes (myosin phosphatase or MLCK) that control the phosphorylation state of MLC2 enables $C$. trachomatis to regulate inclusion extrusion by modulating myosin II activity. But why is this important for $C$. trachomatis? The mrcA mutant showed a slight growth defect in cultured cells that, however, could not be complemented [130]. On the other hand, the ct228 mutant was not impaired for growth in cultured cells but showed a delay in clearance and a reduction in systemic humoral response in a mouse model of infection [140]. This has implications for in vivo infection, also suggested by studies indicating that extrusion facilitates the subsequent contact of $C$. trachomatis with dendritic cells and macrophages [142, 143].

\section{Incs binding 14-3-3 proteins}

The 14-3-3 phospho-serine/phospho-threonine binding proteins are present in all eukaryotic cells, where they have many and varied interacting partners and regulate a wide diversity of cellular processes [144]. Different 14-3-3 protein isoforms have been shown to bind several Inc proteins. The 14-3-3 $\beta$ isoform was even the first host protein shown to bind an Inc (IncG) and to be recruited to the periphery of the inclusion membrane [145]. More recently, immunoprecipitation of Incs ectopically expressed in cultured cells followed by mass spectrometry revealed the binding of different 14-3-3 isoforms to $\operatorname{InaC}(\varepsilon, \eta, \zeta, \gamma, \theta$, and $\beta$ isoforms) [15] and to Inc СT006 ( $\gamma, \beta$, and $\eta$ isoforms) [85]. The interaction between InaC and 14-3-3 $\beta$ and 14-3$3 \varepsilon$ was further validated, and the recruitment of these two 14-3-3 isoforms to the periphery of the inclusion membrane was shown to involve InaC [15]. There is evidence suggesting that $14-3-3 \beta$ sequesters the $B C L 2$ associated agonist of cell death (BAD) protein at the periphery of the inclusion membrane to protect the host cell from apoptosis [146]. However, in general, the role in C. trachomatis host cell infection of the 14-3-3 proteins and of its reported interactions with Inc proteins is unclear.

\section{Incs involved in Inc:Inc heterophilic interactions}

Many Incs have relatively long stretches of their polypeptide chains predicted to be exposed on the host cell cytosol, while others have putative host cytosolic regions of less than 30 amino acid residues [147]. This suggested that Incs predictably less exposed to the host cell cytosol could be mainly involved in Inc:Inc interactions required for the stability of the inclusion or to organize the functions of other host protein-interacting Incs [147]. The latter hypothesis has also been suggested by analyses of the ectopic expression of Incs in cultured human cells [148]. Inc:Inc interactions have been directly screened by bacterial two-hybrid, and this suggested or confirmed several homotypic (IncV, IncD, IncF, IncA, CT222, IPAM, IncC, CT249, and InaC) and heterotypic Inc:Inc interactions [75]. In particular, IncF and CT222 should have small regions exposed to the host cell cytosol and they were shown to bind several other Incs [75]: IncF to IncV, IncD, IncG, IncC, IncA, CT249 and CT850, and CT222 to IncD, IPAM, CT224, and CT850. The CT222:СT850 interaction was also detected in C. trachomatis-infected cells [128]. Furthermore, an IPAM:CpoS interaction revealed by bacterial two-hybrid [75] was also detected in infected cells [98].

Several of the Incs involved in heterophilic Inc:Inc interactions have been localized to ER-inclusion MCSs (IncV, IncD) or to inclusion microdomains (CT222, IPAM, CT224, IncC, CT850). A C. trachomatis incC mutant revealed an unstable vacuolar membrane [100], consistent with the possible involvement of IncC in heterophilic Inc-Inc interactions; however, the disruption of incV, ct224, and ct850 did not lead to unstable inclusions [100].

\section{An inc gene important for virulence in vivo, but inactivat- ed during in vitro passage}

Different lines of evidence indicate that in vitro serial passage of trachoma and genital C. trachomatis strains, but not of LGV strains, leads to the inactivation of the ct135 gene [149-153], encoding an Inc (Table 1). Because the ct135 gene is intact in low-passage genital clinical isolates, this indicates that, at least in these strains, ct135 is under positive selection in vitro, and negative selection in vivo [153]. Accordingly, a C. trachomatis serovar D strain with a single nucleotide insertion in the middle of the ct135 gene (which might correspond to a null mutation) is less virulent in a mouse infection model than an isogenic strain with a single nucleotide deletion in the beginning of the ct135 gene (which might enable the putative production of a near intact CT135 protein) $[149,150]$. In contrast, these two strains do not display differences during their growth in vitro [149]. Therefore, although its mode of action is presently unknown, CT135 is important for $C$. trachomatis virulence in vivo. 
TABLE 2: $C$. trachomatis non-Inc proteins secreted into the host cell cytoplasm, inclusion membrane, or inclusion lumen ${ }^{\text {. }}$

\begin{tabular}{|c|c|c|c|c|}
\hline \multicolumn{3}{|c|}{ Protein (annotation/name) } & \multirow{2}{*}{$\begin{array}{l}\text { Secretion pathway; host cell protein targets; localization in in- } \\
\text { fected host cells; and proposed function(s) and/or activity }\end{array}$} & \multirow[b]{2}{*}{ References } \\
\hline $\begin{array}{l}\text { Strain } \\
\text { D/UW3 }\end{array}$ & $\begin{array}{l}\text { Strain } \\
\text { L2/434 }\end{array}$ & General & & \\
\hline СТ042 & CTL0298 & $\mathrm{Glg} X$ & $\begin{array}{l}\text { Secretion: T3S; targets: } \mathrm{N} / \mathrm{A} ; \text { localization: inclusion lumen and } \\
\text { membrane; function: glycogen hydrolase. }\end{array}$ & [289] \\
\hline СТ049 & CTL0305 & Pls1 & $\begin{array}{l}\text { Secretion: unknown but T3S-independent; targets: unknown; local- } \\
\text { ization: inclusion lumen; function: unknown. }\end{array}$ & [293] \\
\hline СТ050 & CTL0306 & Pls2 & $\begin{array}{l}\text { Secretion: unknown but T3S-independent; targets: unknown; local- } \\
\text { ization: inclusion lumen; function: unknown. }\end{array}$ & [293] \\
\hline СТ089 & CTL0344 & CopN & $\begin{array}{l}\text { Secretion: T3S; targets: unknown; localization: inclusion mem- } \\
\text { brane; function: regulation of the T3S system. }\end{array}$ & {$[23,50]$} \\
\hline CT105 & CTL0360 & CteG & $\begin{array}{l}\text { Secretion: T3S; targets: unknown; localization: Golgi and host cell } \\
\text { plasma membrane; function: modulation of eukaryotic vesicular } \\
\text { trafficking. }\end{array}$ & {$[227,228]$} \\
\hline CT142 & CTL0397 & - & $\begin{array}{l}\text { Secretion: T3S; targets: unknown; localization: inclusion lumen; } \\
\text { function: unknown. }\end{array}$ & {$[227,294]$} \\
\hline CT143 & CTL0398 & - & $\begin{array}{l}\text { Secretion: T3S; targets: unknown; localization: inclusion lumen; } \\
\text { function: possible involvement in inflammatory processes. }\end{array}$ & $\begin{array}{c}{[227,292} \\
294-296] \\
\end{array}$ \\
\hline CT144 & CTL0399 & - & $\begin{array}{l}\text { Secretion: T3S; targets: unknown; localization: inclusion lumen; } \\
\text { function: unknown. }\end{array}$ & $\begin{array}{l}{[227,294,} \\
295]\end{array}$ \\
\hline CT156 & Absent & Lda1 & $\begin{array}{l}\text { Secretion: unknown; targets: unknown; localization: around the } \\
\text { inclusion, overlapping with LD-like structures; function: targeting } \\
\text { LDs. }\end{array}$ & {$[54,219]$} \\
\hline CT163 & CTL0419 & Lda2 & $\begin{array}{l}\text { Secretion: unknown; targets: unknown; localization: around the } \\
\text { inclusion, overlapping with LD-like structures, and within LD bio- } \\
\text { chemical fractions; function: targeting LDs. }\end{array}$ & {$[54,219]$} \\
\hline CT311 & CTL0563 & - & $\begin{array}{l}\text { Secretion: Sec-dependent/T2S; targets: unknown; localization: } \\
\text { inclusion lumen, cytosol and nucleus; function: unknown. }\end{array}$ & {$[32,279]$} \\
\hline CT456 & CTL0716 & TarP & $\begin{array}{l}\text { Secretion: T3S; targets: actin, ABI1, VAV2, PI3K p85 subunit, SHC1; } \\
\text { localization: cytosol, near the nascent inclusion, and membrane } \\
\text { fractions of infected cells; function: actin nucleator; modulation of } \\
\text { actin-mediated changes involved in host cell invasion, and of host } \\
\text { cell survival. }\end{array}$ & $\begin{array}{c}{[158,170} \\
175-178 \\
186,190]\end{array}$ \\
\hline CT473 & CTL0734 & Lda3 & $\begin{array}{l}\text { Secretion: unknown; targets: unknown; localization: around the } \\
\text { inclusion, overlapping with LD-like structures; function: targeting } \\
\text { and modulation of LDs. }\end{array}$ & $\begin{array}{l}{[54,219,} \\
220]\end{array}$ \\
\hline CT529 & CTL0791 & Cap1 & $\begin{array}{l}\text { Secretion: T3S; targets: unknown; localization: inclusion mem- } \\
\text { brane; function: associates with LDs. }\end{array}$ & $\begin{array}{c}{[50,63} \\
221,280] \\
\end{array}$ \\
\hline CT620 & CTL0884 & - & $\begin{array}{l}\text { Secretion: T3S; targets: Hrs/ESCRT machinery; localization: inclu- } \\
\text { sion lumen, cytosol and nucleus; function: unknown. }\end{array}$ & {$[212,214]$} \\
\hline CT621 & CTL0885 & - & $\begin{array}{l}\text { Secretion: T3S; targets: Hrs/ESCRT machinery; localization: inclu- } \\
\text { sion lumen, cytosol and nucleus; function: unknown. }\end{array}$ & {$[212-214]$} \\
\hline CT622 & CTL0886 & - & $\begin{array}{l}\text { Secretion: T3S; targets: unknown; localization: inclusion lumen and } \\
\text { cytosol; function: involved in bacterial infectivity and growth; } \\
\text { structural similarities with GGTases and synthases. }\end{array}$ & {$[200,201]$} \\
\hline CT694 & CTL0063 & TmeA & $\begin{array}{l}\text { Secretion: T3S; targets: AHNAK; localization: cytosol, near the nas- } \\
\text { cent inclusion, and host cell plasma membrane; function: involved } \\
\text { in host cell invasion. }\end{array}$ & $\begin{array}{c}{[185,186,} \\
189-191]\end{array}$ \\
\hline CT695 & CTL0064 & TmeB & $\begin{array}{l}\text { Secretion: T3S; targets: unknown; localization: cytosol, near the } \\
\text { nascent inclusion, and inclusion membrane; function: unknown. }\end{array}$ & {$[185,186]$} \\
\hline CT711 & CTL0080 & - & $\begin{array}{l}\text { Secretion: T3S; targets: Hrs/ESCRT machinery; localization: nucle- } \\
\text { us; function: unknown. }\end{array}$ & {$[212,214]$} \\
\hline CT737 & CTL0106 & NUE & $\begin{array}{l}\text { Secretion: T3S; targets: histones } \mathrm{H} 2 \mathrm{~B}, \mathrm{H} 3 \text { and } \mathrm{H} 4 \text {; localization: nu- } \\
\text { cleus; function: histone methyltransferase. }\end{array}$ & [226] \\
\hline СT795 & CTL0164 & - & $\begin{array}{l}\text { Secretion: Sec-dependent/T2S; targets: unknown; localization: } \\
\text { inclusion lumen and cytosol; function: unknown. }\end{array}$ & [278] \\
\hline
\end{tabular}


TABLE 2: $C$. trachomatis non-Inc proteins secreted into the host cell cytoplasm, inclusion membrane, or inclusion lumen ${ }^{\text {a }}$ (continued).

\begin{tabular}{|c|c|c|c|c|}
\hline \multicolumn{3}{|c|}{ Protein (annotation/name) } & \multirow{2}{*}{$\begin{array}{l}\text { Secretion pathway; host cell protein targets; localization in in- } \\
\text { fected host cells; and proposed function(s) and/or activity }\end{array}$} & \multirow[b]{2}{*}{ References } \\
\hline $\begin{array}{l}\text { Strain } \\
\text { D/UW3 }\end{array}$ & $\begin{array}{l}\text { Strain } \\
\text { L2/434 }\end{array}$ & General & & \\
\hline CT798 & CTL0167 & GlgA & $\begin{array}{l}\text { Secretion: T3S; targets: N/A; localization: inclusion lumen and cy- } \\
\text { tosol; function: glycogen synthase. }\end{array}$ & [288] \\
\hline СТ806 & CTL0175 & Ptr & 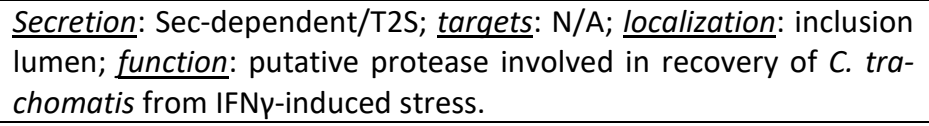 & [292] \\
\hline CT823 & CTL0195 & HtrA & $\begin{array}{l}\text { Secretion: Sec-dependent/T2S; targets: unknown; localization: } \\
\text { inclusion lumen and cytosol; function: serine protease with roles in } \\
\text { the chlamydial periplasm, but unknown function in the host cell } \\
\text { cytosol. }\end{array}$ & {$[261,262]$} \\
\hline CT858 & CTL0233 & CPAF & $\begin{array}{l}\text { Secretion: Sec-dependent/T2S; targets: several, but many shown } \\
\text { to be experimental artifacts; localization: inclusion lumen and cy- } \\
\text { tosol; function: promotion of chlamydial survival in the mouse } \\
\text { lower genital tract; evasion of innate immune responses; chlamyd- } \\
\text { ial lytic exit; inhibition of host cell cytokinesis; inhibition of p65 } \\
\text { nuclear translocation (based on phenotypes displayed by cpaf mu- } \\
\text { tant } C \text {. trachomatis). }\end{array}$ & $\begin{array}{l}{[231,232} \\
234-237 \\
240,241 \\
245,248 \\
250-252 \\
255]\end{array}$ \\
\hline СТ867 & CTL0246 & $\begin{array}{l}\text { ChlaDUB2 } \\
\text { /Cdu2 }\end{array}$ & $\begin{array}{l}\text { Secretion: unknown; targets: unknown; localization: inclusion } \\
\text { membrane and host cell plasma membrane; function: DUB and } \\
\text { deneddylase activities; contributes to Golgi redistribution around } \\
\text { the inclusion. }\end{array}$ & $\begin{array}{l}{[189,204,} \\
206]\end{array}$ \\
\hline CT868 & CTL0247 & $\begin{array}{l}\text { ChlaDUB1/ } \\
\text { Cdu1 }\end{array}$ & $\begin{array}{l}\text { Secretion: unknown; targets: MCL1, IKB } \alpha \text {; localization: inclusion } \\
\text { membrane; function: DUB, deneddylase and acetyl transferase } \\
\text { activities; contributes to Golgi redistribution around the inclusion; } \\
\text { inhibition of NF-KB signalling and of host cell death. }\end{array}$ & $\begin{array}{l}{[11,189} \\
204,206 \\
209]\end{array}$ \\
\hline CT875 & CTL0255 & TepP & $\begin{array}{l}\text { Secretion: T3S; targets: CRK, CRKL, PI3K subunits, and GSK3B; local- } \\
\text { ization: cytosol, near the early vacuole; function: modulation of } \\
\text { host gene expression related with immune signalling in early stag- } \\
\text { es of infection. }\end{array}$ & {$[195,196]$} \\
\hline \multicolumn{3}{|c|}{ pGP3/pORF5 } & $\begin{array}{l}\text { Secretion: unknown; targets: cathelicidin LL-37 (antimicrobial pep- } \\
\text { tide); localization: inclusion lumen and cytosol; function: neutrali- } \\
\text { zation of the LL-37activity, evasion of the acidic barrier in the vagi- } \\
\text { na, modulation of inflammatory responses, inhibition of host cell } \\
\text { apoptosis. }\end{array}$ & $\begin{array}{l}{[268,274-} \\
277]\end{array}$ \\
\hline
\end{tabular}

${ }^{a}$ Only C. trachomatis proteins reported to be experimentally detected in the inclusion membrane, inclusion lumen, host cell cytoplasm or nucleus are listed. In addition, there is functional evidence for secretion and effector role of CT166 (Chlamydia cytotoxin targeting RAC1 that might contribute for downmodulating actin cytoskeleton changes during chlamydial invasion of host cells [197, 199]), CT619/CTL0883 and CT712/CTL0081 (as CT620/CTL0884, CT621/CTL0885, and CT711/CTL0080, listed in Table 2, these two proteins contain the Chlamydiaceaunique DUF582 domain and bind components of the ESCRT machinery [212, 214]), and CT847/CTL0217 (binds GCIP [229]) in the host cell cytoplasm, and of GlgB, GIgP, MalQ and MrsA in the inclusion lumen [14, 289]. See list of abbreviations and main text for abbreviations and protein nomenclature, respectively.

\section{TRACHOMATIS NON-INC PROTEINS DELIVERED TO THE OUTSIDE OF THE INCLUSION}

Besides Incs, 24 C. trachomatis proteins have been shown to be delivered outside of the inclusion and detected in the host cell plasma membrane, cytoplasm or nucleus, and/or at the inclusion membrane (Table 2). Ten of these proteins have also been detected within the inclusion lumen, outside of the chlamydiae (Table 2). Furthermore, although their delivery outside of the inclusion was never formally shown, there are C. trachomatis proteins (CT166, CT619, CT712 and CT849) for which there is evidence for an effector role (see Table 2 footnote). We will not consider C. trachomatis secreted proteins that likely form the T3S system translocon either in the host cell plasma membrane or in the inclusion membrane (CT578/CTL0841/CopB, CT579/CTL0842/CopD, CT860/CTL0235/CopD2, CT861/ CTL0236/CopB2) [63, 154, 155], or the T3S system needle at the bacterial surface (CT666/CTL0035/CdsF) [156], or 
that might control T3S system needle length (CT671/CTL0040/CdsP) [63, 157].

\section{Effector proteins packed in EBs}

The invasion of host cells by EBs involves first interactions between different chlamydial adhesin molecules and diverse eukaryotic receptors [6]. Furthermore, multiple evidence indicates that $C$. trachomatis EBs contain functional T3S systems and are packed with effector proteins injected upon contact of the chlamydiae with host cells [26, 158161]. Some of these effectors have been identified and characterized; they at least modulate post-adhesion chlamydial invasion and interactions of the nascent inclusion with host cells (Figure 4A).

The identification of TarP and characterization of its host cell targets and functions

Invasion of host cells by $C$. trachomatis induces protein tyrosine phosphorylation [162, 163], and involves alterations in the host cell actin cytoskeleton [104, 164]. The alterations in the actin cytoskeleton are dependent on the Rac family small GTPase 1 (RAC1) [165], and on the cell division cycle 42 (CDC42) protein [164], both belonging to the Rho family of small GTPases, involved in the control of the dynamics of microfilaments [166]. During C. trachomatis invasion, RAC1 recruits Wiskott-Aldrich syndrome protein family member 2 (WAVE2) and abl interactor 1 (ABI1), while CDC42 recruits Neural Wiskott-Aldrich syndrome protein (N-WASP), promoting the initiation of actin polymerization by the actin-related protein $2 / 3$ (ARP2/3) complex $[164,167]$. The tour de force that led to the identification of TarP (chlamydial translocated actin-recruiting phosphoprotein) (Table 2) was crucial for the ongoing clarification of how Chlamydia modulate all these processes [158].

Immunoprecipitation with an anti-phosphotyrosine antibody followed by mass spectrometry from protein extracts of cells infected by $C$. trachomatis revealed a tyrosine phosphorylated chlamydial protein [158]. Because the protein was associated with EBs but exposed in the host cell cytosol, it was hypothesized that it could be a T3S substrate, which was confirmed using Yersinia as heterologous bacteria [158]. Furthermore, actin was recruited to sites of tyrosine phosphorylation near EBs invading host cells, and ectopic expression in mammalian cells of the identified chlamydial protein also led to its tyrosine phosphorylation and to F-actin recruitment [158]. This indicated that C. trachomatis EBs use their T3S system to deliver an effector (TarP) into host cells that is then tyrosine phosphorylated, and which is associated with actin polymerization at chlamydial entry sites (Figure 4A).

TarP is present in all C. trachomatis serovars and Chlamydia species $[168,169]$. C. trachomatis TarP includes a tyrosine-rich repeat domain corresponding to the region that is tyrosine phosphorylated [168]. The number of tyrosine-rich repeats is variable among TarP from different C. trachomatis serovars and is absent in TarP from other Chlamydia species [168-170]. Notwithstanding, C. trachomatis TarP is phosphorylated by Abl and Src family tyrosine kinases [171, 172], and possibly by other kinases [173]. In eukaryotic cells, tyrosine phosphorylated proteins are often recognized by SRC homology 2 (SH2) domains in other proteins [174]. In the case of TarP, its tyrosine phosphorylation within host cells has been shown to mediate binding to the SH2 domain-containing adaptor protein 1 (SHC1) and subsequent activation of signalling involving mitogenactivated protein kinases that promotes host cell survival [175] (Figure 4A).

The tyrosine-rich repeats of $C$. trachomatis TarP are also associated with binding to host cell proteins which mediates signalling leading to actin polymerization [176]. Ectopic expression in mammalian cells of a hybrid protein comprising only one of the tyrosine-rich repeats of $C$. trachomatis TarP leads to its tyrosine phosphorylation and to F-actin and RAC1 recruitment [176]. Furthermore, an oligopeptide with a single $C$. trachomatis tyrosine-rich repeat carrying phosphorylated tyrosines pulls down RAC1 and its activators, the $\mathrm{SH} 2$ domain-containing vav guanine nucleotide exchange factor 2 (VAV2), and a complex formed by $A B I 1$, SOS Ras/Rac guanine nucleotide exchange factor 1 (SOS1), and epidermal growth factor receptor pathway substrate 8 (EPS8) [176]. The binding of TarP to the $A B I 1: S O S 1: E P S 8$ complex is likely mediated by $A B I 1$ and is probably indirect, because $A B I 1$ lacks a SH2 domain [176]. The activation of RAC1 by VAV2 requires the phospholipid phosphatidylinositol $(3,4,5)$-trisphosphate (PIP3), which is present at chlamydial entry sites [176]. Accordingly, the $\mathrm{SH} 2$ domain-containing $\mathrm{p} 85$ subunit of a class I phosphatidylinositol 3-kinase (PI3K), which generates PIP3 from plasma membrane-abundant phosphatidylinositol $(4,5)$ bisphosphate (PIP2), also binds to a TarP-derived oligopeptide with phosphorylated tyrosines [176]. VAV2, SOS1, ABI1, and EPS 8 are recruited and colocalize at sites of $C$. trachomatis entry into host cells, and are all required for chlamydial invasion [176]. In agreement with a role of TarP phosphorylation in C. trachomatis invasion, the chlamydial uptake process is inhibited after expression in $C$. trachomatis of a TarP mutant protein lacking the tyrosine-rich repeats [177]. This dominant-negative effect is a consequence of TarP oligomerization through a proline-rich domain $[177,178]$. Overall, this suggests a model in which tyrosine phosphorylated $C$. trachomatis TarP binds and recruits RAC1 activators (VAV2 and the ABI1:SOS1:EPS8 complex), ultimately leading (through WASP2 and $A B I 1$ ) to the initiation of localized actin polymerization by the ARP2/3 complex and promotion of chlamydial invasion of host cells [176] (Figure 4A).

TarP proteins lacking tyrosine-rich repeats also recruit F-actin, indicating that tyrosine phosphorylation of TarP is not an absolute requirement for actin recruitment and host cell invasion [168]. In fact, TarP also possesses globu$\operatorname{lar}(\mathrm{G})$-actin binding and F-actin-binding domains that are present in all $C$. trachomatis serovars and Chlamydia species $[169,178]$ (Figure 4A). TarP binds actin directly, promotes its nucleation in vitro [178], and can cooperate with the ARP2/3 complex to increase the rate of actin polymerization in vitro [179]. The F-actin-binding domains of TarP mediate bundling of actin filaments, an activity that does 

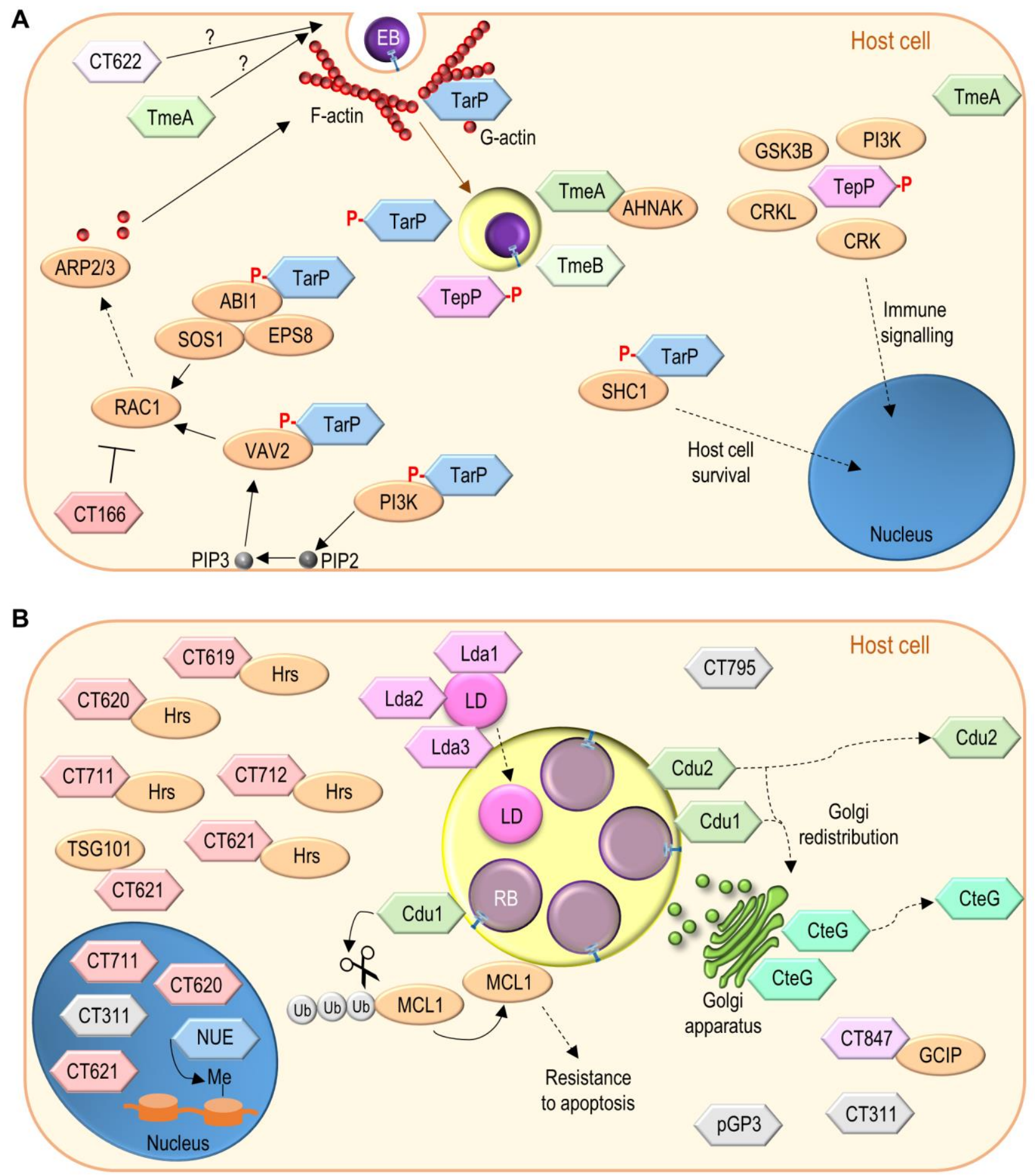

FIGURE 4: Function of non-Inc C. trachomatis effectors. (A) C. trachomatis effectors (TarP, TmeA, TmeB, CT166, CT622) packed in EBs and delivered into host cells during invasion; besides TarP, TmeA and CT622 also promote C. trachomatis invasion but their mode of action is unknown. (B) C. trachomatis non-Inc proteins that have been detected in the host cell cytoplasm, nucleus, or inclusion membrane (Cdu1, Cdu2, CteG, Lda1, Lda2, Lda3, NUE, pGP3, CT311, CT620, CT621, CT711, and CT795; GlgX, CopN, Cap1, GlgA, HtrA, and CPAF are not represented) or for which there is functional evidence for an effector role (CT619, CT712, CT847). It is unclear whether these proteins are delivered into host cells by EBs or by RBs (as represented), or by both chlamydial forms. Among the chlamydial proteins represented and not binding a host cell protein, pGP3 has been shown to interact with the antimicrobial peptide cathelicidin LL-37 but this likely occurs extracellularly [276]. See list of abbreviations, main text, and Table $\mathbf{2}$ for details. 
not require the G-actin binding domain [180]. TarP mutant proteins lacking the $\mathrm{G}$-actin-binding domain inhibit actin polymerization by the wild-type protein and when expressed in C. trachomatis they reduce the ability of the recombinant chlamydiae to invade host cells [177]. Similarly, an antibody specifically recognizing the G-actin-binding domain of TarP inhibits both actin polymerization in vitro and chlamydial entry into host cells [170]. Overall, this indicates that TarP and its actin-binding domains are important for $C$. trachomatis invasion.

In summary, delivery of TarP into host cells by the T3S system in C. trachomatis EBs leads to the tyrosine phosphorylation of the effector within infected cells. This activates signalling pathways likely promoting host cell survival and localized actin polymerization resulting in chlamydial invasion (Figure 4A). Direct actin nucleation and bundling by TarP should also mediate $C$. trachomatis invasion. Furthermore, $C$. caviae TarP has been shown to target focal adhesion kinase (FAK) and vinculin during chlamydial invasion through protein motifs also present in TarP orthologues from other Chlamydia species, including C. trachomatis $[181,182]$. Finally, the $C$. pneumoniae TarP orthologue, which also binds vinculin [183], can stabilize F-actin by preventing the activity of the host actin-severing protein cofilin [184].

\section{The membrane associated TmeA and TmeB: chlamydial} invasion and more

The idea that chlamydial genes with mRNA levels first detected late in the chlamydial developmental cycle could be candidates for encoding proteins packed in EBs led to the identification of $C$. trachomatis TmeA (translocated membrane-associated effector A) and TmeB (Table 2) as T3S effectors $[185,186]$.

TmeA and TmeB are encoded by a small tmeAB operon [186]. They are indeed present in C. trachomatis EBs [159, $185,186]$, and their secretion by Yersinia is T3S-dependent $[185,187]$. IF microscopy of $C$. trachomatis-infected cells revealed that TmeA and TmeB localize in the host cell cytoplasm, nearby the nascent inclusion, between 1-3 $\mathrm{h}$ postinfection $[185,186]$ (Figure 4A). The TEM-1 $\beta$-lactamase reporter assay, enabling to monitor the delivery of bacterial effector proteins into mammalian host cells [188], allowed to detect TmeA and TmeB (and TarP) in the host cell cytoplasm $24 \mathrm{~h}$ post-infection [186]. Furthermore, at $24 \mathrm{~h}$ post-infection, TmeA was detected at the host cell plasma membrane by using the split-GFP technology [189], and TmeB was detected around the inclusion membrane by IF microscopy [186]. Biochemical experiments also showed the association of TmeA with membranes in C. trachomatis-infected cells [190]. In summary, TmeA and TmeB are delivered by $C$. trachomatis into host cells early in infection and they localize near the nascent inclusion. Later in infection, TmeA associates with the host cell plasma membrane and TmeB remains associated with the inclusion membrane.

C. trachomatis tme $A$ and $t m e B$ mutants have been generated $[10,12]$. Characterization of the mutant strains revealed defects of the tmeA mutants for invasion of host cells and in a mouse infection model $[12,191]$, but thus far no defects have been reported for the tme $B$ mutant [191]. The mechanism by which TmeA promotes chlamydial invasion is presently unknown. A yeast two-hybrid screen revealed that TmeA binds human AHNAK nucleoprotein (AHNAK) [185]; this interaction was also detected in mammalian cells infected by $C$. trachomatis for $5 \mathrm{~h}$ [191] (Figure 4A). AHNAK binds actin and mediates F-actin bundling [192, 193], and TmeA can inhibit this actin bundling activity of AHNAK in vitro [191]. However, transient recruitment of endogenous AHNAK to the nascent inclusion is independent of TmeA [191]. Moreover, a C. trachomatis tmeA mutant shows a defect in host cell invasion regardless of the cells being AHNAK-positive or AHNAK knockedout, and there is no defect in invasion associated with infection of AHNAK knocked-out cells by wild-type $C$. trachomatis [191]. Therefore, TmeA is required for efficient invasion of host cells by $C$. trachomatis but this is apparently independent of the TmeA:AHNAK interaction.

\section{Modulation of immune signalling by TepP}

Many T3S effectors require specific bacterial cytosolic chaperones for their proper delivery into target host cells [20]. TarP, TmeA and TmeB had been shown to share the same T3S chaperone (Slc1; SycE-like chaperone 1) [187, 194]. Additional binding partners of Slc1 were then searched for within $C$. trachomatis EBs through immunoprecipitation of Slc1 followed by mass spectrometry analysis of pulled down proteins [195]. This led to the identification of a $C$. trachomatis T3S effector protein that based on its properties was named TepP (translocated early phosphoprotein) (Table 2).

TepP is secreted by Yersinia in a T3S-dependent manner, which is promoted by Slc1 [195], as also observed for other Slc1 partners (TarP, TmeA and TmeB) [187, 194]. As TarP, TmeA, and TmeB (see above), TepP is delivered into the cytoplasm of $C$. trachomatis infected cells and localizes near the nascent inclusion [195] (Figure 4A). Furthermore, as TarP, TepP is rapidly tyrosine phosphorylated by host cell Src family kinases after its chlamydiae-mediated delivery into infected cells $[195,196]$. However, TepP is also phosphorylated at serine residues [195].

Two different tepP mutant strains have been isolated and characterized $[195,196]$. C. trachomatis strains carrying nonsense or inactivating insertion mutations in tep $P$ did not show defects in host cell invasion or in chlamydial growth in HeLa cells $[195,196]$, but the tepP insertional mutant strain was defective for growth in A2EN cervical epithelial cells [196]. Furthermore, A2EN cells infected by both tepP mutant strains showed alterations in the expression of genes associated with innate immune responses, including type I IFN responses, such as reduced induction of IFN-induced peptides with the tetratricopeptide repeat (IFIT) genes [195, 196].

In C. trachomatis-infected cells, TepP has been shown to bind the CRK proto-oncogene, adaptor protein (CRK), CRK like proto-oncogene, adaptor protein (CRKL), glycogen synthase kinase $3 \beta$ (GSK3B), and different subunits of class I PI3K $[195,196]$ (Figure 4A). CRK, CRKL, and PI3K (and 
GSK3B, but to a lesser extent) are recruited to the proximity of the nascent inclusion in a TepP-dependent manner $[195,196]$. Binding to, and recruitment of, at least CRKL and PI3K does not depend on tyrosine phosphorylation of TepP by Src family kinases [196]. However, the induction in the expression of IFIT genes in cells infected by TepPexpressing chlamydiae depends on PI3K [196]. This could be related with increased PI3K activity in the vicinity of the nascent inclusion by TepP-recruited PI3K [196].

In summary, TepP is a $C$. trachomatis T3S effector recruiting CRK and CRKL adaptor proteins, as well as PI3K, to modulate innate immune signalling early in host cell infection that is likely required for chlamydial growth.

Disruption of the host cell actin cytoskeleton by the C. trachomatis cytotoxin

Chlamydial genomes encode proteins displaying homology with the large Clostridium difficile toxins [197], which inactivate Rho family GTPases through their glucosyltransferase activity [198]. Some of these chlamydial proteins show conservation of the amino acid residues critical for the glucosyltransferase activity of large clostridial toxins [197]. This is the case of CT166 (Table 2), encoded by some, but not all, $C$. trachomatis strains. The CT166-encoding strains cause a cytopathic effect (cell rounding and dramatic alterations in the actin cytoskeleton) in cultured cells, and the severity of the effect correlates with the multiplicity of infection [197]. Ectopic expression of CT166 in mammalian cells recapitulates the cytopathic effect observed in C. trachomatis-infected cells [199]. This effect of ectopically expressed CT166 depends on RAC1 and on the conserved amino acid residues required for glucosyltransferase activity of the clostridial toxins [199]. The CT166 protein is present in EBs and can be detected in protein extracts of cells infected by $C$. trachomatis up to $1 \mathrm{~h}$ post-infection [197]. Furthermore, in infected cells, the cytopathic effect does not require chlamydial transcription and translation [197].

In summary, while direct evidence is lacking, CT166 is probably delivered into host cells by EBs through the T3S system of some $C$. trachomatis strains. Within the cytoplasm of infected cells, CT166 likely glucosylates and inactivates RAC1. This can potentially downmodulate the RAC1-mediated signalling resulting in actin cytoskeleton changes required for chlamydial invasion (Figure 4A).

Disruption of the gene encoding the effector protein CT622 results in pleiotropic defects

The $C$. trachomatis CT622 protein was initially identified in the host cell cytosol and within the inclusion lumen [200]. The N-terminal region of CT622 can direct secretion of a hybrid protein by $S$. flexneri in a T3S-dependent manner [201]. Although CT622 has been detected in the host cell cytosol only from $36 \mathrm{~h}$ post-infection $[200,201]$, its presence within EBs bound to a possible T3S chaperone [159, 201], and the phenotypes associated with the ct622 mutant strain (see below) [201], indicate a possible much earlier function in the host cell cytoplasm (Figure 4A).

The 3D structure of the C-terminal of CT622 has been determined by $\mathrm{X}$-ray crystallography and revealed similari- ty with geranylgeranyl transferases (GGTases) and synthases [201]. Proteins with the GGTase activity transfer a 20-carbon lipophilic chain (geranylgeranyl) to the C-terminus of its specific targets [202], which, is for example, essential for the association of RAB proteins with cellular membranes. However, up to now, in vitro GGTase activity has not been detected for CT622 [201]. On the other hand, characterization of a C. trachomatis ct622 mutant revealed several defects during the chlamydial developmental cycle [201]. The mutant strain shows reduced production of infectious progeny that is at least, but not only, related to defects in chlamydial invasion of host cells and in EB to RB conversion [201]. Furthermore, the initial C. trachomatis-dependent protein tyrosine phosphorylation is much reduced after infection by the ct622 mutant strain [201]. Overall, this indicates that CT622 is an effector protein important throughout the developmental cycle of C. trachomatis.

\section{C. trachomatis deubiquitinases}

The reversible post-translational modification of proteins by ubiquitination, or by other ubiquitin-like modifications like neddylation, is fundamental to control several eukaryotic cell processes and is often targeted by pathogens [203]. In the case of $C$. trachomatis, a ubiquitin-based probe was used to search for possible deubiquitinases (DUBs) within infected cells [204]. This eventually led to the identification of two chlamydial DUBs, named Cdu1 (also known as ChlaDUB1) and Cdu2 (also known as ChlaDUB2) [11, 204, 205] (Table 2). Cdu1 or Cdu2 display DUB and deneddylase activities when ectopically expressed in mammalian cells [204]. Furthermore, purified Cdu1 has both DUB and acetyltransferase activities [206]. This in vitro DUB and acetyltransferase activities of Cdu1 involve the same catalytic centre in the enzyme, and the dual specificity is conferred by a helix that can contact either ubiquitin or coenzyme A [206].

In C. trachomatis-infected cells, Cdu1 and Cdu2 were shown to be delivered into the cytoplasm of host cells and, at $24 \mathrm{~h}$ post-infection, they were both detected at the inclusion membrane $[11,189]$ (Figure 4B). However, at $48 \mathrm{~h}$ post-infection, while Cdu1 localizes only at the inclusion membrane, Cdu2 is also detected at the host cell plasma membrane [189] (Figure 4B). Both chlamydial DUBs possess a transmembrane helix within their $\mathrm{N}$-terminal region that might mediate insertion into cellular membranes. Although the mechanism by which Cdu1 and Cdu2 are delivered by the chlamydiae into the cytoplasm of host cells has not been directly addressed, bioinformatics strongly suggests that they are T3S substrates [207].

C. trachomatis cdu1 and cdu2 null-mutants have been isolated and characterized $[11,206]$. By comparison to the wild-type strain, a C. trachomatis cdu1 null-mutant showed reduced generation of infectious progeny in A549 cells (a lung epithelial cell line) [206], or in IFNY-stimulated primary human fimbriae cells [11], but not in HeLa cells [206]. Furthermore, the cdu1 mutant strain displayed a defect in a mouse model of infection [11]. In contrast, a cdu2 nullmutant strain did not show a defect in the generation of 
infectious progeny in both A549 and HeLa cells [206]. Regarding $C$. trachomatis-induced host cell phenotypes, the characteristic Golgi redistribution around the inclusion was not observed in cells infected by cdu1 or cdu2 null mutants [206]. Accordingly, ectopic expression of Cdu1 or Cdu2 in mammalian cells induces Golgi fragmentation; for Cdu1 this is correlated with its DUB activity but not with its acetyltransferase activity [206]. This indicates that, as C. trachomatis InaC (see above), Cdu1 and Cdu2 are involved in Golgi redistribution during chlamydial infection (Figure 4B).

The nuclear factor-kB (NF-kB) family of transcription factors controls several mammalian genes with important roles in immunity [208]. Ectopically expressed Cdu1 suppresses NF-KB activation and binds the NF-KB inhibitor $\alpha$ $(I K B \alpha)$ [209], but it remains unknown whether this is relevant during infection. In addition, Cdu1 binds the host cell protein MCL1 apoptosis regulator, BCL2 family member (MCL1) in C. trachomatis infected cells [11] (Figure 4B). MCL1 is an anti-apoptotic protein [210] involved in the resistance of Chlamydia-infected cells to apoptosis [211]. In C. trachomatis-infected cells, MCL1 is stabilized by deubiquitination, preventing its degradation in the proteasome [11]. In fact, Cdu1 deubiquitinates MCL1 [11] (Figure 4B). Moreover, in cells infected by wild-type $C$. trachomatis, deubiquitinated MCL1 accumulates around the inclusion, while in cells infected by the cdu1 mutant there is an increase in ubiquitinated MCL1 at the inclusion and the overall cellular levels of MCL1 are decreased [11]. Still, cells infected by the cdu1 mutant are not more sensitive to apoptosis than cells infected by the wild-type strain [11]. This could be related to compensatory survival signalling pathways that are increased in cdu1-infected cells [11].

In summary, $C$. trachomatis delivers two DUBs into infected host cells and both enzymes contribute to the characteristic Golgi redistribution around the inclusion. Furthermore, Cdu1 exerts its deubiquitinating activity at the inclusion membrane, helping to stabilize a host cell protein (MCL1) important for apoptosis-resistance in Chlamydiainfected cells.

\section{DUF582-containing $C$. trachomatis effectors}

Each chlamydial genome encodes several proteins possessing a Chlamydiacea-specific domain of unknown function (DUF582) within their primary structure. In C. trachomatis, these DUF582-containing proteins are CT619, СT620, CT621, CT711, and CT712 (Table 2). Although this has not been directly shown for all of them, it is generally assumed that the chlamydial DUF582-containing proteins are T3S substrates delivered into the cytoplasm of infected cells and that at least some of the DUF582 proteins are also transported into the host cell nucleus. This general concept derives from several experiments. First, DUF582-containing proteins from $C$. trachomatis, C. pneumoniae and C. caviae are T3S substrates, as deduced from experiments using S. flexneri as heterologous bacteria [63, 212]. Second, C. trachomatis DUF582-containing proteins have been detected in the cytoplasm (CT620, CT621) and nucleus (CT620, CT621, CT711) of infected cells $[212,213]$ (Figure 4B). Fi- nally, CT620, CT621, and CT711 also localize in the host cell nucleus after their ectopic expression in uninfected human cells [212].

At a functional level, C. trachomatis DUF582-containing proteins have been shown to bind components of the endosomal sorting complexes required for transport (ESCRT) machinery of host cells [214], mostly known for being involved in the formation of multivesicular bodies (MVBs) in the endolysosomal pathway [215]. The interaction between C. trachomatis DUF582 proteins and a component of ESCRT complexes (Hrs) was initially found in yeast twohybrid screens using the C-terminal region of CT619 (containing the DUF582) as bait [214]. Subsequently, by yeast two-hybrid, the C-terminal DUF582-containing regions of CT619, CT711, and CT712 were shown, or confirmed, to bind $\mathrm{Hrs}$, and the N-terminal region of CT619 was shown to bind another component of ESCRT complexes (tumor susceptibility 101 (TSG101)) [214]. Furthermore, co-IP experiments with ectopically expressed proteins indicated an interaction between each of the $C$. trachomatis DUF582 proteins and Hrs, and between CT619 and TSG101 [214]. Thus, C. trachomatis CT619, СT620, CT621, CT711, and CT712 can bind Hrs through their C-terminal DUF582 region, and CT619 can also bind TSG101 through its $\mathrm{N}$-terminal region. The physiological significance of these interactions is presently unclear, as siRNA-mediated depletion of Hrs or TSG101 does not appear to interfere with C. trachomatis internalization or with the chlamydial developmental cycle [214]. Nevertheless, the interaction of DUF582-containing C. trachomatis proteins with components of the ESCRT machinery suggests that these chlamydial effectors could modulate the host cell endocytic pathway or other ESCRT-dependent processes. For example, the ESCRT machinery is also needed for host cell scission events, such as abscission during cytokinesis [215], and it has recently been shown to have a role in C. trachomatis exit by extrusion [216]. It is, however, currently unknown whether $C$. trachomatis DUF582-containing effectors regulate chlamydial extrusion.

\section{Lipid droplet-associated C. trachomatis proteins}

Lipid droplets (LDs) are organelles playing an important role in lipid and energy homeostasis of eukaryotic cells [217]. They are also recognized as modulators of immune responses and are targeted by diverse pathogens [218]. In the case of $C$. trachomatis, the presence of LDs around and within the inclusion [219, 220], and the altered amounts of host cell lipids and proteins in LDs from C. trachomatisinfected cells [219, 221], indicates that these organelles are targeted by Chlamydia. The relevance of LDs for chlamydial infections is further supported by their detection within inclusions from cells of mice that had been infected by the mouse and hamster pathogen C. muridarum [222]. However, analyses of $C$. trachomatis growth in cells lacking LDs have produced conflicting data [221, 223, 224]. Furthermore, chlamydial growth defects observed in cells devoid of LDs [219, 223], appear to relate to reduced activity of long-chain acyl-CoA synthases (ACSLs), which are found 
within the inclusion either in the presence or absence of LDs [223].

Regardless of the role of LDs in chlamydial infections, several $C$. trachomatis proteins have been shown to associate with these organelles. Phenotypic and subcellular localization screens of a large collection of yeast strains expressing $C$. trachomatis proteins revealed four chlamydial LD-associated (Lda) proteins [54, 219]: Lda1, 2, and 3 (Table 2), and also CT257/CTL0509/Lda4, which has not been further studied. Ectopically expressed Lda1, 2 and 3 also associate with LDs in mammalian cells [219]. In C. trachomatis-infected cells, Lda1, 2, and 3 co-localize with LDlike structures surrounding the inclusion [219], and ectopically expressed Lda3 could also be found at the inclusion membrane and lumen [220]. Overall, this suggested a model in which cytoplasmic LDs, associated with Lda3, bind to an unknown Inc and this promotes translocation of LDs into the lumen of the inclusion [220]. Although the data is not consistent between the different studies where this was examined, Incs (IncA, IncG and CT618) [220, 221], the inclusion membrane localized Cap1 (class I accessible protein-1) [221], and Lda2 [219] have been found associated with LDs isolated from $C$. trachomatis-infected cells, providing some support to the model. Furthermore, ectopically expressed CT618 and Cap1 also associate with LDs in mammalian cells [221].

\section{A C. trachomatis nuclear effector that methylates his- tones}

The first $C$. trachomatis genome revealed a gene potentially encoding a protein containing a SET (Su(var)3-9, Enhancer-of-zeste and Trithorax) domain [21], mostly found in eukaryotic histone methyltransferases controlling gene expression and chromatin structure [225]. The C. trachomatis SET domain-containing protein was deduced to be a T3S substrate based on secretion assays using $S$. flexneri as heterologous bacteria [226]. After biochemical fractionation of cells infected by $C$. trachomatis, the SET domaincontaining chlamydial protein was found in the host cell nucleus associated with chromatin [226]. The chlamydial protein, named nuclear effector (NUE), also localized in the nucleus upon ectopic expression in mammalian cells [226]. Furthermore, in an in vitro system, NUE was capable of methylating histones $\mathrm{H} 2 \mathrm{~B}, \mathrm{H} 3$ and $\mathrm{H} 4$ [226]. This showed that NUE is a $C$. trachomatis effector localizing in the nucleus of infected cells where it presumably methylates histones and therefore possibly remodels chromatin (Figure 4B).

\section{From the chlamydiae to the Golgi complex and host cell plasma membrane}

A screen for $C$. trachomatis T3S substrates using Yersinia as heterologous bacteria identified several candidate chlamydial effectors [227]. Additional studies showed that one of these candidates is delivered into the cytoplasm of infected cells, where it initially associates with the Golgi complex [228]. The protein was named CteG (C. trachomatis effector associated with the Golgi) [228] (Figure 4B). However, as chlamydial infection of cultured cells advances in time, CteG is found progressively more associated with the host cell plasma membrane [228]. A C. trachomatis cte $G$ insertional mutant was generated, but it did not show a chlamydial growth defect in cultured cells [228]. Furthermore, cells infected by the cteG mutant did not display an alteration in Golgi redistribution around the inclusion [228]. However, CteG interferes with eukaryotic vesicular trafficking when ectopically expressed in yeast [228]. In summary, CteG is a C. trachomatis effector with dual and sequential localization in infected cells, first associated with the Golgi and then with the host cell plasma membrane (Figure 4B). CteG might interfere with host cell vesicular trafficking, but this remains to be shown in infected mammalian cells.

\section{A C. trachomatis effector that might modulate host cell proliferation}

C. trachomatis protein CT847 was identified as a T3S substrate using Yersinia as heterologous bacteria [229]. A yeast two-hybrid screen revealed that CT847 binds human Grap2 cyclin D-interacting protein (GCIP) [229], which contains a helix-loop-helix and might normally function as a transcription regulator controlling cell proliferation [230]. The interaction between CT847 and GCIP was validated in C. trachomatis-infected cells ectopically expressing GCIP [229] (Figure 4B). Infection of mammalian cells by C. trachomatis leads to a depletion in the cellular levels of GCIP that is prevented by inhibitors of bacterial protein synthesis, of the T3S system, or of the host cell proteasome [229]. Accordingly, siRNA-mediated depletion of GCIP leads to increased production of $C$. trachomatis infectious progeny [229]. Although the delivery of CT847 into host cells by C. trachomatis has never been shown, this suggests that the CT847:GCIP interaction leads to the destruction of GCIP and that this is beneficial for chlamydial infection of host cells.

\section{The intriguing CPAF}

In addition to Cdu1 and Cdu2 (see above), C. trachomatis encodes other proteases and, among them, CPAF (chlamydial protease/proteasome-like activity factor) [231] is probably the most intensively studied chlamydial effector protein [232-237]. Following the previous detection of a chlamydial protease activity within host cell lysates of infected cells [238], CPAF was identified by mass spectrometry after biochemical fractionation of this activity from the cytosol of $C$. trachomatis-infected cells [231]. Subsequently, numerous host cell and chlamydial substrates of CPAF have been identified (reviewed in [239]). However, it was eventually shown that cleavage of most of these proteins by CPAF occurs artificially during the preparation of cell lysates and not within intact infected cells [240]. Nonetheless, biochemical and structural biology studies revealed unambiguously that CPAF is a serine protease produced in the chlamydiae as a $70 \mathrm{kDa}$ protein zymogen [241-244]. In vitro, transient concentration-dependent homodimerization of CPAF leads to autocleavage and formation of a stable homodimer [241, 244]. This homodimer undergoes subsequent autocatalytic processing that removes internal 
inhibitory sequences and leads to the formation of mature activated CPAF [231, 241, 242].

C. trachomatis CPAF has been detected in the cytosol of infected host cells by IF microscopy (e.g. [58, 231, 245, 246]). However, depending on the conditions used in the preparation of the samples, CPAF can be detected solely within the lumen of the inclusion by IF microscopy [247]. Regardless of this, CPAF contains a signal peptide recognized by the Sec system that enables protein transport across the bacterial inner membrane [24]. Moreover, in a C. trachomatis strain defective for an essential component of the chlamydial T2S system [14], CPAF is retained in an inactive form within the chlamydiae [245]. This indicates that the CPAF activation process likely occurs in the inclusion lumen, after the T2S-dependent transport of CPAF from the chlamydial periplasm. The CPAF activation is regulated by human serine peptidase inhibitor 15 (PI15), which has been shown to localize within the inclusion and to bind CPAF [247]. As mentioned above, there is data indicating that CPAF could be transported into the host cell cytosol. However, the underlying hypothetical secretion mechanism is unknown. Another possibility is that, during C. trachomatis host cell infection, active CPAF remains within the inclusion where it might exert its functions until when its cytoplasmic and extracellular targets become accessible by the sequential loss of integrity of the inclusion and host cell plasma membrane.

A C. trachomatis cpaf null-mutant reveals a $\sim 2$ to 3-fold defect in the generation of infectious progeny [245, 247, 248], indicating a function of CPAF during the chlamydial developmental cycle. Accordingly, possible substrates and functions associated with an activity of CPAF in the inclusion lumen and in host cell cytoplasm have been revealed by characterization of cpaf null mutants and/or by using conditions maintaining CPAF inactive in protein extracts from infected cells. A mass spectrometry analysis of lysates from cells infected by a $C$. trachomatis cpaf null mutant and the wild-type CPAF-producing strain, revealed nine chlamydial and six host cell proteins with high likelihood of being less abundant in extracts of cells infected by the CPAF-producing chlamydiae [248]. Remarkably, the chlamydial proteins identified were the five DUF582-containing C. trachomatis effectors (see above), the CT847 effector (see above), and three other T3S system-related proteins [248]. CT620 and CT711 are proteolytically processed in cells infected by CPAF-producing C. trachomatis [212, 248], and CT620 and CT621 have been detected in the inclusion lumen [212]. It is therefore possible that CT620, CT621, and CT711 are CPAF targets. The 6 host proteins identified are all involved in innate immunity [248]. The CPAFdependent alterations in the levels of these proteins are related with reduced translocation to the nucleus of cells infected by wild-type $C$. trachomatis of the 065 subunit of NF-KB [248]. This mechanism of inhibition of the host innate immune response by $C$. trachomatis is likely a consequence of the activity of CPAF on other effectors or T3S system-related proteins [248].

Other possible targets of CPAF in the inclusion lumen are C. trachomatis OmcB [249], which could be related to the redifferentiation of RBs into EBs [249], and PI15 [247], in the context of regulation of CPAF activity within the inclusion [247]. In the host cell cytoplasm, CPAF cleaves vimentin and lamin-associated protein-1 (LAP1; also known as torsin 1A-interacting protein 1 (TOR1AIP1)), but possibly only upon loss of the integrity of the inclusion membrane [245]. Based on phenotypes displayed in cultured cells infected by cpaf null mutant strains, CPAF has been also associated with inhibition of host cell cytokinesis [250] and with C. trachomatis lytic exit [251]. Although the activity of CPAF on vimentin and LAP1 could help to promote the lytic exit [245], these CPAF-dependent effects are probably a consequence of its action on other chlamydial proteins [248, 250, 251].

During chlamydial lytic exit, the cytoplasmic and inclusion contents, including CPAF, are also released. Different data support that extracellular CPAF promotes evasion of the host innate immune response [252-254], which could be related with the role of CPAF in helping $C$. trachomatis survival in the mouse lower genital tract [255]. CPAF cleaves the formyl peptide receptor 2 (FPR2) on the surface of neutrophils, and thereby prevents downstream intracellular signalling normally leading to the activation of neutrophils and of their antimicrobial mechanisms [252] Accordingly, while a C. trachomatis cpaf mutant shows defects in mice infection models, these defects are suppressed in neutrophil-depleted or in FPR2-knock-out mice [252]. Furthermore, CPAF can cleave antimicrobial peptides with antichlamydial activity, such as cathelicidin LL-37 [253], and complement factors C3 and B [254].

In summary, $C$. trachomatis secretes a potent serine protease (CPAF) with functions within host cells, during the chlamydial developmental cycle, as well as in the extracellular space, after the release of the chlamydiae from infected cells. CPAF is conserved in Chlamydiaceae, and in Chlamydia-like organisms infecting amoeba there are homologues showing $30 \%$ of amino acid sequence identity to C. trachomatis CPAF [256]. Therefore, some of the functions of CPAF could be conserved in Chlamydiales.

\section{Chlamydial HtrA and Tsp: proteases that also modulate host cell processes?}

Chlamydial high temperature requirement protein A (HtrA) [257] and tail-specific protease (Tsp) [258] are other C. trachomatis proteases that have been implicated in the subversion of host cell processes.

HtrA serine proteases are conserved in unicellular and multicellular organisms where they mostly play an important role in protein quality control [259]. In Gramnegative bacteria, HtrA proteins are mainly known for functioning in the periplasm, but there is evidence indicating that they can also be transported to the extracellular environment by pathogenic bacteria and have a direct role in host cell subversion [260]. In the case of $C$. trachomatis $\mathrm{HtrA}$, in addition to its expected functions in chlamydial physiology and development [261], the protein has been detected in the host cell cytosol and in the inclusion lumen by IF microscopy [262]. C. trachomatis HtrA possesses a signal peptide recognized by the Sec system [262]. Given 
that HtrA is also detected in the inclusion lumen, the protein could be a T2S substrate. However, besides the detection of $C$. trachomatis HtrA in the host cell cytosol, there is no additional evidence for a possible function of the protein in subverting host cell functions.

Tsps are present in many bacteria where they have diverse housekeeping roles and act by processing the C-terminal region of different target proteins [263]. In C. trachomatis, Tsp has a chaperone activity and functions in protein quality control [264]. Although C. trachomatis Tsp has never been detected in the host cell cytosol, ectopically expressed Tsp can cleave the p65 subunit of NF-KB [258], and Tsp can bind the human steroid receptor RNA activator 1 (SRA1) protein by yeast two-hybrid and in vitro pull-down assays [265]. However, cleavage of p65 is not observed in C. trachomatis-infected cells under controlled conditions of cell lysis [240], and the physiological significance of the Tsp:SRAP1 interaction is unclear [264].

\section{A virulence plasmid-encoded secreted protein}

Most Chlamydia species possess a cryptic plasmid encoding the so-called plasmid glycoproteins (pGPs 1-8) and two small RNAs [266]. C. trachomatis pGP3 has been found associated with the outer membrane of EBs [267], and also in the host cell cytosol and partly in the inclusion lumen [268] (Figure 4B). pGP3 is also found in the cytosol of cells infected by other Chlamydia species carrying the virulence plasmid [268]. However, the secretion pathway by which chlamydiae deliver pGP3 into the host cell cytosol is unknown [266, 268].

pGP3 is an immunodominant antigen, but only the native trimeric form of the protein can be recognized by human antibodies [267, 269, 270]. In fact, pGP3 is present as a trimer both in the chlamydial outer membrane and in the host cell cytosol [270]. The 3D structure of the pGP3 trimer has been determined by X-ray crystallography and one of its domains revealed a fold similar to cytokines of the tumor necrosis factor family [271].

The generation and characterization of $C$. trachomatis and $C$. muridarum strains carrying plasmids with the pgp3 gene inactivated, revealed an important virulence role of pGP3 in mice infection models [272-274]. The attenuation in virulence observed because of the lack of pGP3 was identical to the one observed with plasmidless strains [272, 273]. Experiments with purified pGP3 provided possible explanations for its virulence functions. Purified pGP3 binds to, and neutralizes, cathelicidin LL-37 [275], also a target of CPAF (see above). LL-37 also modulates the immune response, and the binding of pGP3 to this antimicrobial peptide inhibits the LL-37-dependent chemotaxis of neutrophils and cytokine release by epithelial cells [276]. Conversely, pGP3 alone can induce cytokine release by macrophages [268] and neutrophils [276] and, at least in neutrophils, this pro-inflammatory activity is enhanced by the pGP3:LL-37 complex [276]. Purified pGP3 can also inhibit apoptosis in HeLa cells [277]. These pGP3-dependent effects observed with the purified protein could have physiological significance if pGP3 in the host cell cytosol, or in the inclusion lumen, is released into the extracellular mi- lieu after chlamydial lytic exit. Alternatively, pGP3 could potentially mediate the observed effects from the outer membrane of extracellular EBs.

\section{Additional C. trachomatis proteins detected in the host cell cytosol}

The C. trachomatis proteins CT311 [32] and CT795 [278] were also found in the cytosol of host cells by IF microscopy (Table 2 and Figure 4B). Transport of CT311 and CT795 from the chlamydiae into the host cell cytosol can be prevented by a small molecule inhibitor of the Sec system [32, 278]. As both proteins can also be found in the lumen of the inclusion $[32,278]$, this suggests that they could be transported from the periplasm by the chlamydial T2S system. How these two proteins can then access the host cell cytosol is unclear. Little is known about possible effector functions of CT311 and CT795. However, CT311 has been shown to also localize in the nucleus of mammalian cells (Figure 4B), either in C. trachomatis-infected cells or after its ectopic expression [279].

\section{Incs with no bilobed hydrophobic region}

Among the $C$. trachomatis proteins that have been detected in the inclusion membrane but do not possess a bilobed hydrophobic region, Cap1 and CopN are normally classified as Incs [50, 59].

Cap1 was identified as a protein accessing the host cell cytosol based on a screen for chlamydial proteins recognized by a C. trachomatis-specific CD8 ${ }^{+}$T-cell line [280]. Cap1 was then localized to the inclusion membrane [280], which was confirmed in subsequent studies $[50,63]$. Little is known about the function of Cap1, but the protein has been associated with host cell LDs (see above) [221].

Several bacteria harbouring T3S systems have a socalled gatekeeper protein required for secretion of the T3S system translocators and controlling the beginning of effector delivery into host cells, which can involve secretion of the gatekeeper itself [281]. CopN is the likely C. trachomatis T3S system gatekeeper, and it was the first chlamydial protein shown to be a T3S substrate [23]. It was localized in the inclusion membrane [23], which was confirmed in a subsequent study [50]. This localization of $C$. trachomatis CopN could be strictly associated with its regulatory function, but a possible effector role should not be disregarded. For example, $C$. pneumoniae CopN has been shown to interfere with host cell microtubules [282, 283]; however, C. trachomatis CopN does not display this activity on microtubules [282].

\section{TRACHOMATIS PROTEINS SECRETED INTO THE LUMEN OF THE INCLUSION}

In addition to the $C$. trachomatis proteins that localize in the host cell cytoplasm or nucleus, or in the inclusion membrane, and that are also found in the lumen of the inclusion (GlgX, CT311, CT620, СT621, СT622, CT795, GIgA, HtrA, CPAF, and pGP3; Table 2), there are at least six C. trachomatis proteins that localize within the lumen of the inclusion and which thus far have not been localized in 
the host cell cytoplasm (PIs1, Pls2, CT142, CT143, CT144, and Ptr; Table 2). Furthermore, in addition to $\mathrm{GlgX}$ and $\mathrm{GlgA}$, there is indirect functional evidence for a localization of other $C$. trachomatis glycogen metabolizing enzymes in the inclusion lumen.

\section{The glycogen metabolizing enzymes}

C. trachomatis possesses the genes encoding the proteins required for glycogen synthesis (GlgA, GlgB, GlcC) and hydrolysis (GlgX, GlgP, and MalQ) [21]. For glycogenesis, GlgC converts glucose 1-phosphate into ADP-glucose, which is then used by the glycogen synthase GlgA to generate a linear chain of $\alpha 1,4$-linked glucose molecules; lastly, the branching enzyme GlgB produces glycogen from $\alpha 1,4-$ linked glucose. For glycogenolysis, the activity of GlgX, GlgP and MalQ degrades glycogen into glucose 1-phosphate (Figure 5A).

There is a Chlamydia virulence plasmid-dependent accumulation of glycogen in the lumen of the inclusion of C. trachomatis and C. muridarum [284, 285]. The plasmiddependency is partially explained because plasmidencoded pGP4 is required for the normal expression of $\operatorname{glgA}[286,287]$. Furthermore, GlgA can be detected in the inclusion lumen and in the host cell cytosol by IF microscopy [288], and there is evidence that it can be imported from the host cell cytosol into the inclusion lumen [289]. In addition, GIgA and GlgB, but not GlgC, possess a T3S signal recognized by $S$. flexneri [289], and $C$. trachomatis strains with mutations in GlgB show an accumulation of aggregates within the inclusion possibly corresponding to unbranched glycogen [14]. Altogether, this indicates that GlgA and GlgB should function in the inclusion lumen (Figure 5A). Differently from other bacterial glycogen synthases, chlamydial GIgA can use both ADP- and UDPglucose as substrate [289]. Accordingly, in C. trachomatisinfected cells, the host transporter SLC35D2 is recruited to the inclusion membrane and likely mediates the transport of UDP-glucose into the lumen of inclusion [289] (Figure 5A). Thus, C. trachomatis should mediate the T3Sdependent transport of GlgA and GIgB into the inclusion lumen, and the ability of GIgA to use UDP-glucose as substrate enables the chlamydiae to synthesize glycogen in this confined compartment (Figure 5A). However, the C. trachomatis T2S system should also play a role in the chlamydial glycogen metabolism because a strain with a mutation in an essential component of this protein transport system shows abnormal glycogen aggregates within the inclusion [14]. Finally, the accumulation of glycogen in the $C$. trachomatis inclusion also depends, but to a lesser extent, on its transport in bulk from the host cell cytosol (Figure 5A), which brings along the host glycogen synthase Gys1 [289].

It is unclear how the accumulation of glycogen within the inclusion benefits chlamydiae. By one side, a plasmidless $C$. trachomatis strain and a $g \lg B$ mutant do not show a defect in the generation of infectious progeny [14, 286]. On the other side, depletion of the host glycogen synthase Gys1 leads to a reduction in the production of C. trachomatis and C. muridarum infectious progeny, and
C. muridarum strains with mutations in GlgA are defective in the generation of infectious progeny [289]. C. trachomatis $\mathrm{GlgP}, \mathrm{GlgX}$, and MalQ also possess a T3S signal recognized by $S$. flexneri and at least GlgX has been detected in the inclusion lumen and membrane by IF microscopy [289]. Therefore, C. trachomatis should be able to hydrolyse glycogen in the inclusion lumen into glucose 1-phosphate (Figure 5A). Because EBs do not uptake glucose 1-phosphate [289], its conversion into glucose 6-phosphate (which EBs can uptake) might be performed within the inclusion by a $C$. trachomatis phosphoglucomutase (MrsA), which also possesses a T3S signal recognized by S. flexneri [289] (Figure 5A).

\section{A secreted protein mediating recovery from stress- induced persistence}

In cultured cells infected by $C$. trachomatis, nutrient deprivation, or exposure to certain cytokines or antibiotics, can lead to the reversible formation of non-dividing aberrant RBs, a persister-like chlamydial form (reviewed in [290]) (Figure 1), which might be important in vivo [290, 291]. A genetic screen for $C$. trachomatis mutants showing defects in recovery from stress-induced persistence, identified the gene encoding a putative protease, Ptr [292]. A C. trachomatis ptr null mutant shows a defect in recovery from IFN $\gamma$-induced stress, but not from penicillin-induced stress [292] (Figure 5B). By IF microscopy, Ptr was found in the inclusion lumen outside of the chlamydiae [292] (Figure 5B). Ptr possesses a putative signal peptide recognized by the Sec system [292], and its localization in the inclusion lumen suggests it should be a T2S substrate. However, the mechanism by which Ptr functions is currently unknown.

\section{Proteins of unknown function secreted into the inclusion lumen}

C. trachomatis encodes proteins showing similarity to the autotransporter passenger domain of chlamydial PmpC that were named Pmp-like secreted (PIs) proteins [293]. By IF microscopy, Pls1 and PIs2 were localized to the inclusion lumen, where they appear as globular structures outside of the chlamydiae [293] (Figure 5A). PIs1 and PIs2 lack obvious Sec-dependent signal peptides [293]. Thus, it is currently unclear how they are secreted into the lumen of the inclusion [293]. Microinjection of C. trachomatis-infected cells with anti-PIs1 and anti-PIs2 antibodies inhibits inclusion expansion, suggesting that Pls1 and Pls2 could be important for C. trachomatis and/or inclusion growth [293].

The $C$. trachomatis genes ct142, ct143, and ct144 genes are organized in an operon encoding three T3S substrates $[227,294]$. Strikingly, by IF microscopy, CT142, CT143, and CT144 appear in globular structures outside of chlamydiae resembling those seen with anti-Pls1 and anti-PIs2 antibodies [293-295] (Figure 5A). Furthermore, CT142, CT143, and CT144 co-localize with each other within the inclusion lumen, suggesting that they could be part of protein complexes [294]. Purified CT143 can induce pro-inflammatory cytokine secretion by THP1 macrophages [296], but the significance of this finding is unclear. 
A

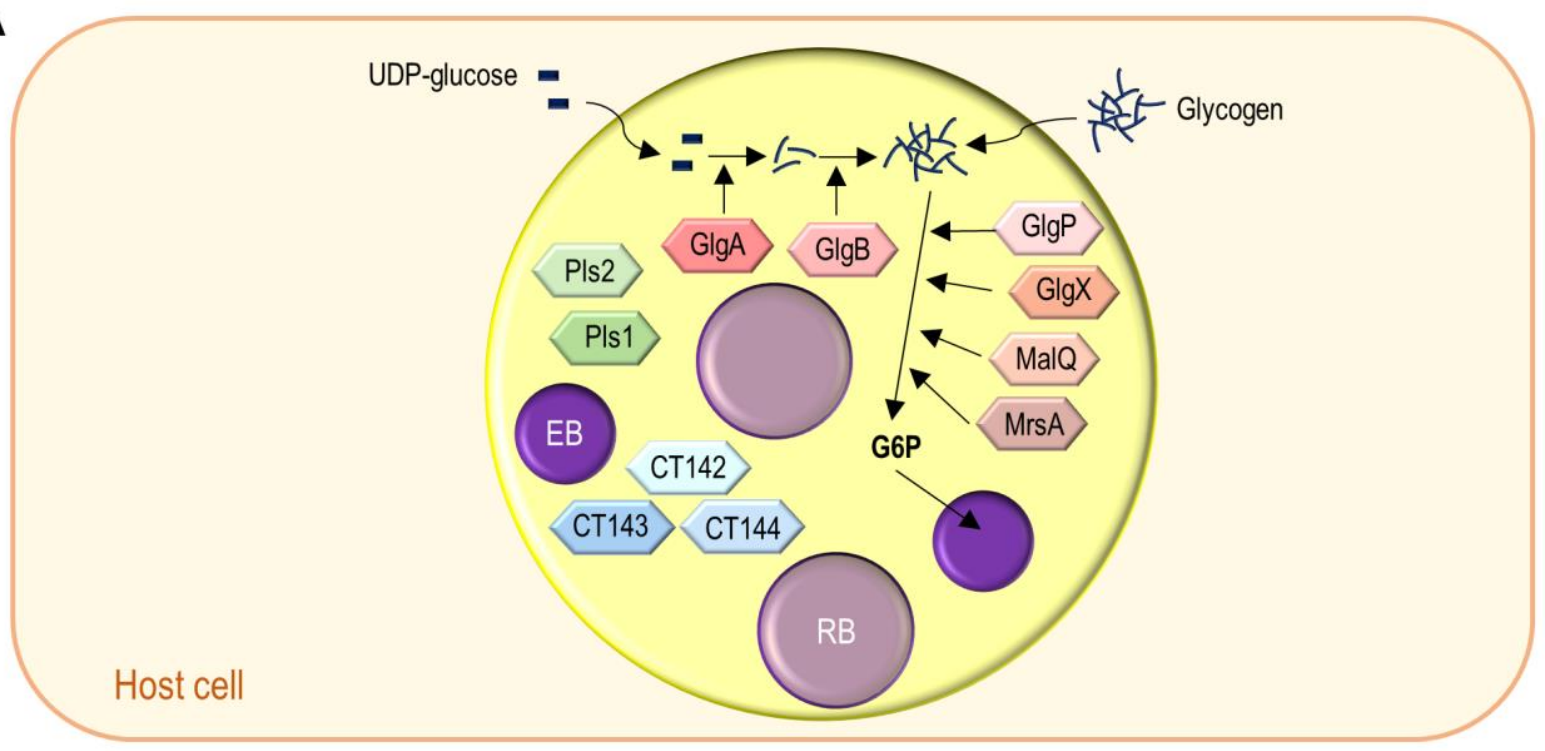

B
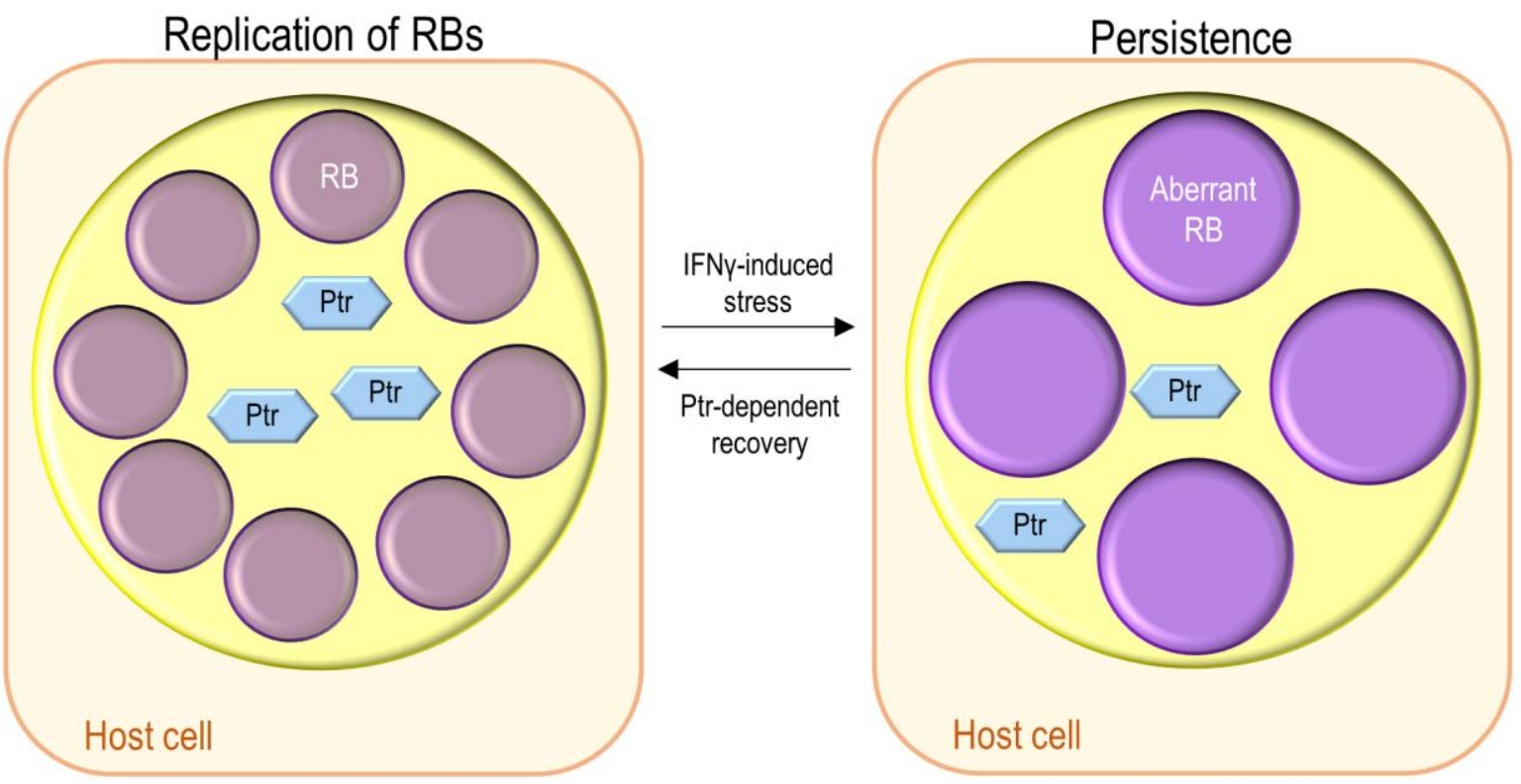

FIGURE 5: $C$. trachomatis proteins secreted into the inclusion lumen. (A) C. trachomatis glycogen metabolizing enzymes shown (GlgA and $\mathrm{GlgX}$ ) or deduced (GlgB, GlgP, MalQ, and MrsA) to localize in the inclusion lumen, and C. trachomatis proteins (PIs1, PIs2, CT142, CT143, and CT144) of unknown function appearing in the inclusion lumen, by IF microscopy, as large globular structures; G6P, glucose 6phosphate. (B) C. trachomatis putative protease Ptr that specifically mediates the recovery from IFNY-induced chlamydial persistence. See list of abbreviations, main text, and Table 2 for details.

In summary, Pls1, PIs2, CT142, CT143, and CT144 have unknown function but they are secreted into the lumen of the inclusion where they appear as globular structures, as detected by IF microscopy (Figure 5A). Coincidently, the genes encoding PIs1, PIs2, CT142, CT143, CT144, and also the glycogen synthase GIgA (see above), are amongst the C. trachomatis chromosomal genes more clearly upregulated by the Chlamydia virulence plasmid through pGP4 $[287,295]$.

\section{CONCLUSIONS AND OUTLOOKS}

C. trachomatis has been shown to deliver at least $~ 60$ proteins into the inclusion membrane and cytoplasm of host cells that function as effectors (Tables 1 and 2). Moreover, there are numerous putative Incs that have never been localized to the inclusion membrane $[42,43]$, and many candidate chlamydial T3S substrates whose characterization has not been further reported $[63,227]$. Even if several of these proteins could be false hits, the actual number of $C$. trachomatis proteins delivered into the inclusion 
membrane and host cell cytoplasm might be 70-90. In addition, C. trachomatis also secretes proteins into the inclusion lumen (Table 2 and Figure 5). Considering that a typical C. trachomatis genome encodes $~ 900$ proteins [21], $>7 \%$, and possibly $10 \%$, of the coding capacity is devoted to produce effector proteins acting outside of the chlamydiae, in the host cell cytoplasm, within the inclusion lumen, and/or extracellularly.

A feature of pathogenic bacteria delivering high numbers of effectors into host cells is redundancy, which can be, for example, effectors with similar activity and functions or effectors with different activity but targeting the same host cell process [297]. Considering that C. trachomatis genomes are relatively small $(\sim 1 \mathrm{Mb})$ and underwent extensive reductive evolution $[21,298]$, it could be expected that redundancy might be less pronounced than what is observed in other intracellular pathogens, such as in Legionella pneumophila [297]. However, thus far, no C. trachomatis effector gene has been shown to be essential, and the analysis of some effector gene mutants suggests possible redundancy. Overall, this indicates that some type of redundancy might also be relevant among chlamydial effectors.

Another feature of pathogenic bacteria carrying several effector genes is that some of them were acquired through horizontal gene transfer [299-301]. Given the obligate intracellular nature of Chlamydia, horizontal gene transfer is less important, but not irrelevant [302], in chlamydial evolution than in other bacterial pathogens. For example, pathogenicity islands are virtually non-existent in the genome of $C$. trachomatis. However, genes encoding Inc proteins and other T3S substrates have been shown to be encoded within operons [51, 186, 294]. Apart from suggesting a related function of effectors encoded within the same operon, the reasons beyond this genetic organization only in some cases is presently unclear.

Timely transport of $C$. trachomatis proteins into the inclusion membrane and host cell cytoplasm

C. trachomatis delivers at least six effector proteins (TarP, TmeA, TmeB, TepP, and possibly CT166 and CT622) into the cytoplasm of host cells from extracellular adhering EBs and/or shortly after their internalization (Figure 4A). Some of these effectors are important for chlamydial invasion (TarP, CT622, and TmeA), host cell survival (TarP) and immune signalling (TepP). Furthermore, $\operatorname{TarP}[168,186]$, CT622 [200, 201], TmeA [186, 189], and TmeB [186] have been detected in the host cell cytoplasm several hours after invasion; therefore, they should have additional functions other than during chlamydial entry. It is possible that, similarly to Salmonella effector proteins [303], some of the C. trachomatis effectors packed in EBs downmodulate the alterations in the actin cytoskeleton that promote chlamydial invasion. An obvious candidate is CT166, which can potentially inactivate the TarP-dependent activation of RAC1. However, while the activity of Salmonella effectors causes reversible changes in Rho family proteins [303], the glucosylating activity of CT166 on RAC1 should be irreversible. Furthermore, CT166 is not expressed by all C. tra- chomatis strains. Another key aspect that remains unclear is how the nascent inclusion limits interactions with the endosomal pathway to prevent chlamydial destruction in a phagolysosome. This early subversion of the endocytic pathway occurs even in the absence of chlamydial protein synthesis [304]. Therefore, the relevant effector(s) are surely among the proteins packed in EBs [159].

After C. trachomatis uptake by host cells, chlamydial gene expression leads to the production and secretion of effector proteins that influence the subsequent stages of the developmental cycle. This group of effectors is largely comprised by early-cycle Incs, which modulate interactions with host cell vesicular trafficking (IncE and CpoS), help the migration of the nascent inclusion to the centrosomal region (CT850), establish ER-inclusion MCSs and promote the non-vesicular transport of sphingomyelin into the inclusion (IncV and IncD), and mediate inclusion membrane stability (CpoS, IncC, CT383). IncV might even be delivered earlier into the inclusion membrane as it is present in EBs [159]. A detailed understanding of how $C$. trachomatis modulates these processes remains to be established. For example, it is still unclear how the inclusion intercepts vesicular trafficking from the TGN to selectively acquire sphingolipids and cholesterol [115-117, 305], and exactly how it continues to avoid fusion with hydrolytic-rich lysosomes [304, 306].

As the developmental cycle continues, several other chlamydial effectors are delivered into the cytoplasm of host cells. These effectors mediate fusion between inclusions (InCA), continue subverting host cell vesicular trafficking (IncA, and perhaps CteG and DUF582-containing CT619, CT620, CT621, CT711, and CT712), modulate microtubules (IPAM) and mediate their modification (InaC), promote the assembly of F-actin (InaC) and the redistribution of the Golgi around the inclusion (InaC, Cdu1 and Cdu2), and possibly promote the acquisition of LDs by the inclusion (Lda1, Lda2, and Lda3), interfere with host cell transcription (NUE), and modulate host cell death (CpoS and Cdu1). Finally, chlamydial host cell exit is also controlled by Incs (MrcA and CT228), and by the Chlamydia virulence plasmid, likely through the regulation of expression of T3S effectors and/or of CPAF [251, 295]. Even after chlamydial exit from infected cells, some $C$. trachomatis effectors concomitantly released from the inclusion lumen and/or host cell cytosol continue to function extracellularly, as is the case of evasion of the innate immune response by CPAF, and possibly by pGP3. Evidently, much remains to be understood about the subversion of all these processes by $C$. trachomatis.

The inclusion lumen: more than just housing chlamydiae The inclusion lumen is a functionally and metabolically important compartment of $C$. trachomatis-infected host cells. For this, C. trachomatis secretes proteins into the inclusion lumen synthesizing and hydrolysing glycogen [289], mediating chlamydial recovery from IFN $\gamma$-induced stress [292], with unknown function, and/or perhaps en route to the inclusion membrane or host cell cytoplasm. Furthermore, even if chemical fixation in preparation of samples for microscopy can create artifacts [307], host cell 
cytoplasmic glycogen [289], different host cell proteins $[223,247,289,308,309]$, and LDs [220] and peroxisomes [310] have been detected within the lumen of the inclusion. The mechanisms involved in the transport of these large host cell molecules and organelles into the inclusion are largely unknown. Some of the chlamydial proteins found in the inclusion lumen have also been detected in the host cell cytoplasm (СT311, СT620, СT621, СT622, CT795, GIgA, HtrA, CPAF, and pGP3). It is unclear whether this is due to partial leakage from the T3S system, to intermediates in the transport to the host cell cytoplasm, or if these proteins have functions in both the inclusion lumen and host cell cytosol. It has been suggested that outer membrane vesicles could be involved in the transport of CT311, CT795, $\mathrm{HtrA}$ and CPAF from the periplasm, passing through the inclusion lumen into the host cell cytosol $[24,32,239,262$, 278]. However, as shown for CPAF [14] and deduced by analogy for CT311 and CT795, they are possibly transported into the inclusion lumen by the $C$. trachomatis $\mathrm{T} 2 \mathrm{~S}$ system. Assuming this is the case, it is unknown how these proteins can reach the host cell cytoplasm before the permeabilization of the inclusion membrane that precedes chlamydial lytic exit.

\section{The importance and some particularities of the $C$. tra- chomatis T3S system}

Most, if not all, of the proteins delivered by $C$. trachomatis into the inclusion membrane and host cell cytoplasm are transported by the T3S system. C. trachomatis EBs appear to be better equipped for T3S than RBs [159], suggesting that this protein transport pathway might be mostly operative before the completion of the $E B$ to $R B$ transition and after the RB to EB re-differentiation. In the T3S pathway, effector proteins travel through a conduit formed by an export apparatus in the bacterial inner membrane linked to a hollow needle-like structure extending from the bacterial surface and connected to a pore complex formed by type III secreted translocator proteins in a target cell membrane [20] (Figure 2). Surprisingly, some $C$. trachomatis T3S substrates are transported into the inclusion lumen $[289,294]$. Considering the T3S pathway, it is presently unknown how such chlamydial T3S-dependent transport into the inclusion lumen can occur. Along the same line, an outstanding question is how Incs are inserted into the inclusion membrane. At least two models can be conceived: i) Incs are first transported into the host cell cytosol and then inserted into the inclusion membrane; ii) Incs are delivered directly into the inclusion membrane by lateral partition through the T3S system translocon pore. There is currently no data to support one model or the other. There is also the general question of how T3S effectors containing transmembrane segments, such as Incs, are not targeted to the bacterial inner membrane [311]. Finally, it is likely that a C. trachomatis mutant with an essential T3S system gene inactivated would be non-viable. Therefore, although a formality in most cases, final demonstration that Incs and other chlamydial proteins are T3S substrates will require the generation of a chlamydial conditional mutant, which has not been described yet.

\section{Final remarks}

C. trachomatis delivers many effector proteins into host cells, and into the lumen of the inclusion, and these proteins interfere with a wide diversity of host cell processes to promote chlamydial invasion, survival, growth, development and dissemination. Although enormous progress has been achieved in recent years elucidating the functions of these chlamydial secreted proteins, we are most likely only seeing the tip of the iceberg. The generation of $C$. trachomatis mutants on relevant genes and their careful characterization in infected cells and in animal models of infection, together with molecular, cell and structural biology studies, will certainly provide explanations to some of the current outstanding issues and originate new concepts as well as additional questions. It might also establish a relation between effector function and $C$. trachomatisrelated pathogenicity. This will expand our fundamental understanding of host-pathogen interactions and of chlamydial and host cell biology, which is critical to devise novel prophylactic and therapeutic approaches against infectious diseases.

\section{ACKNOWLEDGMENTS}

Work in LJM laboratory is supported by Fundação para a Ciência e a Tecnologia (FCT/MCTES) through grants PTDC/IMI$\mathrm{MIC} / 1300 / 2014$ and PTDC/BIA-MIC/28503/2017, and by the Applied Molecular Biosciences Unit (UCIBIO), which is financed by national funds from FCT/MCTES (UID/Multi/04378/2019) and co-financed by the European Regional Development Fund (ERDF) under the PT2020 Partnership Agreement (POCl-010145-FEDER-007728). JNB is supported by PhD fellowship $\mathrm{PD} / \mathrm{BD} / 128214 / 2016$ within the scope of the PhD program Molecular Biosciences (PD/00133/2012) funded by FCT/MCTES.

\section{CONFLICT OF INTEREST}

The authors declare no conflict of interest.

\section{COPYRIGHT}

(C) 2019 Bugalhão and Mota. This is an open-access article released under the terms of the Creative Commons Attribution (CC BY) license, which allows the unrestricted use, distribution, and reproduction in any medium, provided the original author and source are acknowledged.

Please cite this article as: Joana N. Bugalhão and Luís Jaime Mota (2019). The multiple functions of the numerous Chlamydia trachomatis secreted proteins: the tip of the iceberg. Microbial Cell 6(9): 414-449. doi: 10.15698/mic2019.09.691 


\section{REFERENCES}

1. O'Connell CM, Ferone ME (2016). Chlamydia trachomatis Genital Infections. Microbial Cell 3(9): 390-403. doi $10.15698 / \mathrm{mic} 2016.09 .525$

2. Taylor HR, Burton MJ, Haddad D, West S, Wright H (2014) Trachoma. Lancet 384(9960):2142-52. doi: 10.1016/S01406736(13)62182-0

3. Horn M (2008). Chlamydiae as symbionts in eukaryotes. Annu Rev Microbiol 62: 113-131. doi: 0.1146/annurev.micro.62.081307.162818

4. Phillips S, Quigley BL, Timms P (2019). Seventy Years of Chlamydia Vaccine Research - Limitations of the Past and Directions for the Future. Front Microbiol 10: 70. doi: 10.3389/fmicb.2019.00070

5. Abdelrahman YM, Belland RJ (2005). The chlamydial developmental cycle. FEMS Microbiol Rev 29(5): 949-959. doi 10.1016/j.femsre.2005.03.002

6. Elwell C, Mirrashidi K, Engel J (2016). Chlamydia cell biology and pathogenesis. Nat Rev Microbiol 14(6): 385-400. doi: 10.1038/nrmicro.2016.30

7. Agaisse H, Derre I (2013). A C. trachomatis cloning vector and the generation of $\mathrm{C}$. trachomatis strains expressing fluorescent proteins under the control of a $C$. trachomatis promoter. PLoS ONE 8(2): e57090. doi: 10.1371/journal.pone.0057090

8. Johnson CM, Fisher DJ (2013). Site-specific, insertional inactivation of incA in Chlamydia trachomatis using a group II intron. PLoS ONE 8(12): e83989. doi: 10.1371/journal.pone.0083989

9. Wickstrum J, Sammons LR, Restivo KN, Hefty PS (2013). Conditional gene expression in Chlamydia trachomatis using the tet system. PLoS ONE 8(10): e76743. doi: 10.1371/journal.pone.0076743

10. Mueller KE, Wolf K, Fields KA (2016). Gene Deletion by Fluorescence-Reported Allelic Exchange Mutagenesis in Chlamydia trachomatis. mBio 7(1): e01817-01815. doi: 10.1128/mBio.01817-15

11. Fischer A, Harrison KS, Ramirez Y, Auer D, Chowdhury SR, Prusty BK, Sauer F, Dimond Z, Kisker C, Scott Hefty P, Rudel T (2017). Chlamydia trachomatis-containing vacuole serves as deubiquitination platform to stabilize $\mathrm{Mcl}-1$ and to interfere with host defense. elife 6 : e21465. doi: 10.7554/eLife. 21465

12. Keb G, Hayman R, Fields KA (2018). Floxed-Cassette Allelic Exchange Mutagenesis Enables Markerless Gene Deletion in Chlamydia trachomatis and Can Reverse Cassette-Induced Polar Effects. J Bacteriol 200(24): e00479-18. doi: 10.1128/JB.00479-18

13. Kari L, Goheen MM, Randall LB, Taylor LD, Carlson JH, Whitmire WM, Virok D, Rajaram K, Endresz V, McClarty G, Nelson DE, Caldwell HD (2011). Generation of targeted Chlamydia trachomatis null mutants. Proc Natl Acad Sci U S A 108(17): 7189-7193. doi 10.1073/pnas.1102229108

14. Nguyen BD, Valdivia RH (2012). Virulence determinants in the obligate intracellular pathogen Chlamydia trachomatis revealed by forward genetic approaches. Proc Natl Acad Sci U S A 109(4): 1263 1268. doi: $10.1073 /$ pnas.1117884109

15. Kokes M, Dunn JD, Granek JA, Nguyen BD, Barker JR, Valdivia RH Bastidas RJ (2015). Integrating chemical mutagenesis and wholegenome sequencing as a platform for forward and reverse genetic analysis of Chlamydia. Cell Host Microbe 17(5): 716-725. doi 10.1016/j.chom.2015.03.014

16. Rahnama M, Fields KA (2018). Transformation of Chlamydia: current approaches and impact on our understanding of chlamydial infection biology. Microbes Infect 20(7-8): 445-450. doi: 10.1016/j.micinf.2018.01.002
17. Wang $Y$, Kahane $S$, Cutcliffe LT, Skilton RJ, Lambden PR, Clarke IN (2011). Development of a transformation system for Chlamydia trachomatis: restoration of glycogen biosynthesis by acquisition of a plasmid shuttle vector. PLoS Pathog 7(9): e1002258. doi: 10.1371/journal.ppat.1002258

18. Costa TR, Felisberto-Rodrigues C, Meir A, Prevost MS, Redzej A, Trokter M, Waksman G (2015). Secretion systems in Gram-negative bacteria: structural and mechanistic insights. Nat Rev Microbiol 13(6): 343-359. doi: 10.1038/nrmicro3456

19. Tsirigotaki A, De Geyter J, Sostaric N, Economou A, Karamanou S (2017). Protein export through the bacterial Sec pathway. Nat Rev Microbiol 15(1): 21-36. doi: 10.1038/nrmicro.2016.161

20. Galan JE, Lara-Tejero M, Marlovits TC, Wagner S (2014). Bacterial type III secretion systems: specialized nanomachines for protein delivery into target cells. Annu Rev Microbiol 68: 415-438. doi: 10.1146/annurev-micro-092412-155725

21. Stephens RS, Kalman S, Lammel C, Fan J, Marathe R, Aravind L, Mitchell W, Olinger L, Tatusov RL, Zhao Q, Koonin EV, Davis RW (1998). Genome sequence of an obligate intracellular pathogen of humans: Chlamydia trachomatis. Science 282(5389): 754-759. doi: 10.1126/science.282.5389.754

22. Stephens RS, Lammel CJ (2001). Chlamydia outer membrane protein discovery using genomics. Curr Opin Microbiol 4(1): 16-20. doi: 10.1016/s1369-5274(00)00158-2

23. Fields KA, Hackstadt T (2000). Evidence for the secretion of Chlamydia trachomatis CopN by a type III secretion mechanism. Mol Microbiol 38(5): 1048-1060. doi: 10.1046/j.1365-2958.2000.02212.x

24. Chen D, Lei L, Lu C, Flores R, DeLisa MP, Roberts TC, Romesberg FE, Zhong $G$ (2010). Secretion of the chlamydial virulence factor CPAF requires the Sec-dependent pathway. Microbiology 156 (Pt 10): 3031 3040. doi: 10.1099/mic.0.040527-0

25. Kari L, Southern TR, Downey CJ, Watkins HS, Randall LB, Taylor LD, Sturdevant GL, Whitmire WM, Caldwell HD (2014). Chlamydia trachomatis Polymorphic Membrane Protein D Is a Virulence Factor Involved in Early Host-Cell Interactions. Infect Immun 82(7): 27562762. doi: 10.1128/IAI.01686-14

26. Fields KA, Mead DJ, Dooley CA, Hackstadt T (2003). Chlamydia trachomatis type III secretion: evidence for a functional apparatus during early-cycle development. Mol Microbiol 48(3): 671-683. doi: 10.1046/j.1365-2958.2003.03462.x

27. Kiselev AO, Skinner MC, Lampe MF (2009). Analysis of pmpD ex pression and PmpD post-translational processing during the life cycle of Chlamydia trachomatis serovars A, D, and L2. PLoS One 4(4): e5191. doi: 10.1371/journal.pone.0005191

28. Swanson KA, Taylor LD, Frank SD, Sturdevant GL, Fischer ER, Carlson JH, Whitmire WM, Caldwell HD (2009). Chlamydia trachomatis polymorphic membrane protein $D$ is an oligomeric autotransporter with a higher-order structure. Infect Immun 77(1): 508-516. doi: 10.1128/IAI.01173-08

29. Liu X, Afrane M, Clemmer DE, Zhong G, Nelson DE (2010). Identification of Chlamydia trachomatis outer membrane complex proteins by differential proteomics. J Bacteriol 192(11): 2852-2860. doi: 10.1128/JB.01628-09

30. Muschiol S, Bailey L, Gylfe A, Sundin C, Hultenby K, Bergstrom S, Elofsson M, Wolf-Watz H, Normark S, Henriques-Normark B (2006). A small-molecule inhibitor of type III secretion inhibits different stages of the infectious cycle of Chlamydia trachomatis. Proc Natl Acad Sci U S A 103(39): 14566-14571. doi: 10.1073/pnas.0606412103

31. Wolf K, Betts HJ, Chellas-Gery B, Hower S, Linton CN, Fields KA (2006). Treatment of Chlamydia trachomatis with a small molecule 
inhibitor of the Yersinia type III secretion system disrupts progression of the chlamydial developmental cycle. Mol Microbiol 61(6): 15431555. doi: 10.1111/j.1365-2958.2006.05347.x

32. Lei L, Qi M, Budrys N, Schenken R, Zhong G (2011). Localization of Chlamydia trachomatis hypothetical protein CT311 in host cell cytoplasm. Microb Pathog 51(3): 101-109. doi: 10.1016/j.micpath.2011.05.002

33. Slepenkin A, Enquist PA, Hagglund U, de la Maza LM, Elofsson M, Peterson EM (2007). Reversal of the antichlamydial activity of putative type III secretion inhibitors by iron. Infect Immun 75(7): 3478-3489. doi: 10.1128/iai.00023-07

34. Engstrom P, Nguyen BD, Normark J, Nilsson I, Bastidas RJ, Gylfe A, Elofsson M, Fields KA, Valdivia RH, Wolf-Watz H, Bergstrom S (2013). Mutations in hemG mediate resistance to salicylidene acylhydrazides, demonstrating a novel link between protoporphyrinogen oxidase (HemG) and Chlamydia trachomatis infectivity. J Bacteriol 195(18): 4221-4230. doi: 10.1128/JB.00506-13

35. Becker E, Hegemann JH (2014). All subtypes of the Pmp adhesin family are implicated in chlamydial virulence and show speciesspecific function. Microbiology Open 3(4): 544-556. doi: 10.1002/mbo3.186

36. Fadel S, Eley A (2007). Chlamydia trachomatis OmcB protein is a surface-exposed glycosaminoglycan-dependent adhesin. J Med Microbiol 56(Pt 1): 15-22. doi: 10.1099/jmm.0.46801-0

37. Su H, Raymond L, Rockey DD, Fischer E, Hackstadt T, Caldwell HD (1996). A recombinant Chlamydia trachomatis major outer membrane protein binds to heparan sulfate receptors on epithelial cells. Proc Natl Acad Sci U S A 93(20): 11143-11148. doi: 10.1073/pnas.93.20.11143

38. Su H, Watkins NG, Zhang YX, Caldwell HD (1990). Chlamydia trachomatis-host cell interactions: role of the chlamydial major outer membrane protein as an adhesin. Infect Immun 58(4): 1017-1025. PMID: 2318528

39. Sun G, Pal S, Sarcon AK, Kim S, Sugawara E, Nikaido H, Cocco MJ, Peterson EM, de la Maza LM (2007). Structural and functional analyses of the major outer membrane protein of Chlamydia trachomatis. J Bacteriol 189(17): 6222-6235. doi: 10.1128/JB.00552-07

40. Stallmann S, Hegemann JH (2016). The Chlamydia trachomatis Ctad1 invasin exploits the human integrin beta1 receptor for host cell entry. Cell Microbiol 18(5): 761-775. doi: 10.1111/cmi.12549

41. Rockey DD, Scidmore MA, Bannantine JP, Brown WJ (2002). Proteins in the chlamydial inclusion membrane. Microbes Infect 4(3): 333-340. doi: 10.1016/s1286-4579(02)01546-0

42. Dehoux P, Flores R, Dauga C, Zhong G, Subtil A (2011). Multigenome identification and characterization of chlamydiae-specific type III secretion substrates: the Inc proteins. BMC genomics 12: 109. doi: 10.1186/1471-2164-12-109

43. Lutter El, Martens C, Hackstadt T (2012). Evolution and conservation of predicted inclusion membrane proteins in chlamydiae. Comp Funct Genomics 2012: 362104. doi: 10.1155/2012/362104

44. Heinz E, Rockey DD, Montanaro J, Aistleitner K, Wagner M, Horn $M$ (2010). Inclusion membrane proteins of Protochlamydia amoebophila UWE25 reveal a conserved mechanism for host cell interaction among the Chlamydiae. J Bacteriol 192(19): 5093-5102. doi: 10.1128/JB.00605-10

45. Rockey DD, Heinzen RA, Hackstadt T (1995). Cloning and characterization of a Chlamydia psittaci gene coding for a protein localized in the inclusion membrane of infected cells. Mol Microbiol 15(4): 617626. doi: 10.1111/j.1365-2958.1995.tb02371.x
46. Rockey DD, Rosquist JL (1994). Protein antigens of Chlamydia psittaci present in infected cells but not detected in the infectious elementary body. Infect Immun 62(1): 106-112. PMID: 8262615

47. Bannantine JP, Rockey DD, Hackstadt T (1998). Tandem genes of Chlamydia psittaci that encode proteins localized to the inclusion membrane. Mol Microbiol 28(5): 1017-1026. doi: 10.1046/j.13652958.1998.00867.x

48. Bannantine JP, Stamm WE, Suchland RJ, Rockey DD (1998). Chlamydia trachomatis IncA is localized to the inclusion membrane and is recognized by antisera from infected humans and primates. Infect Immun 66(12): 6017-6021. PMID: 9826388

49. Bannantine JP, Griffiths RS, Viratyosin W, Brown WJ, Rockey DD (2000). A secondary structure motif predictive of protein localization to the chlamydial inclusion membrane. Cell Microbiol 2(1): 35-47. doi: 10.1046/j.1462-5822.2000.00029.x

50. Li Z, Chen C, Chen D, Wu Y, Zhong Y, Zhong G (2008). Characterization of fifty putative inclusion membrane proteins encoded in the Chlamydia trachomatis genome. Infect Immun 76(6): 2746-2757. doi: 10.1128/iai.00010-08

51. Scidmore-Carlson MA, Shaw El, Dooley CA, Fischer ER, Hackstadt T (1999). Identification and characterization of a Chlamydia trachomatis early operon encoding four novel inclusion membrane proteins. Mol Microbiol 33(4): 753-765. doi: 10.1046/j.1365-2958.1999.01523.x

52. Shaw El, Dooley CA, Fischer ER, Scidmore MA, Fields KA, Hackstadt $T$ (2000). Three temporal classes of gene expression during the Chlamydia trachomatis developmental cycle. Mol Microbiol 37(4): 913925. doi: 10.1046/j.1365-2958.2000.02057.x

53. Starnbach MN, Loomis WP, Ovendale P, Regan D, Hess B, Alderson $M R$, Fling SP (2003). An inclusion membrane protein from Chlamydia trachomatis enters the MHC class I pathway and stimulates a CD8+ T cell response. J Immunol 171(9): 4742-4749. doi 10.4049/jimmunol.171.9.4742

54. Sisko JL, Spaeth K, Kumar Y, Valdivia RH (2006). Multifunctional analysis of Chlamydia-specific genes in a yeast expression system. Mol Microbiol 60(1): 51-66. doi: 10.1111/j.1365-2958.2006.05074.x

55. Chen C, Chen D, Sharma J, Cheng W, Zhong Y, Liu K, Jensen J, Shain $\mathrm{R}$, Arulanandam B, Zhong $\mathrm{G}$ (2006). The hypothetical protein CT813 is localized in the Chlamydia trachomatis inclusion membrane and is immunogenic in women urogenitally infected with $C$. trachomatis. Infect Immun 74(8): 4826-4840. doi: 10.1128/IAI.00081-06

56. Sharma J, Zhong Y, Dong F, Piper JM, Wang G, Zhong G (2006). Profiling of human antibody responses to Chlamydia trachomatis urogenital tract infection using microplates arrayed with 156 chlamydial fusion proteins. Infect Immun 74(3): 1490-1499. doi: 10.1128/IAI.74.3.1490-1499.2006

57. Jia TJ, Liu DW, Luo JH, Zhong GM (2007). Localization of the hypothetical protein CT249 in the Chlamydia trachomatis inclusion membrane. Wei Sheng Wu Xue Bao 47(4): 645-648. PMID: 17944365

58. Bauler LD, Hackstadt T (2014). Expression and targeting of secreted proteins from Chlamydia trachomatis. J Bacteriol 196(7): 13251334. doi: 10.1128/JB.01290-13

59. Weber MM, Bauler LD, Lam J, Hackstadt T (2015). Expression and localization of predicted inclusion membrane proteins in Chlamydia trachomatis. Infect Immun 83(12): 4710-4718. doi: 10.1128/IAI.01075-15

60. Hsia RC, Pannekoek Y, Ingerowski E, Bavoil PM (1997). Type III secretion genes identify a putative virulence locus of Chlamydia. Mol Microbiol 25(2): 351-359. doi: 10.1046/j.1365-2958.1997.4701834.x 
61. Subtil A, Blocker A, Dautry-Varsat A (2000). Type III secretion system in Chlamydia species: identified members and candidates. Microbes Infect 2(4): 367-369. doi: 10.1016/s1286-4579(00)00335-x

62. Subtil A, Parsot C, Dautry-Varsat A (2001). Secretion of predicted Inc proteins of Chlamydia pneumoniae by a heterologous type III machinery. Mol Microbiol 39(3): 792-800. doi: 10.1046/j.13652958.2001.02272.x

63. Subtil A, Delevoye C, Balana ME, Tastevin L, Perrinet S, DautryVarsat A (2005). A directed screen for chlamydial proteins secreted by a type III mechanism identifies a translocated protein and numerous other new candidates. Mol Microbiol 56(6): 1636-1647. doi: 10.1111/j.1365-2958.2005.04647.x

64. Almeida F, Borges V, Ferreira R, Borrego MJ, Gomes JP, Mota LJ (2012). Polymorphisms in Inc Proteins and Differential Expression of inc Genes among Chlamydia trachomatis Strains Correlate with Invasiveness and Tropism of Lymphogranuloma Venereum Isolates. J Bacteriol 194(23): 6574-6585. doi: 10.1128/JB.01428-12

65. Belland RJ, Zhong G, Crane DD, Hogan D, Sturdevant D, Sharma J, Beatty WL, Caldwell HD (2003). Genomic transcriptional profiling of the developmental cycle of Chlamydia trachomatis. Proc Natl Acad Sci U S A 100(14): 8478-8483. doi: 10.1073/pnas.1331135100

66. Nicholson TL, Olinger L, Chong K, Schoolnik G, Stephens RS (2003). Global stage-specific gene regulation during the developmental cycle of Chlamydia trachomatis. J Bacteriol 185(10): 3179-3189. doi: 10.1128/jb.185.10.3179-3189.2003

67. Hackstadt T, Fischer ER, Scidmore MA, Rockey DD, Heinzen RA (1997). Origins and functions of the chlamydial inclusion. Trends Microbiol 5(7): 288-293. doi: 10.1016/s0966-842x(97)01061-5

68. Hackstadt T, Scidmore-Carlson MA, Shaw El, Fischer ER (1999). The Chlamydia trachomatis IncA protein is required for homotypic vesicle fusion. Cell Microbiol 1(2): 119-130. doi: 10.1046/j.14625822.1999.00012.x

69. Suchland RJ, Rockey DD, Bannantine JP, Stamm WE (2000). Isolates of Chlamydia trachomatis that occupy nonfusogenic inclusions lack IncA, a protein localized to the inclusion membrane. Infect Immun 68(1): 360-367. doi: 10.1128/iai.68.1.360-367.2000

70. Pannekoek Y, Spaargaren J, Langerak AA, Merks J, Morre SA, van der Ende A (2005). Interrelationship between polymorphisms of incA, fusogenic properties of Chlamydia trachomatis strains, and clinical manifestations in patients in The Netherlands. J Clin Microbiol 43(5): 2441-2443. doi: 10.1128/JCM.43.5.2441-2443.2005

71. Weber MM, Noriea NF, Bauler LD, Lam JL, Sager J, Wesolowski J, Paumet F, Hackstadt T (2016). A Functional Core of IncA Is Required for Chlamydia trachomatis Inclusion Fusion. J Bacteriol 198(8): 13471355. doi: 10.1128/JB.00933-15

72. Wang $T$, Li L, Hong W (2017). SNARE proteins in membrane trafficking. Traffic 18(12): 767-775. doi: 10.1111/tra.12524

73. Delevoye C, Nilges M, Dautry-Varsat A, Subtil A (2004). Conservation of the biochemical properties of IncA from Chlamydia trachomatis and Chlamydia caviae: oligomerization of IncA mediates interaction between facing membranes. J Biol Chem 279(45): 46896-46906. doi: 10.1074/jbc.M407227200

74. Delevoye C, Nilges M, Dehoux P, Paumet F, Perrinet S, DautryVarsat A, Subtil A (2008). SNARE protein mimicry by an intracellular bacterium. PLoS Pathog 4(3): e1000022. doi: 10.1371/journal.ppat.1000022

75. Gauliard E, Ouellette SP, Rueden KJ, Ladant D (2015). Characterization of interactions between inclusion membrane proteins from Chlamydia trachomatis. Front Cell Infect Microbiol 5: 13. doi: 10.3389/fcimb.2015.00013
76. Ronzone E, Wesolowski J, Bauler LD, Bhardwaj A, Hackstadt T, Paumet $F$ (2014). An alpha-helical core encodes the dual functions of the chlamydial protein IncA. J Biol Chem 289(48): 33469-33480. doi: 10.1074/jbc.M114.592063

77. Ronzone E, Paumet F (2013). Two coiled-coil domains of Chlamydia trachomatis IncA affect membrane fusion events during infection. PLoS One 8(7): e69769. doi: 10.1371/journal.pone.0069769

78. Cingolani G, McCauley M, Lobley A, Bryer AJ, Wesolowski J, Greco DL, Lokareddy RK, Ronzone E, Perilla JR, Paumet F (2019). Structural basis for the homotypic fusion of chlamydial inclusions by the SNARElike protein IncA. Nat Commun 10(1): 2747. doi: 10.1038/s41467-01910806-9

79. Brett TJ, Legendre-Guillemin V, McPherson PS, Fremont DH (2006). Structural definition of the F-actin-binding THATCH domain from HIP1R. Nat Struct Mol Biol 13(2): 121-130. doi: 10.1038/nsmb1043

80. Paumet F, Wesolowski J, Garcia-Diaz A, Delevoye C, Aulner N, Shuman HA, Subtil A, Rothman JE (2009). Intracellular bacteria encode inhibitory SNARE-like proteins. PLoS ONE 4(10): e7375. doi: 10.1371/journal.pone.0007375

81. Geisler WM, Suchland RJ, Rockey DD, Stamm WE (2001). Epidemiology and clinical manifestations of unique Chlamydia trachomatis isolates that occupy nonfusogenic inclusions. J Infect Dis 184(7): 879884. doi: $10.1086 / 323340$

82. Xia M, Suchland RJ, Bumgarner RE, Peng T, Rockey DD, Stamm WE (2005). Chlamydia trachomatis variant with nonfusing inclusions: growth dynamic and host-cell transcriptional response. J Infect Dis 192(7): 1229-1236. doi: 10.1086/444394

83. Burd C, Cullen PJ (2014). Retromer: a master conductor of endosome sorting. Cold Spring Harb Perspect Biol 6(2): a016774. doi: 10.1101/cshperspect.a016774

84. Aeberhard L, Banhart S, Fischer M, Jehmlich N, Rose L, Koch S, Laue M, Renard BY, Schmidt F, Heuer D (2015). The Proteome of the Isolated Chlamydia trachomatis Containing Vacuole Reveals a Complex Trafficking Platform Enriched for Retromer Components. PLoS Pathog 11(6): e1004883. doi: 10.1371/journal.ppat.1004883

85. Mirrashidi KM, Elwell CA, Verschueren E, Johnson JR, Frando A, Von Dollen J, Rosenberg O, Gulbahce N, Jang G, Johnson T, Jager S, Gopalakrishnan AM, Sherry J, Dunn JD, Olive A, Penn B, Shales M, Cox JS, Starnbach MN, Derre I, Valdivia R, Krogan NJ, Engel J (2015). Global Mapping of the Inc-Human Interactome Reveals that Retromer Restricts Chlamydia Infection. Cell Host Microbe 18(1): 109-121. doi: 10.1016/j.chom.2015.06.004

86. Elwell CA, Czudnochowski N, von Dollen J, Johnson JR, Nakagawa R, Mirrashidi K, Krogan NJ, Engel JN, Rosenberg OS (2017). Chlamydia interfere with an interaction between the mannose-6-phosphate receptor and sorting nexins to counteract host restriction. elife 6: e22709. doi: 10.7554/eLife.22709

87. Paul B, Kim HS, Kerr MC, Huston WM, Teasdale RD, Collins BM (2017). Structural basis for the hijacking of endosomal sorting nexin proteins by Chlamydia trachomatis. elife 6: e22311. doi: 10.7554/eLife. 22311

88. Sun $Q$, Yong $X$, Sun X, Yang F, Dai Z, Gong Y, Zhou L, Zhang X, Niu D, Dai L, Liu JJ, Jia D (2017). Structural and functional insights into sorting nexin 5/6 interaction with bacterial effector IncE. Signal Transduct Target Ther 2: 17030. doi: 10.1038/sigtrans.2017.30

89. Pfeffer SR (2009). Multiple routes of protein transport from endosomes to the trans Golgi network. FEBS Lett 583(23): 3811-3816. doi: 10.1016/j.febslet.2009.10.075

90. Elwell C, Engel J (2018). Emerging Role of Retromer in Modulating Pathogen Growth. Trends Microbiol 26(9): 769-780. doi: 10.1016/j.tim.2018.04.001 
91. Stenmark H (2009). Rab GTPases as coordinators of vesicle traffic. Nat Rev Mol Cell Biol 10(8): 513-525. doi: 10.1038/nrm2728

92. Rzomp KA, Scholtes LD, Briggs BJ, Whittaker GR, Scidmore MA (2003). Rab GTPases are recruited to chlamydial inclusions in both a species-dependent and species-independent manner. Infect Immun 71(10): 5855-5870. doi: 10.1128/iai.71.10.5855-5870.2003

93. Capmany A, Damiani MT (2010). Chlamydia trachomatis intercepts Golgi-derived sphingolipids through a Rab14-mediated transport required for bacterial development and replication. PLoS One 5(11): e14084. doi: 10.1371/journal.pone.0014084

94. Gambarte Tudela J, Capmany A, Romao M, Quintero C, MisereyLenkei S, Raposo G, Goud B, Damiani MT (2015). The late endocytic Rab39a GTPase regulates the interaction between multivesicular bodies and chlamydial inclusions. J Cell Sci 128(16): 3068-3081. doi: 10.1242/jcs.170092

95. Gambarte Tudela J, Buonfigli J, Lujan A, Alonso Bivou M, Cebrian I, Capmany A, Damiani MT (2019). Rab39a and Rab39b Display Different Intracellular Distribution and Function in Sphingolipids and Phospholipids Transport. Int J Mol Sci 20(7): E1688. doi: 10.3390/ijms20071688

96. Faris R, Merling M, Andersen SE, Dooley CA, Hackstadt T, Weber MM (2019). Chlamydia trachomatis CT229 Subverts Rab GTPaseDependent CCV Trafficking Pathways to Promote Chlamydial Infection. Cell Rep 26(12): 3380-3390. doi: 10.1016/j.celrep.2019.02.079

97. Rzomp KA, Moorhead AR, Scidmore MA (2006). The GTPase Rab4 interacts with Chlamydia trachomatis inclusion membrane protein CT229. Infect Immun 74(9): 5362-5373. doi: 10.1128/IAI.00539-06

98. Sixt BS, Bastidas RJ, Finethy R, Baxter RM, Carpenter VK, Kroemer G, Coers J, Valdivia RH (2017). The Chlamydia trachomatis Inclusion Membrane Protein CpoS Counteracts STING-Mediated Cellular Surveillance and Suicide Programs. Cell Host Microbe 21(1): 113-121. doi: 10.1016/j.chom.2016.12.002

99. Rejman Lipinski A, Heymann J, Meissner C, Karlas A, Brinkmann V, Meyer TF, Heuer D (2009). Rab6 and Rab11 regulate Chlamydia trachomatis development and golgin-84-dependent Golgi fragmentation. PLoS Pathog 5(10): e1000615. doi: 10.1371/journal.ppat.1000615

100. Weber MM, Lam JL, Dooley CA, Noriea NF, Hansen BT, Hoyt FH, Carmody AB, Sturdevant GL, Hackstadt T (2017). Absence of Specific Chlamydia trachomatis Inclusion Membrane Proteins Triggers Premature Inclusion Membrane Lysis and Host Cell Death. Cell Rep 19(7): 1406-1417. doi: 10.1016/j.celrep.2017.04.058

101. Lamkanfi M, Dixit VM (2010). Manipulation of host cell death pathways during microbial infections. Cell Host Microbe 8(1): 44-54. doi: 10.1016/j.chom.2010.06.007

102. Kumar Y, Valdivia RH (2009). Leading a sheltered life: intracellular pathogens and maintenance of vacuolar compartments. Cell Host Microbe 5(6): 593-601. doi: 10.1016/j.chom.2009.05.014

103. Fredlund J, Enninga J (2014). Cytoplasmic access by intracellular bacterial pathogens. Trends Microbiol 22(3): 128-137. doi: 10.1016/j.tim.2014.01.003

104. Carabeo RA, Grieshaber SS, Fischer E, Hackstadt T (2002). Chlamydia trachomatis induces remodeling of the actin cytoskeleton during attachment and entry into HeLa cells. Infect Immun 70(7): 37933803. doi: 10.1128/iai.70.7.3793-3803.2002

105. Hybiske K, Stephens RS (2007). Mechanisms of host cell exit by the intracellular bacterium Chlamydia. Proc Natl Acad Sci U S A 104(27): 11430-11435. doi: 10.1073/pnas.0703218104

106. Kumar $\mathrm{Y}$, Valdivia RH (2008). Actin and intermediate filaments stabilize the Chlamydia trachomatis vacuole by forming dynamic structural scaffolds. Cell Host Microbe 4(2): 159-169. doi: 10.1016/j.chom.2008.05.018

107. Volceanov L, Herbst K, Biniossek M, Schilling O, Haller D, Nolke T, Subbarayal P, Rudel T, Zieger B, Hacker G (2014). Septins arrange Factin-containing fibers on the Chlamydia trachomatis inclusion and are required for normal release of the inclusion by extrusion. mBio 5(5): e01802-01814. doi: 10.1128/mBio.01802-14

108. Al-Zeer MA, Al-Younes HM, Kerr M, Abu-Lubad M, Gonzalez E, Brinkmann V, Meyer TF (2014). Chlamydia trachomatis remodels stable microtubules to coordinate Golgi stack recruitment to the chlamydial inclusion surface. Mol Microbiol 94(6): 1285-1297. doi: 10.1111/mmi.12829

109. Dumoux M, Menny A, Delacour D, Hayward RD (2015). A Chlamydia effector recruits CEP170 to reprogram host microtubule organization. J Cell Sci 128(18): 3420-3434. doi: 10.1242/jcs.169318

110. Tarbet HJ, Dolat L, Smith TJ, Condon BM, O'Brien ET, 3rd, Valdivia $\mathrm{RH}$, Boyce $\mathrm{M}$ (2018). Site-specific glycosylation regulates the form and function of the intermediate filament cytoskeleton. elife 7: e31807. doi: 10.7554/eLife.31807

111. Heuer D, Lipinski AR, Machuy N, Karlas A, Wehrens A, Siedler F, Brinkmann V, Meyer TF (2009). Chlamydia causes fragmentation of the Golgi compartment to ensure reproduction. Nature 457(7230): 731-735. doi: 10.1038/nature07578

112. Wesolowski J, Weber MM, Nawrotek A, Dooley CA, Calderon M, St Croix CM, Hackstadt T, Cherfils J, Paumet F (2017). Chlamydia Hijacks ARF GTPases To Coordinate Microtubule Posttranslational Modifications and Golgi Complex Positioning. mBio 8(3): e02280-16. doi: 10.1128/mBio.02280-16

113. Donaldson JG, Jackson CL (2011). ARF family G proteins and their regulators: roles in membrane transport, development and disease. Nat Rev Mol Cell Biol 12(6): 362-375. doi: 10.1038/nrm3117

114. Cohen S, Valm AM, Lippincott-Schwartz J (2018). Interacting organelles. Curr Opin Cell Biol 53: 84-91. doi: 10.1016/j.ceb.2018.06.003

115. Hackstadt T, Scidmore MA, Rockey DD (1995). Lipid metabolism in Chlamydia trachomatis-infected cells: directed trafficking of Golgiderived sphingolipids to the chlamydial inclusion. Proc Natl Acad Sci U S A 92(11): 4877-4881. doi: 10.1073/pnas.92.11.4877

116. Hackstadt T, Rockey DD, Heinzen RA, Scidmore MA (1996). Chlamydia trachomatis interrupts an exocytic pathway to acquire endogenously synthesized sphingomyelin in transit from the Golgi apparatus to the plasma membrane. Embo J 15(5): 964-977. doi: 10.1002/j.14602075.1996.tb00433.x

117. Scidmore MA, Fischer ER, Hackstadt T (1996). Sphingolipids and glycoproteins are differentially trafficked to the Chlamydia trachomatis inclusion. J Cell Biol 134(2): 363-374. doi: 10.1083/jcb.134.2.363

118. Beatty WL (2006). Trafficking from CD63-positive late endocytic multivesicular bodies is essential for intracellular development of Chlamydia trachomatis. J Cell Sci 119(Pt 2): 350-359. doi: 10.1242/jcs.02733

119. Hanada K (2014). Co-evolution of sphingomyelin and the ceramide transport protein CERT. Biochim Biophys Acta 1841(5): 704719. doi: 10.1016/j.bbalip.2013.06.006

120. Derre I, Swiss R, Agaisse H (2011). The lipid transfer protein CERT interacts with the Chlamydia inclusion protein IncD and participates to ER-Chlamydia inclusion membrane contact sites. PLoS Pathog 7(6): e1002092. doi: 10.1371/journal.ppat.1002092

121. van Ooij C, Kalman L, van I, Nishijima M, Hanada K, Mostov K, Engel JN (2000). Host cell-derived sphingolipids are required for the 
intracellular growth of Chlamydia trachomatis. Cell Microbiol 2(6): 627-637. doi: 10.1046/j.1462-5822.2000.00077.x

122. Elwell CA, Jiang S, Kim JH, Lee A, Wittmann T, Hanada K, Melancon P, Engel JN (2011). Chlamydia trachomatis co-opts GBF1 and CERT to acquire host sphingomyelin for distinct roles during intracellular development. PLoS Pathog 7(9): e1002198. doi: 10.1371/journal.ppat.1002198

123. Dumoux M, Clare DK, Saibil HR, Hayward RD (2012). Chlamydiae assemble a pathogen synapse to hijack the host endoplasmic reticulum. Traffic 13(12): 1612-1627. doi: 10.1111/tra.12002

124. Agaisse H, Derre I (2014). Expression of the effector protein IncD in Chlamydia trachomatis mediates recruitment of the lipid transfer protein CERT and the endoplasmic reticulum-resident protein VAPB to the inclusion membrane. Infect Immun 82(5): 2037-2047. doi: 10.1128/IAI.01530-14

125. Stanhope R, Flora E, Bayne C, Derre I (2017). IncV, a FFAT motifcontaining Chlamydia protein, tethers the endoplasmic reticulum to the pathogen-containing vacuole. Proc Natl Acad Sci U S A 114(45): 12039-12044. doi: 10.1073/pnas.1709060114

126. Clausen JD, Christiansen G, Holst HU, Birkelund S (1997). Chlamydia trachomatis utilizes the host cell microtubule network during early events of infection. Mol Microbiol 25(3): 441-449. doi: 10.1046/j.1365-2958.1997.4591832.x

127. Grieshaber SS, Grieshaber NA, Hackstadt T (2003). Chlamydia trachomatis uses host cell dynein to traffic to the microtubuleorganizing center in a p50 dynamitin-independent process. J Cell Sci 116(Pt 18): 3793-3802. doi: 10.1242/jcs.00695

128. Mital J, Miller NJ, Fischer ER, Hackstadt T (2010). Specific chlamydial inclusion membrane proteins associate with active Src family kinases in microdomains that interact with the host microtubule network. Cell Microbiol 12(9): 1235-1249. doi: 10.1111/j.14625822.2010.01465.x

129. Mital J, Hackstadt T (2011). Diverse requirements for SRC-family tyrosine kinases distinguish chlamydial species. mBio 2(2): e00031-11 . doi: 10.1128/mBio.00031-11

130. Nguyen PH, Lutter El, Hackstadt T (2018). Chlamydia trachomatis inclusion membrane protein MrcA interacts with the inositol 1,4,5trisphosphate receptor type 3 (ITPR3) to regulate extrusion formation. PLoS Pathog 14(3): e1006911. doi: 10.1371/journal.ppat.1006911

131. Agaisse H, Derre I (2015). STIM1 Is a Novel Component of ERChlamydia trachomatis Inclusion Membrane Contact Sites. PLoS One 10(4): e0125671. doi: 10.1371/journal.pone.0125671

132. Mital J, Lutter El, Barger AC, Dooley CA, Hackstadt T (2015). Chlamydia trachomatis inclusion membrane protein CT850 interacts with the dynein light chain DYNLT1 (Tctex1). Biochem Biophys Res Commun 462(2): 165-170. doi: 10.1016/j.bbrc.2015.04.116

133. Alzhanov DT, Weeks SK, Burnett JR, Rockey DD (2009). Cytokinesis is blocked in mammalian cells transfected with Chlamydia trachomatis gene CT223. BMC Microbiol 9: 2. doi: 10.1186/1471-2180-9-2

134. Bocker S, Heurich A, Franke C, Monajembashi S, Sachse K, Saluz HP, Hanel F (2014). Chlamydia psittaci inclusion membrane protein IncB associates with host protein Snapin. Int J Med Microbiol 304(56): 542-553. doi: 10.1016/j.ijmm.2014.03.005

135. Almeida F, Luis MP, Pereira IS, Pais SV, Mota $\amalg$ (2018). The Human Centrosomal Protein CCDC146 Binds Chlamydia trachomatis Inclusion Membrane Protein CT288 and Is Recruited to the Periphery of the Chlamydia-Containing Vacuole. Front Cell Infect Microbiol 8: 254. doi: $10.3389 /$ fcimb.2018.00254
136. Vicente-Manzanares M, Ma X, Adelstein RS, Horwitz AR (2009). Non-muscle myosin II takes centre stage in cell adhesion and migration. Nat Rev Mol Cell Biol 10(11): 778-790. doi: 10.1038/nrm2786

137. Kiss A, Erdodi F, Lontay B (2019). Myosin phosphatase: Unexpected functions of a long-known enzyme. Biochim Biophys Acta Mol Cell Res 1866(1): 2-15. doi: 10.1016/j.bbamcr.2018.07.023

138. Lutter El, Barger AC, Nair V, Hackstadt T (2013). Chlamydia trachomatis Inclusion Membrane Protein CT228 Recruits Elements of the Myosin Phosphatase Pathway to Regulate Release Mechanisms. Cell Rep 3(6): 1921-1931. doi: 10.1016/j.celrep.2013.04.027

139. Prole DL, Taylor CW (2016). Inositol 1,4,5-trisphosphate receptors and their protein partners as signalling hubs. J Physiol 594(11): 2849-2866. doi: 10.1113/JP271139

140. Shaw JH, Key CE, Snider TA, Sah P, Shaw El, Fisher DJ, Lutter El (2018). Genetic Inactivation of Chlamydia trachomatis Inclusion Membrane Protein CT228 Alters MYPT1 Recruitment, Extrusion Production, and Longevity of Infection. Front Cell Infect Microbiol 8(415. doi: 10.3389/fcimb.2018.00415.

141. Soboloff J, Rothberg BS, Madesh M, Gill DL (2012). STIM proteins: dynamic calcium signal transducers. Nat Rev Mol Cell Biol 13(9): 549565. doi: $10.1038 / \mathrm{nrm} 3414$

142. Sherrid AM, Hybiske K (2017). Chlamydia trachomatis Cellular Exit Alters Interactions with Host Dendritic Cells. Infect Immun 85(5). doi: 10.1128/IAI.00046-17

143. Zuck M, Ellis T, Venida A, Hybiske K (2017). Extrusions are phagocytosed and promote Chlamydia survival within macrophages. Cell Microbiol 19(4). doi: 10.1111/cmi.12683

144. Aitken A (2006). 14-3-3 proteins: a historic overview. Semin Cancer Biol 16(3): 162-172. doi: 10.1016/j.semcancer.2006.03.005

145. Scidmore MA, Hackstadt T (2001). Mammalian 14-3-3beta associates with the Chlamydia trachomatis inclusion membrane via its interaction with IncG. Mol Microbiol 39(6): 1638-1650. doi: 10.1046/j.1365-2958.2001.02355.x

146. Verbeke P, Welter-Stahl L, Ying S, Hansen J, Hacker G, Darville T, Ojcius DM (2006). Recruitment of BAD by the Chlamydia trachomatis vacuole correlates with host-cell survival. PLoS Pathog 2(5): e45. doi: 10.1371/journal.ppat.0020045

147. Moore ER, Ouellette SP (2014). Reconceptualizing the chlamydial inclusion as a pathogen-specified parasitic organelle: an expanded role for Inc proteins. Frontiers in cellular and infection microbiology 4: 157. doi: 10.3389/fcimb.2014.00157

148. Mital J, Miller NJ, Dorward DW, Dooley CA, Hackstadt T (2013). Role for chlamydial inclusion membrane proteins in inclusion membrane structure and biogenesis. PLoS ONE 8(5): e63426. doi: 10.1371/journal.pone.0063426

149. Sturdevant GL, Kari L, Gardner DJ, Olivares-Zavaleta N, Randall LB, Whitmire WM, Carlson JH, Goheen MM, Selleck EM, Martens C, Caldwell HD (2010). Frameshift mutations in a single novel virulence factor alter the in vivo pathogenicity of Chlamydia trachomatis for the female murine genital tract. Infect Immun 78(9): 3660-3668. doi: 10.1128/IAI.00386-10

150. Sturdevant GL, Zhou B, Carlson JH, Whitmire WM, Song L, Caldwell HD (2014). Infectivity of urogenital Chlamydia trachomatis plasmid-deficient, CT135-null, and double-deficient strains in female mice. Pathog Dis 71(1): 90-92. doi: 10.1111/2049-632X.12121

151. Borges V, Pinheiro $M$, Antelo M, Sampaio DA, Vieira L, Ferreira R, Nunes A, Almeida F, Mota LJ, Borrego MJ, Gomes JP (2015). Chlamydia trachomatis In Vivo to In Vitro Transition Reveals Mechanisms of Phase Variation and Down-Regulation of Virulence Factors. PLoS One 10(7): e0133420. doi: 10.1371/journal.pone. 0133420 
152. Borges V, Ferreira R, Nunes A, Sousa-Uva M, Abreu M, Borrego MJ, Gomes JP (2013). Effect of long-term laboratory propagation on Chlamydia trachomatis genome dynamics. Infect Genet Evol 17: 2332. doi: 10.1016/j.meegid.2013.03.035

153. Bonner C, Caldwell HD, Carlson JH, Graham MR, Kari L, Sturdevant GL, Tyler S, Zetner A, McClarty G (2015). Chlamydia trachomatis virulence factor CT135 is stable in vivo but highly polymorphic in vitro. Pathog Dis 73(6): ftv043. doi: 10.1093/femspd/ftv043

154. Fields KA, Fischer ER, Mead DJ, Hackstadt T (2005). Analysis of putative Chlamydia trachomatis chaperones Scc2 and Scc3 and their use in the identification of type III secretion substrates. J Bacteriol 187(18): 6466-6478. doi: 10.1128/JB.187.18.6466-6478.2005

155. Chellas-Gery B, Wolf K, Tisoncik J, Hackstadt T, Fields KA (2011). Biochemical and localization analyses of putative type III secretion translocator proteins CopB and CopB2 of Chlamydia trachomatis reveal significant distinctions. Infect Immun 79(8): 3036-3045. doi: 10.1128/IAI.00159-11

156. Betts HJ, Twiggs LE, Sal MS, Wyrick PB, Fields KA (2008). Bioinformatic and biochemical evidence for the identification of the type III secretion system needle protein of Chlamydia trachomatis. J Bacteriol 190(5): 1680-1690. doi: 10.1128/JB.01671-07

157. Lorenzini E, Singer A, Singh B, Lam R, Skarina T, Chirgadze NY, Savchenko A, Gupta RS (2010). Structure and protein-protein interaction studies on Chlamydia trachomatis protein CT670 (YscO Homolog). J Bacteriol 192(11): 2746-2756. doi: 10.1128/JB.01479-09

158. Clifton DR, Fields KA, Grieshaber SS, Dooley CA, Fischer ER, Mead DJ, Carabeo RA, Hackstadt T (2004). A chlamydial type III translocated protein is tyrosine-phosphorylated at the site of entry and associated with recruitment of actin. Proc Natl Acad Sci U S A 101(27): 1016610171. doi: 10.1073/pnas.0402829101

159. Saka HA, Thompson JW, Chen YS, Kumar Y, Dubois LG, Moseley MA, Valdivia RH (2011). Quantitative proteomics reveals metabolic and pathogenic properties of Chlamydia trachomatis developmental forms. Mol Microbiol 82(5): 1185-1203. doi: 10.1111/j.13652958.2011.07877.x

160. Nans A, Saibil HR, Hayward RD (2014). Pathogen-host reorganization during Chlamydia invasion revealed by cryo-electron tomography. Cell Microbiol 16(10): 1457-1472. doi: 10.1111/cmi.12310

161. Nans A, Kudryashev M, Saibil HR, Hayward RD (2015). Structure of a bacterial type III secretion system in contact with a host membrane in situ. Nature communications 6: 10114 . doi: 10.1038/ncomms10114

162. Birkelund S, Johnsen H, Christiansen G (1994). Chlamydia trachomatis serovar L2 induces protein tyrosine phosphorylation during uptake by HeLa cells. Infect Immun 62(11): 4900-4908. PMID: 7523300

163. Fawaz FS, van Ooij C, Homola E, Mutka SC, Engel JN (1997). Infection with Chlamydia trachomatis alters the tyrosine phosphorylation and/or localization of several host cell proteins including cortactin. Infect Immun 65(12): 5301-5308. PMID: 9393830

164. Ford C, Nans A, Boucrot E, Hayward RD (2018). Chlamydia exploits filopodial capture and a macropinocytosis-like pathway for host cell entry. PLoS Pathog 14(5): e1007051. doi: 10.1371/journal.ppat.1007051

165. Carabeo RA, Grieshaber SS, Hasenkrug A, Dooley C, Hackstadt T (2004). Requirement for the Rac GTPase in Chlamydia trachomatis invasion of non-phagocytic cells. Traffic 5(6): 418-425. doi: 10.1111/j.1398-9219.2004.00184.x

166. Hall A (2012). Rho family GTPases. Biochem Soc Trans 40(6): 1378-1382. doi: 10.1042/BST20120103
167. Carabeo RA, Dooley CA, Grieshaber SS, Hackstadt T (2007). Rac interacts with Abi-1 and WAVE2 to promote an Arp2/3-dependent actin recruitment during chlamydial invasion. Cell Microbiol 9(9): 2278-2288. doi: 10.1111/j.1462-5822.2007.00958.x

168. Clifton DR, Dooley CA, Grieshaber SS, Carabeo RA, Fields KA, Hackstadt T (2005). Tyrosine phosphorylation of the chlamydial effector protein Tarp is species specific and not required for recruitment of actin. Infect Immun 73(7): 3860-3868. doi: 10.1128/IAI.73.7.38603868.2005

169. Lutter El, Bonner C, Holland MJ, Suchland RJ, Stamm WE, Jewett TJ, McClarty G, Hackstadt T (2010). Phylogenetic analysis of Chlamydia trachomatis Tarp and correlation with clinical phenotype. Infect Immun 78(9): 3678-3688. doi: 10.1128/IAI.00515-10

170. Jewett TJ, Miller NJ, Dooley CA, Hackstadt T (2010). The conserved Tarp actin binding domain is important for chlamydial invasion. PLoS Pathog 6(7): e1000997. doi: 10.1371/journal.ppat.1000997

171. Jewett TJ, Dooley CA, Mead DJ, Hackstadt T (2008). Chlamydia trachomatis tarp is phosphorylated by src family tyrosine kinases. Biochem Biophys Res Commun 371(2): 339-344. doi 10.1016/j.bbrc.2008.04.089

172. Elwell CA, Ceesay A, Kim JH, Kalman D, Engel JN (2008). RNA interference screen identifies Abl kinase and PDGFR signaling in Chlamydia trachomatis entry. PLoS Pathog 4(3): e1000021. doi: 10.1371/journal.ppat.1000021

173. Mehlitz A, Banhart S, Hess S, Selbach M, Meyer TF (2008). Complex kinase requirements for Chlamydia trachomatis Tarp phosphorylation. FEMS Microbiol Lett 289(2): 233-240. doi: 10.1111/j.15746968.2008.01390.x

174. Liu BA, Nash PD (2012). Evolution of SH2 domains and phosphotyrosine signalling networks. Philos Trans R Soc Lond B Biol Sci 367(1602): 2556-2573. doi: 10.1098/rstb.2012.0107

175. Mehlitz A, Banhart S, Maurer AP, Kaushansky A, Gordus AG, Zielecki J, Macbeath G, Meyer TF (2010). Tarp regulates early Chlamydia-induced host cell survival through interactions with the human adaptor protein SHC1. J Cell Biol 190(1): 143-157. doi: 10.1083/jcb.200909095

176. Lane BJ, Mutchler C, Al Khodor S, Grieshaber SS, Carabeo RA (2008). Chlamydial entry involves TARP binding of guanine nucleotide exchange factors. PLoS Pathog 4(3): e1000014. doi: 10.1371/journal.ppat.1000014

177. Parrett CJ, Lenoci RV, Nguyen B, Russell L, Jewett TJ (2016). Targeted Disruption of Chlamydia trachomatis Invasion by in Trans Expression of Dominant Negative Tarp Effectors. Front Cell Infect Microbiol 6: 84. doi: 10.3389/fcimb.2016.00084

178. Jewett TJ, Fischer ER, Mead DJ, Hackstadt T (2006). Chlamydial TARP is a bacterial nucleator of actin. Proc Natl Acad Sci U S A 103(42): 15599-15604. doi: 10.1073/pnas.0603044103

179. Jiwani S, Ohr RJ, Fischer ER, Hackstadt T, Alvarado S, Romero A, Jewett TJ (2012). Chlamydia trachomatis Tarp cooperates with the Arp2/3 complex to increase the rate of actin polymerization. Biochem Biophys Res Commun 420(4): 816-821. doi: 10.1016/j.bbrc.2012.03.080

180. Jiwani S, Alvarado S, Ohr RJ, Romero A, Nguyen B, Jewett TJ (2013). Chlamydia trachomatis Tarp harbors distinct $G$ and $F$ actin binding domains that bundle actin filaments. J Bacteriol 195(4): 708716. doi: 10.1128/JB.01768-12

181. Thwaites T, Nogueira AT, Campeotto I, Silva AP, Grieshaber SS, Carabeo RA (2014). The Chlamydia effector TarP mimics the mammalian leucine-aspartic acid motif of paxillin to subvert the focal adhesion kinase during invasion. J Biol Chem 289(44): 30426-30442. doi: 10.1074/jbc.M114.604876 
182. Thwaites TR, Pedrosa AT, Peacock TP, Carabeo RA (2015). Vinculin Interacts with the Chlamydia Effector TarP Via a Tripartite Vinculin Binding Domain to Mediate Actin Recruitment and Assembly at the Plasma Membrane. Front Cell Infect Microbiol 5: 88 . doi: 10.3389/fcimb.2015.00088

183. Braun C, Alcazar-Roman AR, Laska A, Molleken K, Fleig U, Hegemann JH (2019). CPn0572, the C. pneumoniae ortholog of TarP, reorganizes the actin cytoskeleton via a newly identified F-actin binding domain and recruitment of vinculin. PLoS One 14(1): e0210403. doi: 10.1371/journal.pone.0210403

184. Zrieq R, Braun C, Hegemann JH (2017). The Chlamydia pneumoniae Tarp Ortholog CPn0572 Stabilizes Host F-Actin by Displacement of Cofilin. Front Cell Infect Microbiol 7: 511. doi: 10.3389/fcimb.2017.00511

185. Hower S, Wolf K, Fields KA (2009). Evidence that CT694 is a novel Chlamydia trachomatis T3S substrate capable of functioning during invasion or early cycle development. Mol Microbiol 72(6): 1423-1437. doi: 10.1111/j.1365-2958.2009.06732.x

186. Mueller KE, Fields KA (2015). Application of beta-lactamase reporter fusions as an indicator of effector protein secretion during infections with the obligate intracellular pathogen Chlamydia trachomatis. PLoS One 10(8): e0135295. doi: 10.1371/journal.pone.0135295

187. Pais SV, Milho C, Almeida F, Mota LJ (2013). Identification of novel type III secretion chaperone-substrate complexes of Chlamydia trachomatis. PLoS ONE 8(2): e56292. doi: 10.1371/journal.pone.0056292

188. Charpentier X, Oswald E (2004). Identification of the secretion and translocation domain of the enteropathogenic and enterohemorrhagic Escherichia coli effector Cif, using TEM-1 beta-lactamase as a new fluorescence-based reporter. J Bacteriol 186(16): 5486-5495. doi: 10.1128/JB.186.16.5486-5495.2004

189. Wang X, Hybiske K, Stephens RS (2018). Direct visualization of the expression and localization of chlamydial effector proteins within infected host cells. Pathog Dis 76(2). doi: 10.1093/femspd/fty011

190. Bullock HD, Hower S, Fields KA (2012). Domain Analyses Reveal That Chlamydia trachomatis CT694 Protein Belongs to the Membranelocalized Family of Type III Effector Proteins. J Biol Chem 287(33): 28078-28086. doi: 10.1074/jbc.M112.386904

191. McKuen MJ, Mueller KE, Bae YS, Fields KA (2017). FluorescenceReported Allelic Exchange Mutagenesis Reveals a Role for Chlamydia trachomatis TmeA in Invasion That Is Independent of Host AHNAK. Infect Immun 85(12): e00640-17. doi: 10.1128/IAI.00640-17

192. Hohaus A, Person V, Behlke J, Schaper J, Morano I, Haase H (2002). The carboxyl-terminal region of ahnak provides a link between cardiac L-type Ca2+ channels and the actin-based cytoskeleton. FASEB J 16(10): 1205-1216. doi: 10.1096/fj.01-0855com

193. Haase H, Pagel I, Khalina Y, Zacharzowsky U, Person V, Lutsch G, Petzhold D, Kott M, Schaper J, Morano I (2004). The carboxyl-terminal ahnak domain induces actin bundling and stabilizes muscle contraction. FASEB J 18(7): 839-841. doi: 10.1096/fj.03-0446fje

194. Brinkworth AJ, Malcolm DS, Pedrosa AT, Roguska K, Shahbazian S, Graham JE, Hayward RD, Carabeo RA (2011). Chlamydia trachomatis SIc1 is a type III secretion chaperone that enhances the translocation of its invasion effector substrate TARP. Mol Microbiol 82(1): 131-144. doi: 10.1111/j.1365-2958.2011.07802.x

195. Chen YS, Bastidas RJ, Saka HA, Carpenter VK, Richards KL, Plano GV, Valdivia RH (2014). The Chlamydia trachomatis type III secretion chaperone SIc1 engages multiple early effectors, including TepP, a tyrosine-phosphorylated protein required for the recruitment of CrklII to nascent inclusions and innate immune signaling. PLoS Pathog 10(2): e1003954. doi: 10.1371/journal.ppat.1003954
196. Carpenter V, Chen YS, Dolat L, Valdivia RH (2017). The Effector TepP Mediates Recruitment and Activation of Phosphoinositide 3Kinase on Early Chlamydia trachomatis Vacuoles. mSphere 2(4). doi: 10.1128/mSphere.00207-17

197. Belland RJ, Scidmore MA, Crane DD, Hogan DM, Whitmire W, McClarty G, Caldwell HD (2001). Chlamydia trachomatis cytotoxicity associated with complete and partial cytotoxin genes. Proc Natl Acad Sci U S A 98(24): 13984-13989. doi: 10.1073/pnas.241377698

198. Chandrasekaran R, Lacy DB (2017). The role of toxins in Clostridium difficile infection. FEMS Microbiol Rev 41(6): 723-750. doi: 10.1093/femsre/fux048

199. Thalmann J, Janik K, May M, Sommer K, Ebeling J, Hofmann F, Genth H, Klos A (2010). Actin re-organization induced by Chlamydia trachomatis serovar D--evidence for a critical role of the effector protein CT166 targeting Rac. PLoS One 5(3): e9887. doi: 10.1371/journal.pone.0009887

200. Gong S, Lei L, Chang X, Belland R, Zhong G (2011). Chlamydia trachomatis secretion of hypothetical protein CT622 into host cell cytoplasm via a secretion pathway that can be inhibited by the type III secretion system inhibitor compound 1. Microbiology 157(Pt 4): 1134 1144. doi: 10.1099/mic.0.047746-0

201. Cosse MM, Barta ML, Fisher DJ, Oesterlin LK, Niragire B, Perrinet S, Millot GA, Hefty PS, Subtil A (2018). The Loss of Expression of a Single Type 3 Effector (CT622) Strongly Reduces Chlamydia trachomatis Infectivity and Growth. Front Cell Infect Microbiol 8: 145. doi: 10.3389/fcimb.2018.00145

202. Nguyen UT, Goody RS, Alexandrov K (2010). Understanding and exploiting protein prenyltransferases. Chembiochem 11(9): 1194 1201. doi: $10.1002 /$ cbic. 200900727

203. Rytkonen A, Holden DW (2007). Bacterial interference of ubiquitination and deubiquitination. Cell Host Microbe 1(1): 13-22. doi: 10.1016/j.chom.2007.02.003

204. Misaghi S, Balsara ZR, Catic A, Spooner E, Ploegh HL, Starnbach $\mathrm{MN}$ (2006). Chlamydia trachomatis-derived deubiquitinating enzymes in mammalian cells during infection. Mol Microbiol 61(1): 142-150. doi: 10.1111/j.1365-2958.2006.05199.x

205. Claessen JHL, Witte MD, Yoder NC, Zhu AY, Spooner E, Ploegh HL (2013). Catch-and-release probes applied to semi-intact cells reveal ubiquitin-specific protease expression in Chlamydia trachomatis infection. Chembiochem 14(3): 343-352. doi: 10.1002/cbic.201200701

206. Pruneda JN, Bastidas RJ, Bertsoulaki E, Swatek KN, Santhanam B, Clague MJ, Valdivia RH, Urbe S, Komander D (2018). A Chlamydia effector combining deubiquitination and acetylation activities induces Golgi fragmentation. Nat Microbiol 3(12): 1377-1384. doi: 10.1038/s41564-018-0271-y

207. Samudrala R, Heffron F, McDermott JE (2009). Accurate prediction of secreted substrates and identification of a conserved putative secretion signal for type III secretion systems. PLoS Pathog 5(4): e1000375. doi: 10.1371/journal.ppat.1000375

208. Hayden MS, Ghosh S (2008). Shared principles in NF-kappaB signaling. Cell 132(3): 344-362. doi: 10.1016/j.cell.2008.01.020

209. Le Negrate G, Krieg A, Faustin B, Loeffler M, Godzik A, Krajewski $S$, Reed JC (2008). ChlaDub1 of Chlamydia trachomatis suppresses NFkappaB activation and inhibits IkappaBalpha ubiquitination and degradation. Cell Microbiol 10(9): 1879-1892. doi: 10.1111/j.1462 5822.2008.01178.x

210. Kale J, Osterlund EJ, Andrews DW (2018). BCL-2 family proteins: changing partners in the dance towards death. Cell Death Differ 25(1): 65-80. doi: $10.1038 / c d d .2017 .186$ 
211. Sharma M, Machuy N, Bohme L, Karunakaran K, Maurer AP, Meyer TF, Rudel T (2011). HIF-1alpha is involved in mediating apoptosis resistance to Chlamydia trachomatis-infected cells. Cell Microbiol 13(10): 1573-1585. doi: 10.1111/j.1462-5822.2011.01642.x

212. Muschiol S, Boncompain G, Vromman F, Dehoux P, Normark S, Henriques-Normark B, Subtil A (2011). Identification of a family of effectors secreted by the type III secretion system that are conserved in pathogenic Chlamydiae. Infect Immun 79(2): 571-580. doi: 10.1128/IAI.00825-10

213. Hobolt-Pedersen AS, Christiansen G, Timmerman E, Gevaert K, Birkelund S (2009). Identification of Chlamydia trachomatis CT621, a protein delivered through the type III secretion system to the host cell cytoplasm and nucleus. FEMS Immunol Med Microbiol 57(1): 46-58. doi: 10.1111/j.1574-695X.2009.00581.x

214. Vromman F, Perrinet S, Gehre L, Subtil A (2016). The DUF582 Proteins of Chlamydia trachomatis Bind to Components of the ESCRT Machinery, Which Is Dispensable for Bacterial Growth In vitro. Front Cell Infect Microbiol 6: 123. doi: 10.3389/fcimb.2016.00123

215. Henne WM, Buchkovich NJ, Emr SD (2011). The ESCRT pathway. Dev Cell 21(1): 77-91. doi: 10.1016/j.devcel.2011.05.015

216. Zuck M, Hybiske K (2019). The Chlamydia trachomatis Extrusion Exit Mechanism Is Regulated by Host Abscission Proteins. Microorganisms 7(5): E149. doi: 10.3390/microorganisms7050149

217. Olzmann JA, Carvalho $P$ (2019). Dynamics and functions of lipid droplets. Nat Rev Mol Cell Biol 20(3): 137-155. doi: 10.1038/s41580018-0085-z

218. Roingeard P, Melo RC (2017). Lipid droplet hijacking by intracellular pathogens. Cell Microbiol 19(1). doi: 10.1111/cmi.12688

219. Kumar Y, Cocchiaro J, Valdivia RH (2006). The obligate intracellular pathogen Chlamydia trachomatis targets host lipid droplets. Curr Biol 16(16): 1646-1651. doi: 10.1016/j.cub.2006.06.060

220. Cocchiaro JL, Kumar Y, Fischer ER, Hackstadt T, Valdivia RH (2008). Cytoplasmic lipid droplets are translocated into the lumen of the Chlamydia trachomatis parasitophorous vacuole. Proc Natl Acad Sci U S A 105(27): 9379-9384. doi: 10.1073/pnas.0712241105

221. Saka HA, Thompson JW, Chen YS, Dubois LG, Haas JT, Moseley A, Valdivia RH (2015). Chlamydia trachomatis Infection Leads to Defined Alterations to the Lipid Droplet Proteome in Epithelial Cells. PLoS One 10(4): e0124630. doi: 10.1371/journal.pone.0124630

222. Rank RG, Whittimore J, Bowlin AK, Wyrick PB (2011). In vivo ultrastructural analysis of the intimate relationship between polymorphonuclear leukocytes and the chlamydial developmental cycle. Infect Immun 79(8): 3291-3301. doi: 10.1128/IAI.00200-11

223. Recuero-Checa MA, Sharma M, Lau C, Watkins PA, Gaydos CA, Dean D (2016). Chlamydia trachomatis growth and development requires the activity of host Long-chain Acyl-CoA Synthetases (ACSLS). Sci Rep 6: 23148. doi: 10.1038/srep23148

224. Sharma M, Recuero-Checa MA, Fan FY, Dean D (2018). Chlamydia trachomatis regulates growth and development in response to host cell fatty acid availability in the absence of lipid droplets. Cell Microbiol 20(2). doi: 10.1111/cmi.12801

225. Dillon SC, Zhang X, Trievel RC, Cheng X (2005). The SET-domain protein superfamily: protein lysine methyltransferases. Genome Biol 6(8): 227. doi: 10.1186/gb-2005-6-8-227

226. Pennini ME, Perrinet S, Dautry-Varsat A, Subtil A (2010). Histone methylation by NUE, a novel nuclear effector of the intracellular pathogen Chlamydia trachomatis. PLoS Pathog 6(7): e1000995. doi: 10.1371/journal.ppat.1000995

227. da Cunha M, Milho C, Almeida F, Pais SV, Borges V, Mauricio R, Borrego MJ, Gomes JP, Mota $L J$ (2014). Identification of type III secre- tion substrates of Chlamydia trachomatis using Yersinia enterocolitica as a heterologous system. BMC Microbiol 14: 40. doi: 10.1186/1471 2180-14-40

228. Pais SV, Key CE, Borges V, Pereira IS, Gomes JP, Fisher DJ, Mota LJ (2019). CteG is a Chlamydia trachomatis effector protein that associates with the Golgi complex of infected host cells. Sci Rep 9(1): 6133. doi: 10.1038/s41598-019-42647-3

229. Chellas-Gery B, Linton CN, Fields KA (2007). Human GCIP interacts with CT847, a novel Chlamydia trachomatis type III secretion substrate, and is degraded in a tissue-culture infection model. Cell Microbiol 9(10): 2417-2430. doi: 10.1111/j.1462-5822.2007.00970.x

230. Fujisawa K, Terai S, Matsumoto T, Takami T, Yamamoto N, Nishina H, Furutani-Seiki M, Sakaida I (2015). Evidence for a Role of the Transcriptional Regulator Maid in Tumorigenesis and Aging. PLoS One 10(6): e0129950. doi: 10.1371/journal.pone.0129950

231. Zhong G, Fan P, Ji H, Dong F, Huang Y (2001). Identification of a chlamydial protease-like activity factor responsible for the degradation of host transcription factors. J Exp Med 193(8): 935-942. doi: 10.1084/jem.193.8.935

232. T AC, Yang Z, Ojcius D, Zhong G (2013). A path forward for the chlamydial virulence factor CPAF. Microbes Infect 15(14-15): 10261032. doi: 10.1016/j.micinf.2013.09.008

233. Hacker G (2014). The chlamydial protease CPAF: important or not, important for what? Microbes Infect 16(5): 367-370. doi: 10.1016/j.micinf.2014.02.008

234. Hacker G, Heuer D, Ojcius DM (2014). Is the hoopla over CPAF justified? Pathog Dis 72(1): 1-2. doi: 10.1111/2049-632X.12211

235. Bavoil PM, Byrne GI (2014). Analysis of CPAF mutants: new functions, new questions (the ins and outs of a chlamydial protease). Pathog Dis 71(3): 287-291. doi: 10.1111/2049-632X.12194

236. Zhong $G$ (2014). Question the questions on CPAF. Pathog Dis 72(1): 3-4. doi: 10.1111/2049-632X.12205

237. Tan M, Sutterlin C (2014). The Chlamydia protease CPAF: caution, precautions and function. Pathog Dis 72(1): 7-9. doi: 10.1111/2049$632 \times .12213$

238. Zhong G, Liu L, Fan T, Fan P, Ji H (2000). Degradation of transcription factor RFX5 during the inhibition of both constitutive and interferon gamma-inducible major histocompatibility complex class I expression in chlamydia-infected cells. J Exp Med 191(9): 1525-1534. doi: 10.1084/jem.191.9.1525

239. Zhong $G$ (2011). Chlamydia trachomatis secretion of proteases for manipulating host signaling pathways. Front Microbiol 2: 14. doi: 10.3389/fmicb.2011.00014

240. Chen AL, Johnson KA, Lee JK, Sutterlin C, Tan M (2012). CPAF: a Chlamydial protease in search of an authentic substrate. PLoS Pathog 8(8): e1002842. doi: 10.1371/journal.ppat.1002842

241. Huang Z, Feng Y, Chen D, Wu X, Huang S, Wang X, Xiao X, Li W, Huang N, Gu L, Zhong G, Chai J (2008). Structural basis for activation and inhibition of the secreted chlamydia protease CPAF. Cell Host Microbe 4(6): 529-542. doi: 10.1016/j.chom.2008.10.005

242. Dong F, Pirbhai M, Zhong Y, Zhong G (2004). Cleavage-dependent activation of a chlamydia-secreted protease. Mol Microbiol 52(5): 1487-1494. doi: 10.1111/j.1365-2958.2004.04072.x

243. Dong F, Sharma J, Xiao Y, Zhong Y, Zhong G (2004). Intramolecular dimerization is required for the chlamydia-secreted protease CPAF to degrade host transcriptional factors. Infect Immun 72(7): 38693875. doi: 10.1128/IAI.72.7.3869-3875.2004

244. Paschen SA, Christian JG, Vier J, Schmidt F, Walch A, Ojcius DM, Hacker $\mathrm{G}$ (2008). Cytopathicity of Chlamydia is largely reproduced by 
expression of a single chlamydial protease. J Cell Biol 182(1): 117-127. doi: $10.1083 /$ jcb.200804023

245. Snavely EA, Kokes M, Dunn JD, Saka HA, Nguyen BD, Bastidas RJ, McCafferty DG, Valdivia RH (2014). Reassessing the role of the secreted protease CPAF in Chlamydia trachomatis infection through genetic approaches. Pathog Dis 71(3):336-51. doi: 10.1111/2049-632X.12179

246. Yang Z, Tang L, Sun X, Chai J, Zhong G (2015). Characterization of CPAF critical residues and secretion during Chlamydia trachomatis infection. Infect Immun 83(6): 2234-2241. doi: 10.1128/IAI.00275-15

247. Prusty BK, Chowdhury SR, Gulve N, Rudel T (2018). Peptidase Inhibitor 15 (PI15) Regulates Chlamydial CPAF Activity. Front Cell Infect Microbiol 8: 183. doi: 10.3389/fcimb.2018.00183

248. Patton MJ, McCorrister S, Grant C, Westmacott G, Fariss R, Hu P, Zhao K, Blake M, Whitmire B, Yang C, Caldwell HD, McClarty G (2016). Chlamydial Protease-Like Activity Factor and Type III Secreted Effectors Cooperate in Inhibition of p65 Nuclear Translocation. mBio 7(5): e01427-16. doi: 10.1128/mBio.01427-16

249. Hou S, Lei L, Yang Z, Qi M, Liu Q, Zhong G (2013). Chlamydia trachomatis outer membrane complex protein $B(\mathrm{OmcB})$ is processed by the protease CPAF. J Bacteriol 195(5): 951-957. doi: 10.1128/JB.02087-12

250. Brown HM, Knowlton AE, Snavely E, Nguyen BD, Richards TS, Grieshaber SS (2014). Multinucleation during $C$. trachomatis infections is caused by the contribution of two effector pathways. PLoS One 9(6): e100763. doi: 10.1371/journal.pone.0100763

251. Yang C, Starr T, Song L, Carlson JH, Sturdevant GL, Beare PA, Whitmire WM, Caldwell HD (2015). Chlamydial Lytic Exit from Host Cells Is Plasmid Regulated. mBio 6(6): e01648-01615. doi: 10.1128/mBio.01648-15

252. Rajeeve K, Das S, Prusty BK, Rudel T (2018). Chlamydia trachomatis paralyses neutrophils to evade the host innate immune response. Nat Microbiol 3(7): 824-835. doi: 10.1038/s41564-018-0182-y

253. Tang L, Chen J, Zhou Z, Yu P, Yang Z, Zhong G (2015). Chlamydiasecreted protease CPAF degrades host antimicrobial peptides. Microbes Infect 17(6): 402-408. doi: 10.1016/j.micinf.2015.02.005

254. Yang Z, Tang L, Zhou Z, Zhong G (2016). Neutralizing antichlamydial activity of complement by chlamydia-secreted protease CPAF. Microbes Infect 18(11): 669-674. doi: 10.1016/j.micinf.2016.07.002

255. Yang Z, Tang L, Shao L, Zhang Y, Zhang T, Schenken R, Valdivia R, Zhong $G$ (2016). The Chlamydia-Secreted Protease CPAF Promotes Chlamydial Survival in the Mouse Lower Genital Tract. Infect Immun 84(9): 2697-2702. doi: 10.1128/IAI.00280-16

256. Dong F, Zhong Y, Arulanandam B, Zhong G (2005). Production of a proteolytically active protein, chlamydial protease/proteasome-like activity factor, by five different Chlamydia species. Infect Immun 73(3): 1868-1872. doi: 10.1128/IAI.73.3.1868-1872.2005

257. Huston WM, Swedberg JE, Harris JM, Walsh TP, Mathews SA, Timms $P$ (2007). The temperature activated HtrA protease from pathogen Chlamydia trachomatis acts as both a chaperone and protease at 37 degrees C. FEBS Lett 581(18): 3382-3386. doi: 10.1016/j.febslet.2007.06.039

258. Lad SP, Li J, da Silva Correia J, Pan Q, Gadwal S, Ulevitch RJ, Li E (2007). Cleavage of p65/RelA of the NF-kappaB pathway by Chlamydia. Proc Natl Acad Sci U S A 104(8): 2933-2938. doi: 10.1073/pnas.0608393104

259. Clausen T, Kaiser M, Huber R, Ehrmann M (2011). HTRA proteases: regulated proteolysis in protein quality control. Nat Rev Mol Cell Biol 12(3): 152-162. doi: 10.1038/nrm3065
260. Wessler S, Schneider G, Backert S (2017). Bacterial serine protease HtrA as a promising new target for antimicrobial therapy? Cell Commun Signal 15(1): 4. doi: 10.1186/s12964-017-0162-5

261. Marsh JW, Ong VA, Lott WB, Timms P, Tyndall JD, Huston WM (2017). CtHtrA: the lynchpin of the chlamydial surface and a promising therapeutic target. Future Microbiol 12: $817-829$. doi: $10.2217 / \mathrm{fmb}$ 2017-0017

262. Wu X, Lei L, Gong S, Chen D, Flores R, Zhong G (2011). The chlamydial periplasmic stress response serine protease cHtrA is secreted into host cell cytosol. BMC Microbiol 11: 87. doi: 10.1186/1471-2180$11-87$

263. Lawrence A, Nicholls SK, Stansfield SH, Huston WM (2014). Characterization of the tail-specific protease (Tsp) from Legionella. J Gen Appl Microbiol 60(3): 95-100. doi: 10.2323/jgam.60.95

264. Kohlmann F, Shima K, Hilgenfeld R, Solbach W, Rupp J, Hansen G (2015). Structural basis of the proteolytic and chaperone activity of Chlamydia trachomatis CT441. J Bacteriol 197(1): 211-218. doi: 10.1128/JB.02140-14

265. Borth N, Massier J, Franke C, Sachse K, Saluz HP, Hanel F (2010). Chlamydial protease CT441 interacts with SRAP1 co-activator of estrogen receptor alpha and partially alleviates its co-activation activity. J Steroid Biochem Mol Biol 119(1-2): 89-95. doi: 10.1016/j.jsbmb.2010.01.004

266. Zhong G (2017). Chlamydial Plasmid-Dependent Pathogenicity. Trends Microbiol 25(2): 141-152. doi: 10.1016/j.tim.2016.09.006

267. Comanducci M, Cevenini R, Moroni A, Giuliani MM, Ricci S, Scarlato V, Ratti $G$ (1993). Expression of a plasmid gene of Chlamydia trachomatis encoding a novel $28 \mathrm{kDa}$ antigen. J Gen Microbiol 139(5): 1083-1092. doi: 10.1099/00221287-139-5-1083

268. Li Z, Chen D, Zhong Y, Wang S, Zhong G (2008). The chlamydial plasmid-encoded protein pgp3 is secreted into the cytosol of Chlamydia-infected cells. Infect Immun 76(8): 3415-3428. doi: 10.1128/IAI.01377-07

269. Li Z, Zhong Y, Lei L, Wu Y, Wang S, Zhong G (2008). Antibodies from women urogenitally infected with $C$. trachomatis predominantly recognized the plasmid protein pgp3 in a conformation-dependent manner. BMC Microbiol 8: 90. doi: 10.1186/1471-2180-8-90

270. Chen D, Lei L, Lu C, Galaleldeen A, Hart PJ, Zhong G (2010). Characterization of Pgp3, a Chlamydia trachomatis plasmid-encoded immunodominant antigen. J Bacteriol 192(22): 6017-6024. doi: 10.1128/JB.00847-10

271. Galaleldeen A, Taylor AB, Chen D, Schuermann JP, Holloway SP, Hou S, Gong S, Zhong G, Hart PJ (2013). Structure of the Chlamydia trachomatis immunodominant antigen Pgp3. J Biol Chem 288(30): 22068-22079. doi: 10.1074/jbc.M113.475012

272. Ramsey KH, Schripsema JH, Smith BJ, Wang Y, Jham BC, O'Hagan KP, Thomson NR, Murthy AK, Skilton RJ, Chu P, Clarke IN (2014). Plasmid CDS5 influences infectivity and virulence in a mouse model of Chlamydia trachomatis urogenital infection. Infect Immun 82(8): 3341-3349. doi: 10.1128/IAI.01795-14

273. Liu Y, Huang Y, Yang Z, Sun Y, Gong S, Hou S, Chen C, Li Z, Liu Q, Wu Y, Baseman J, Zhong G (2014). Plasmid-encoded Pgp3 is a major virulence factor for Chlamydia muridarum to induce hydrosalpinx in mice. Infect Immun 82(12): 5327-5335. doi: 10.1128/IAI.02576-14

274. Zhang T, Huo Z, Ma J, He C, Zhong G (2019). The Plasmid-Encoded pGP3 Promotes Chlamydia Evasion of Acidic Barriers in Both Stomach and Vagina. Infect Immun 87(5). doi: 10.1128/IAI.00844-18

275. Hou S, Dong X, Yang Z, Li Z, Liu Q, Zhong G (2015). Chlamydial plasmid-encoded virulence factor Pgp3 neutralizes the antichlamydial 
activity of human cathelicidin LL-37. Infect Immun 83(12): 4701-4709. doi: 10.1128/IAI.00746-15

276. Hou S, Sun $X$, Dong $X$, Lin $H$, Tang L, Xue M, Zhong G (2019). Chlamydial plasmid-encoded virulence factor Pgp3 interacts with human cathelicidin peptide LL-37 to modulate immune response. Microbes Infect 21(1): 50-55. doi: 10.1016/j.micinf.2018.06.003

277. Zou Y, Lei W, Su S, Bu J, Zhu S, Huang Q, Li Z (2019). Chlamydia trachomatis plasmid-encoded protein Pgp3 inhibits apoptosis via the PI3K-AKT-mediated MDM2-p53 axis. Mol Cell Biochem 452(1-2): 167176. doi: 10.1007/s11010-018-3422-9

278. Qi M, Lei L, Gong S, Liu Q, DeLisa MP, Zhong G (2011). Chlamydia trachomatis secretion of an immunodominant hypothetical protein (CT795) into host cell cytoplasm. J Bacteriol 193(10): 2498-2509. doi: 10.1128/JB.01301-10

279. Lei L, Dong X, Li Z, Zhong G (2013). Identification of a novel nuclear localization signal sequence in Chlamydia trachomatis-secreted hypothetical protein CT311. PLoS ONE 8(5): e64529. doi: 10.1371/journal.pone.0064529

280. Fling SP, Sutherland RA, Steele LN, Hess B, D'Orazio SE, Maisonneuve J, Lampe MF, Probst P, Starnbach MN (2001). CD8+ T cells recognize an inclusion membrane-associated protein from the vacuolar pathogen Chlamydia trachomatis. Proc Natl Acad Sci U S A 98(3): 1160-1165. doi: 10.1073/pnas.98.3.1160

281. Archuleta TL, Spiller BW (2014). A gatekeeper chaperone complex directs translocator secretion during type three secretion. PLoS Pathog 10(11): e1004498. doi: 10.1371/journal.ppat.1004498

282. Huang J, Lesser CF, Lory S (2008). The essential role of the CopN protein in Chlamydia pneumoniae intracellular growth. Nature 456(7218): 112-115. doi: 10.1038/nature07355

283. Archuleta TL, Du Y, English CA, Lory S, Lesser C, Ohi MD, Ohi R, Spiller BW (2011). The Chlamydia effector chlamydial outer protein $\mathrm{N}$ (CopN) sequesters tubulin and prevents microtubule assembly. J Biol Chem 286(39): 33992-33998. doi: 10.1074/jbc.M111.258426

284. Gordon FB, Quan AL (1965). Occurence of Glycogen in Inclusions of the Psittacosis-Lymphogranuloma Venereum-Trachoma Agents. J Infect Dis 115: 186-196. doi: 10.1093/infdis/115.2.186

285. Matsumoto A, Izutsu H, Miyashita N, Ohuchi M (1998). Plaque formation by and plaque cloning of Chlamydia trachomatis biovar trachoma. J Clin Microbiol 36(10): 3013-3019. doi: 10.1016/0147619x(87)90063-1

286. Carlson JH, Whitmire WM, Crane DD, Wicke L, Virtaneva K, Sturdevant DE, Kupko JJ, 3rd, Porcella SF, Martinez-Orengo N, Heinzen RA, Kari L, Caldwell HD (2008). The Chlamydia trachomatis plasmid is a transcriptional regulator of chromosomal genes and a virulence factor. Infect Immun 76(6): 2273-2283. doi: 10.1128/IAI.00102-08

287. Song L, Carlson JH, Whitmire WM, Kari L, Virtaneva K, Sturdevant DE, Watkins H, Zhou B, Sturdevant GL, Porcella SF, McClarty G, Caldwell HD (2013). Chlamydia trachomatis plasmid-encoded Pgp4 is a transcriptional regulator of virulence-associated genes. Infect Immun 81(3): 636-644. doi: 10.1128/IAI.01305-12

288. Lu C, Lei L, Peng B, Tang L, Ding H, Gong S, Li Z, Wu Y, Zhong G (2013). Chlamydia trachomatis GlgA Is Secreted into Host Cell Cytoplasm. PLoS ONE 8(7): e68764. doi: 10.1371/journal.pone.0068764

289. Gehre L, Gorgette O, Perrinet S, Prevost MC, Ducatez M, Giebel AM, Nelson DE, Ball SG, Subtil A (2016). Sequestration of host metabolism by an intracellular pathogen. elife 5: e12552. doi: 10.7554/eLife. 12552

290. Panzetta ME, Valdivia RH, Saka HA (2018). Chlamydia Persistence: A Survival Strategy to Evade Antimicrobial Effects in-vitro and in-vivo. Front Microbiol 9: 3101. doi: 10.3389/fmicb.2018.03101
291. Lewis ME, Belland RJ, AbdelRahman YM, Beatty WL, Aiyar AA, Zea AH, Greene SJ, Marrero L, Buckner LR, Tate DJ, McGowin CL, Kozlowski PA, O'Brien M, Lillis RA, Martin DH, Quayle AJ (2014). Morphologic and molecular evaluation of Chlamydia trachomatis growth in human endocervix reveals distinct growth patterns. Frontiers Cell Infect Microbiol 4:71. doi: 10.3389/fcimb.2014.00071

292. Panzetta ME, Lujan AL, Bastidas RJ, Damiani MT, Valdivia RH, Saka HA (2019). Ptr/CTL0175 Is Required for the Efficient Recovery of Chlamydia trachomatis From Stress Induced by Gamma-Interferon. Front Microbiol 10: 756. doi: 10.3389/fmicb. 2019.00756

293. Jorgensen I, Valdivia RH (2008). Pmp-like proteins Pls1 and Pls2 are secreted into the lumen of the Chlamydia trachomatis inclusion. Infect Immun 76(9): 3940-3950. doi: 10.1128/IAI.00632-08

294. da Cunha M, Pais SV, Bugalhao JN, Mota $\sqcup$ (2017). The Chlamydia trachomatis type III secretion substrates CT142, CT143, and CT144 are secreted into the lumen of the inclusion. PLoS One 12(6): e0178856. doi: 10.1371/journal.pone.0178856

295. Patton MJ, Chen CY, Yang C, McCorrister S, Grant C, Westmacott G, Yuan XY, Ochoa E, Fariss R, Whitmire WM, Carlson JH, Caldwell HD, McClarty G (2018). Plasmid Negative Regulation of CPAF Expression Is Pgp4 Independent and Restricted to Invasive Chlamydia trachomatis Biovars. mBio 9(1): e02164-17. doi: 10.1128/mBio.02164-17

296. Jia L, Sun F, Wang J, Gong D, Yang L (2019). Chlamydia trachomatis ct143 stimulates secretion of proinflammatory cytokines via activating the p38/MAPK signal pathway in THP-1 cells. Mol Immunol 105: 233-239. doi: 10.1016/j.molimm.2018.12.007

297. Ghosh S, O'Connor TJ (2017). Beyond Paralogs: The Multiple Layers of Redundancy in Bacterial Pathogenesis. Front Cell Infect Microbiol 7: 467. doi: 10.3389/fcimb.2017.00467

298. Borges V, Nunes A, Ferreira R, Borrego MJ, Gomes JP (2012). Directional Evolution of Chlamydia trachomatis Towards Nichespecific Adaptation. J Bacteriol 194(22):6143-53. doi: 10.1128/JB.01291-12

299. Boyd EF, Carpenter MR, Chowdhury N (2012). Mobile effector proteins on phage genomes. Bacteriophage 2(3): 139-148. doi: 10.4161/bact.21658

300. Stavrinides J, McCann HC, Guttman DS (2008). Host-pathogen interplay and the evolution of bacterial effectors. Cell Microbiol 10(2): 285-292. doi: 10.1111/j.1462-5822.2007.01078.x

301. Brown NF, Finlay BB (2011). Potential origins and horizontal transfer of type III secretion systems and effectors. Mob Genet Elements 1(2): 118-121. doi: 10.4161/mge.1.2.16733

302. Kim H, Kwak W, Yoon SH, Kang DK, Kim H (2018). Horizontal gene transfer of Chlamydia: Novel insights from tree reconciliation. PLoS One 13(4): e0195139. doi: 10.1371/journal.pone.0195139

303. Patel JC, Galan JE (2005). Manipulation of the host actin cytoskeleton by Salmonella--all in the name of entry. Curr Opin Microbiol 8(1): 10-15. doi: 10.1016/j.mib.2004.09.001

304. Scidmore MA, Fischer ER, Hackstadt T (2003). Restricted fusion of Chlamydia trachomatis vesicles with endocytic compartments during the initial stages of infection. Infect Immun 71(2): 973-984. doi: 10.1128/iai.71.2.973-984.2003

305. Carabeo RA, Mead DJ, Hackstadt T (2003). Golgi-dependent transport of cholesterol to the Chlamydia trachomatis inclusion. Proc Natl Acad Sci U S A 100(11): 6771-6776. doi: 10.1073/pnas.1131289100

306. Scidmore MA, Rockey DD, Fischer ER, Heinzen RA, Hackstadt T (1996). Vesicular interactions of the Chlamydia trachomatis inclusion are determined by chlamydial early protein synthesis rather than route of entry. Infect Immun 64(12): 5366-5372. PMID: 8945589 
307. Kokes M, Valdivia RH (2015). Differential Translocation of Host Cellular Materials into the Chlamydia trachomatis Inclusion Lumen during Chemical Fixation. PLoS ONE 10(10): e0139153. doi: 10.1371/journal.pone.0139153

308. Soupene E, Rothschild J, Kuypers FA, Dean D (2012). Eukaryotic protein recruitment into the Chlamydia inclusion: implications for survival and growth. PLoS One 7(5): e36843. doi: 10.1371/journal.pone.0036843

309. Soupene E, Wang D, Kuypers FA (2015). Remodeling of host phosphatidylcholine by Chlamydia acyltransferase is regulated by acyl-
CoA binding protein ACBD6 associated with lipid droplets. Microbiology Open 4(2): 235-251. doi: 10.1002/mbo3.234

310. Boncompain G, Muller C, Meas-Yedid V, Schmitt-Kopplin P, Lazarow PB, Subtil A (2014). The intracellular bacteria Chlamydia hijack peroxisomes and utilize their enzymatic capacity to produce bacteriaspecific phospholipids. PLoS One 9(1): e86196. doi: 10.1371/journal.pone.0086196

311. Krampen L, Malmsheimer S, Grin I, Trunk T, Luhrmann A, de Gier JW, Wagner S (2018). Revealing the mechanisms of membrane protein export by virulence-associated bacterial secretion systems. Nat Commun 9(1): 3467. doi: 10.1038/s41467-018-05969-w 